\title{
DESIGN AND ANALYSIS OF OFF-GRID SOLAR SYSTEM FOR DC LOAD OF A HOUSE IN PAKISTAN
}

\author{
By \\ Chaudhry Bilal Muzaffar
}

Student ID\# 201890442

\begin{abstract}
A thesis submitted to the
School of Graduate Studies

in partial fulfillment of the requirements for the degree of

Master of Engineering

Faculty of Engineering and Applied Science

Memorial University of Newfoundland
\end{abstract}

May 2021

St. John's Newfoundland and Labrador Canada 


\begin{abstract}
Solar energy is the cleanest and most developed form of renewable energy. In order to be completely independent of the grid source we need to have off grid solar system. This thesis presents a model in which we have designed an off-grid DC solar system using homer pro. We have used 8 batteries, $36 \mathrm{PV}$ modules to make a DC system that would be sufficient enough to provide the requirement of home with load of $7.81 \mathrm{kWh} / \mathrm{day}$. We then designed two further systems with DC generator, PV and Battery bank. The Homer pro results for each case are elaborated in the thesis. Steady state as well as dynamic system modelling is included which are done on the MATLAB. We have designed MPPT(maximum power point tracker is an electronic DC to DC converter that optimizes the match between the solar array (PV panels), and the battery bank or utility grid) for capturing maximum power. Along with design and modelling, the safety measures are also given. The safety device, working principle and the method to use them is also discussed in the thesis. Presented results will help further in the design of small scaled off grid solar systems that would be sufficient to provide the electricity in the remote area and on the small scale. This research also will help in designing the solar system for the DC load.
\end{abstract}




\section{Acknowledgement}

The author would like to convey his earnest gratitude and respect to his supervisor Dr. M. Tariq Iqbal, for his encouragement, guidance, support, and positive feedback throughout the development of this thesis.

The author profoundly appreciates the financial support of the Natural Science and Engineering Research Council (NSERC) and the Graduate Fellowship from Memorial University of Newfoundland. This work would not have been possible without their support.

The author would like to thank Memorial University of Newfoundland for all kinds of support throughout this journey. 


\section{List Of contents}

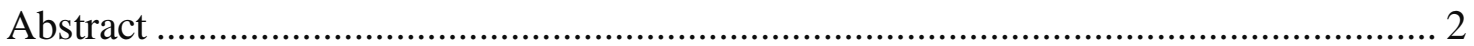

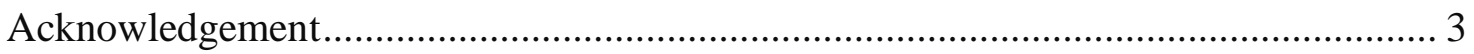

1. INTRODUCTION AND LITERATURE REVIEW ................................... 10

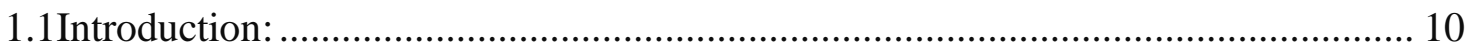

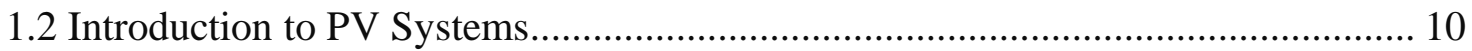

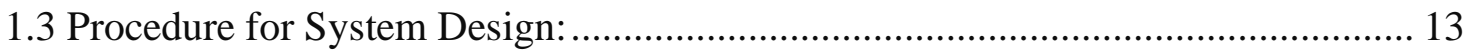

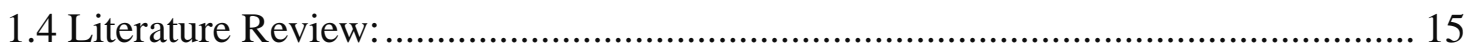

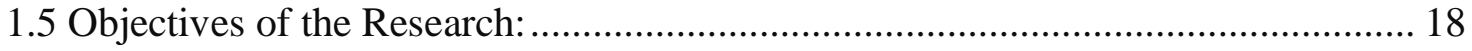

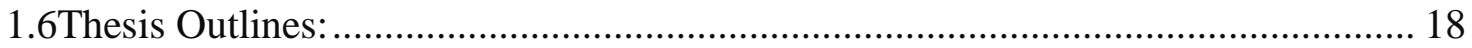

2. SITE SELECTION AND SYSTEM SIZING ...................................................... 19

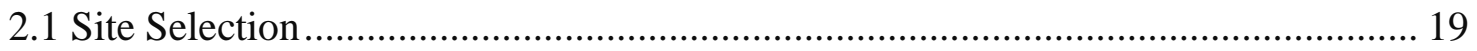

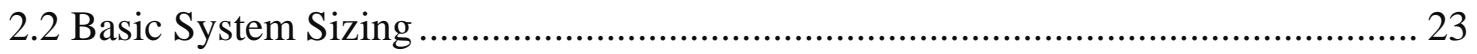

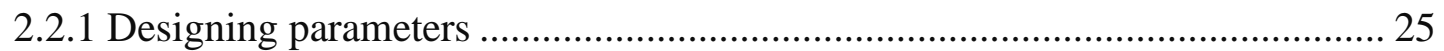

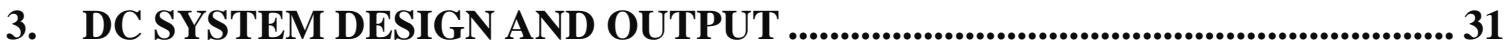

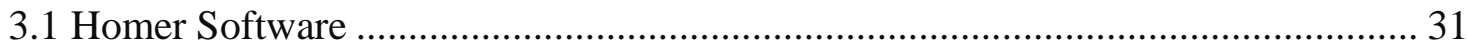

3.2 Components of the homer: ..................................................................... 31

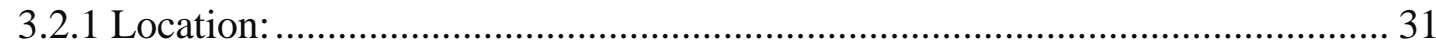

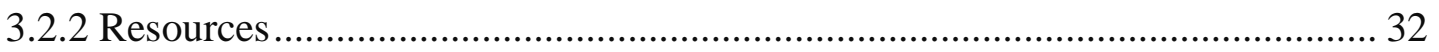

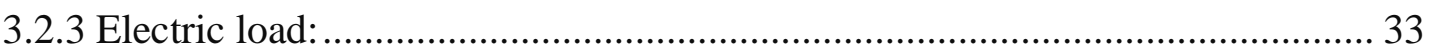




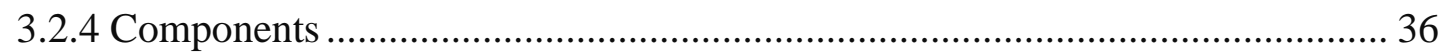

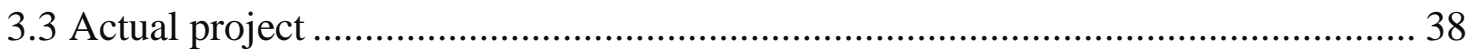

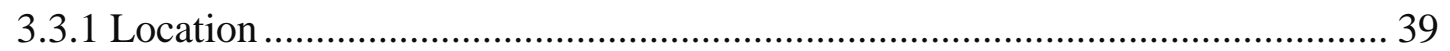

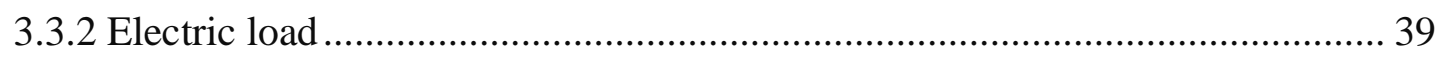

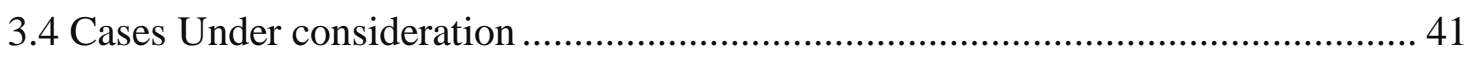

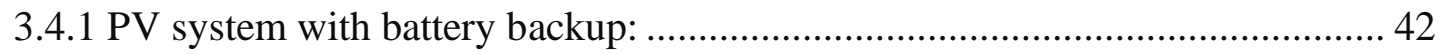

3.4.2 PV system and DC generator backup.......................................................... 48

3.4.3 PV panels, DC generator and Battery bank combined ...................................... 54

4. DYNAMIC MODELLING OF THE DESIGNED SYSTEM................................. 62

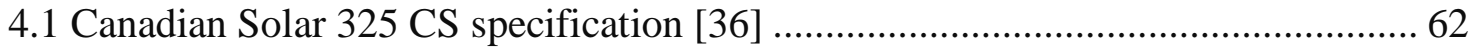

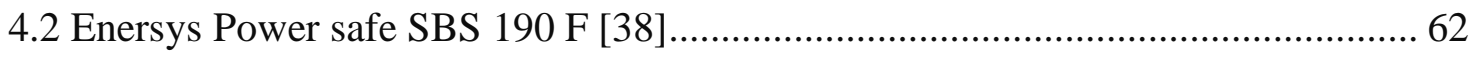

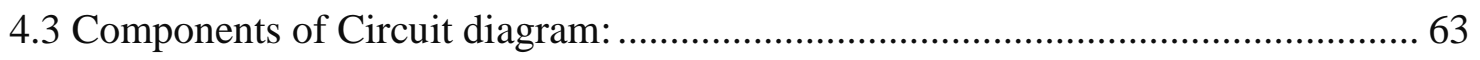

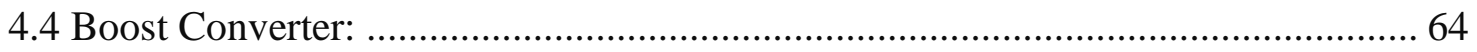

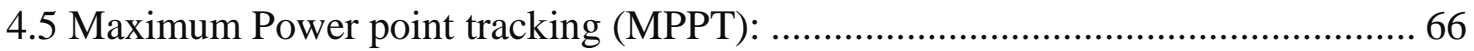

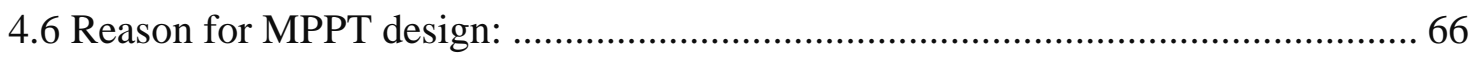

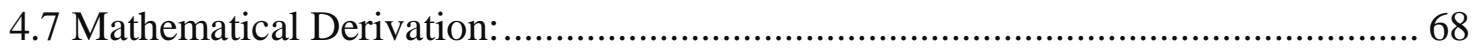

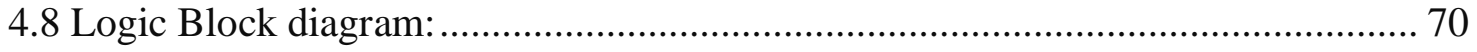

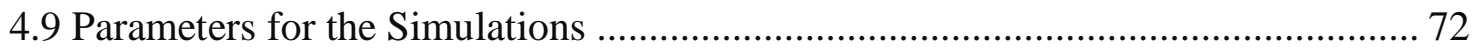

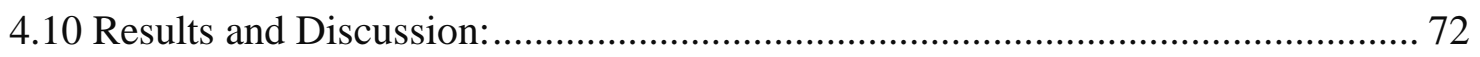

5. SAFTEY \& PRECAUTIONS OF AC \& DC SYSTEMS ....................................... 75

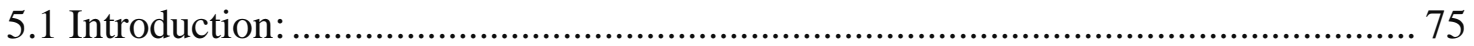




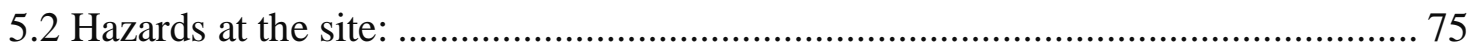

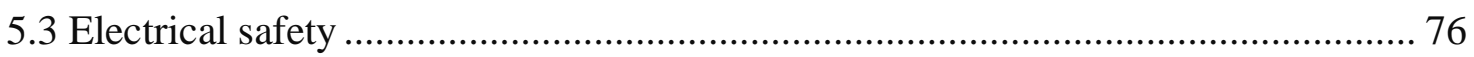

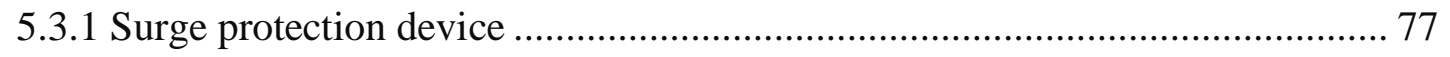

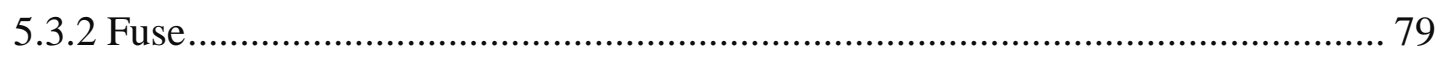

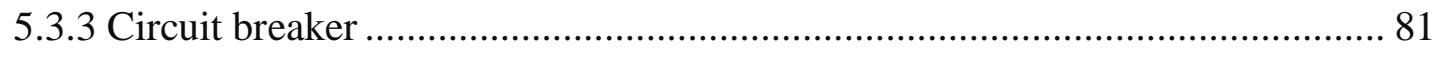

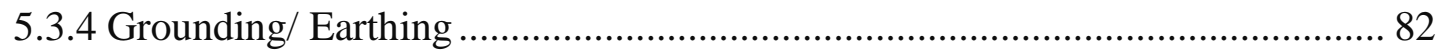

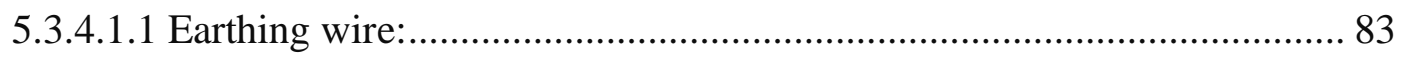

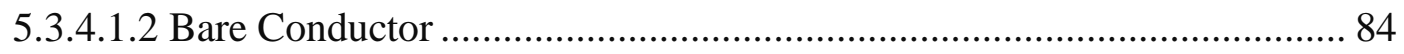

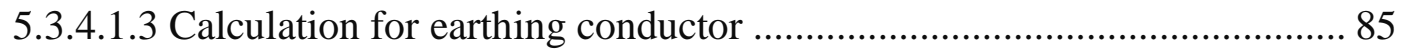

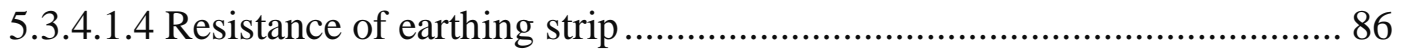

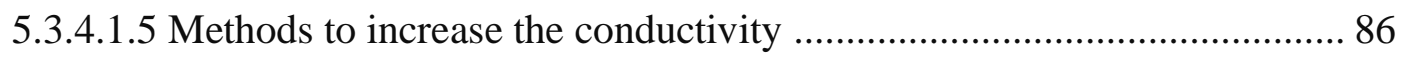

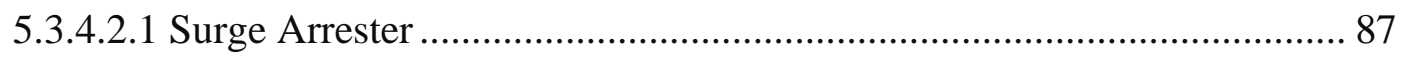

5.2.4.3.2 Air termination systems: .................................................................... 92

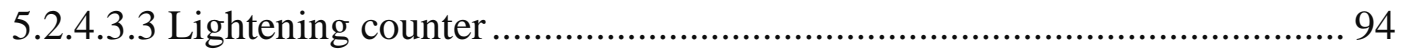

6. CONCLUSIONS AND FURTURE WORK......................................................... 95

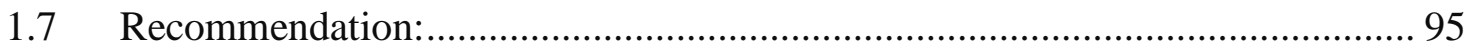

7. REFERENCES: ..................................................................................................................... 97

\section{List of Figures:}

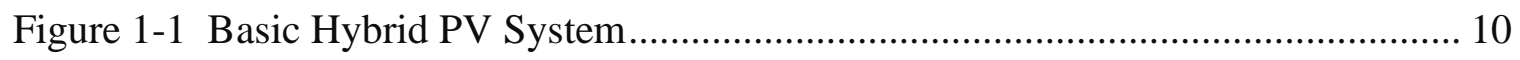

Figure 1-2: Different Kinds of PV Cells ..................................................................... 11

Figure 1-3: Battery Density Comparison .................................................................... 12 


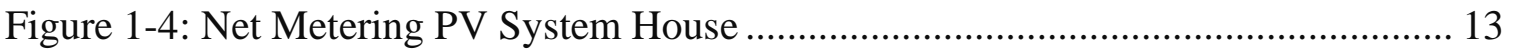

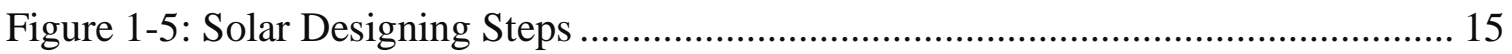

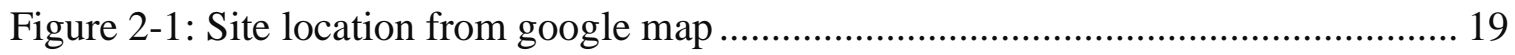

Figure 2-2: Global radiation map of Pakistan ............................................................. 20

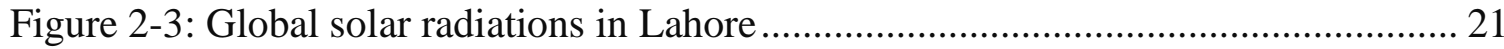

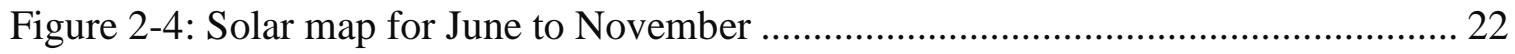

Figure 2-5: Annual Direct Normal Solar Radiation................................................... 22

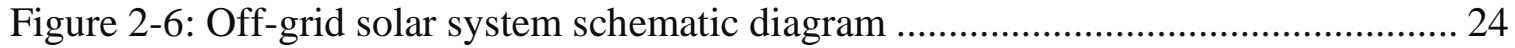

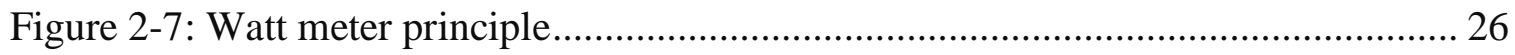

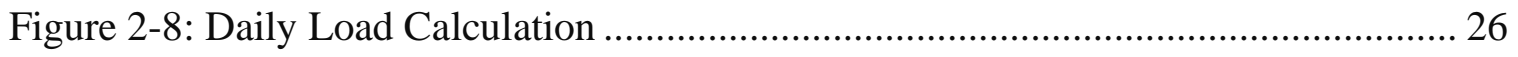

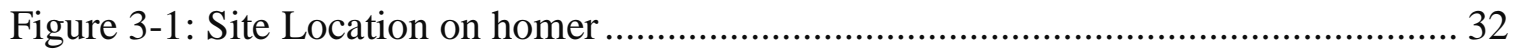

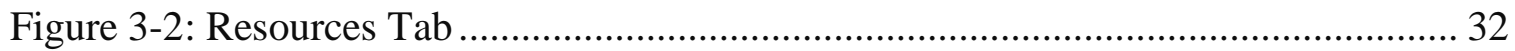

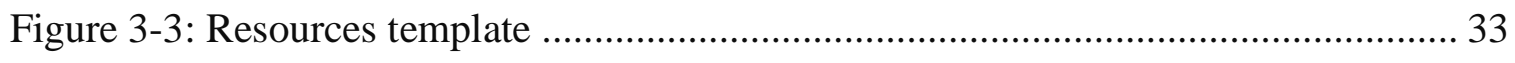

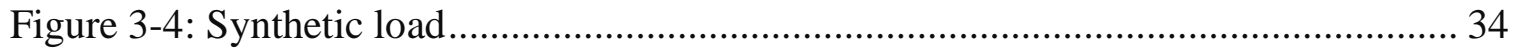

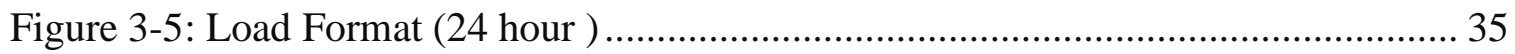

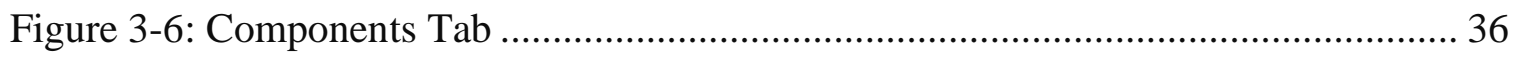

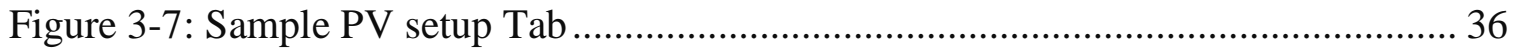

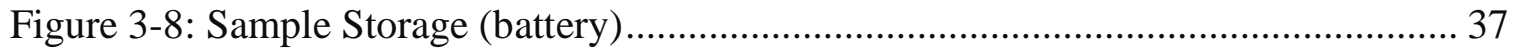

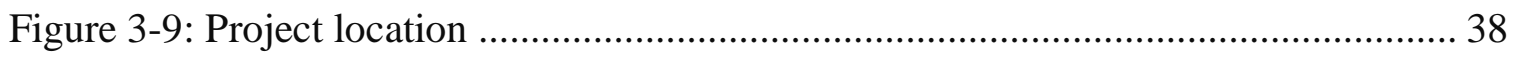

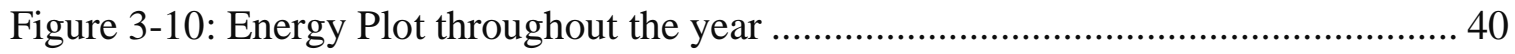

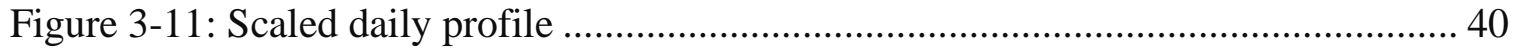

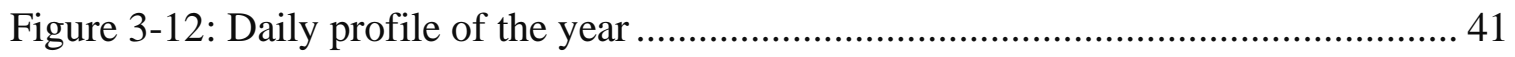

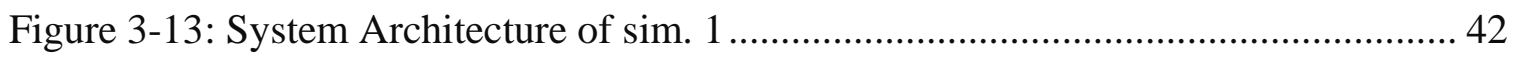

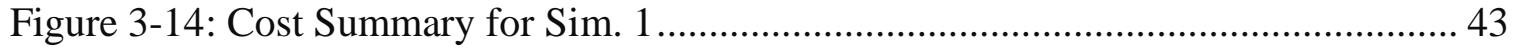

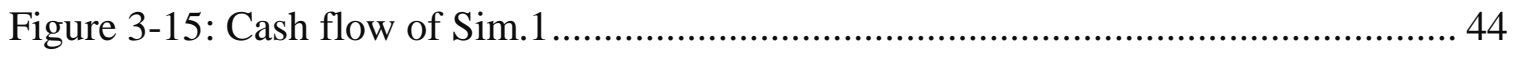

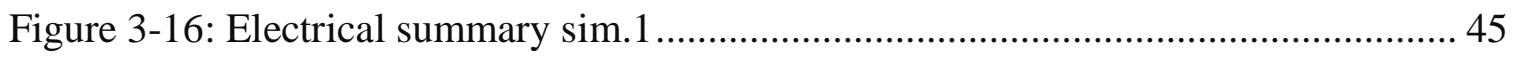

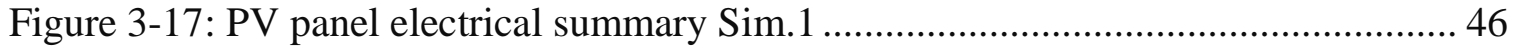

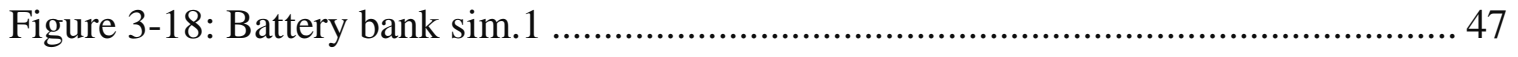

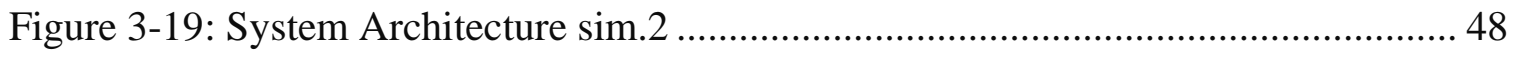




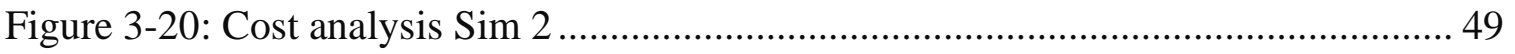

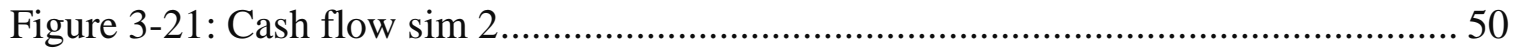

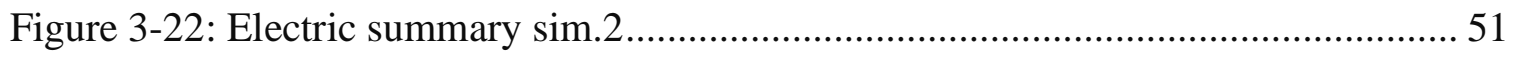

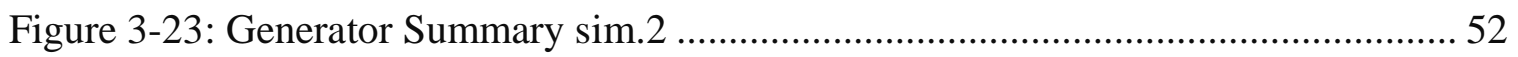

Figure 3-24: Fuel Summary Sim.2 ……………………………………………. 53

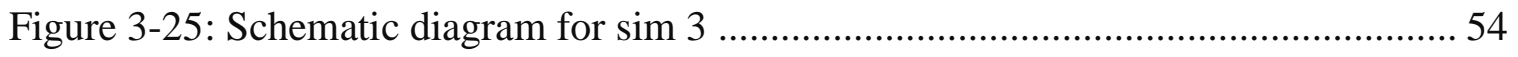

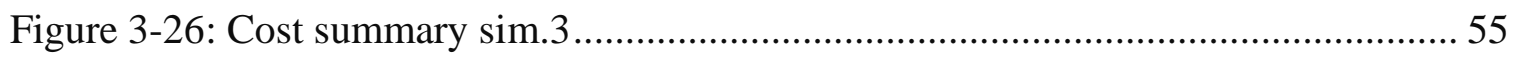

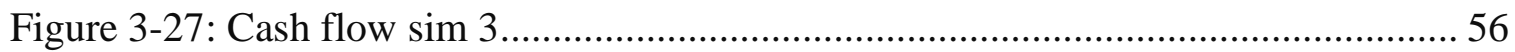

Figure 3-28: Electrical summary sim. 3 ………………….................................... 57

Figure 3-29: PV panel details Sim.3 ................................................................... 58

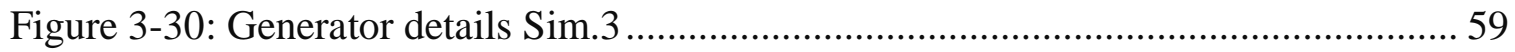

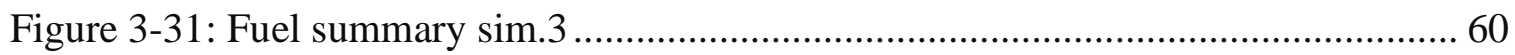

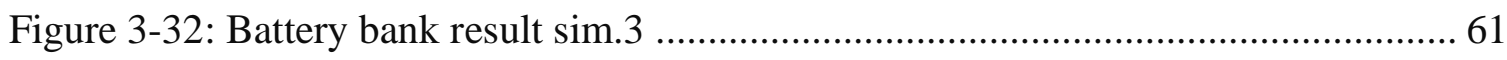

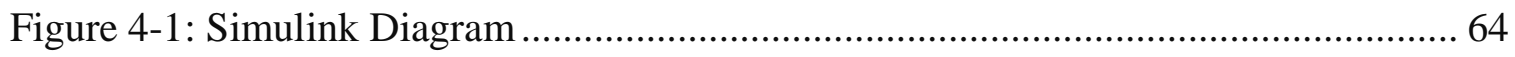

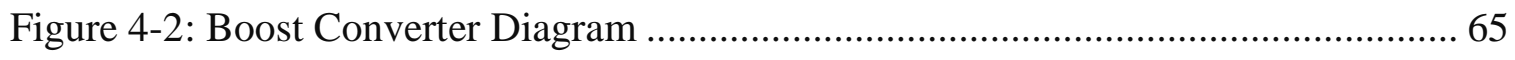

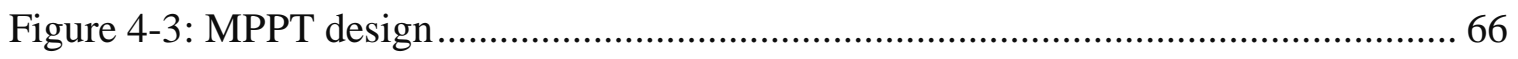

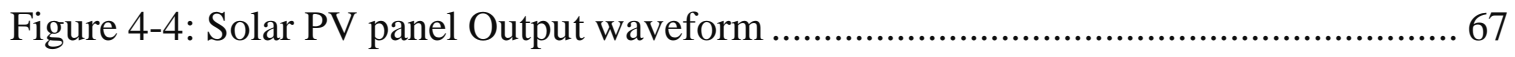

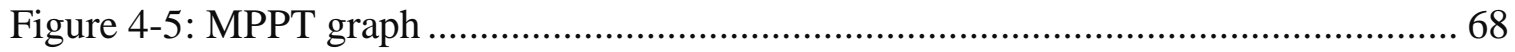

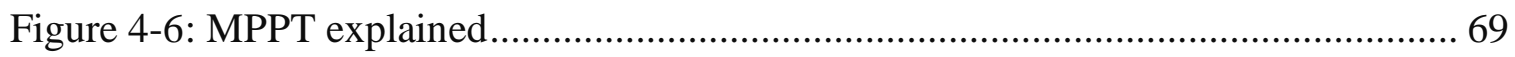

Figure 4-7: Block Diagram of P\& O algorithm ........................................................ 71

Figure 4-8: Current and Voltage waveform.................................................................. 72

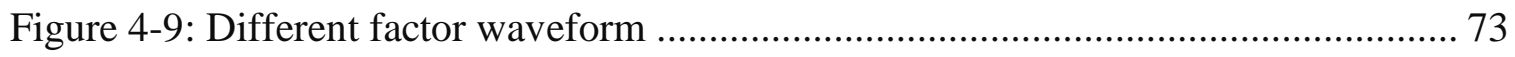

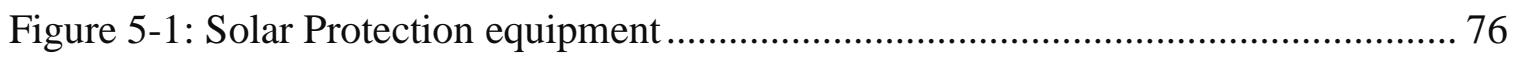

Figure 5-2: Surge voltage waveform ...................................................................... 77

Figure 5-3: SPD installation Scheme …………………….................................... 78

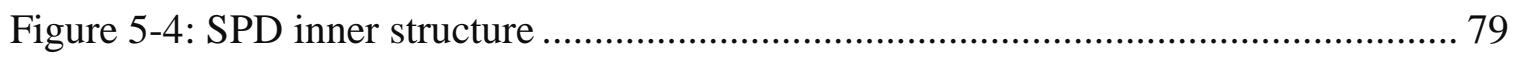

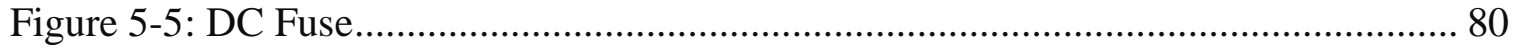

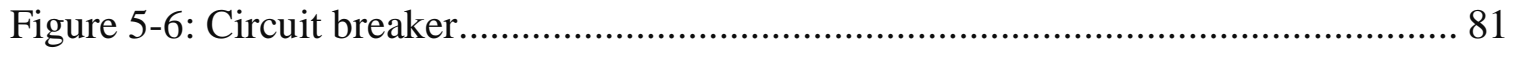

Figure 5-7: Schematic of Short circuiting .................................................................. 83 


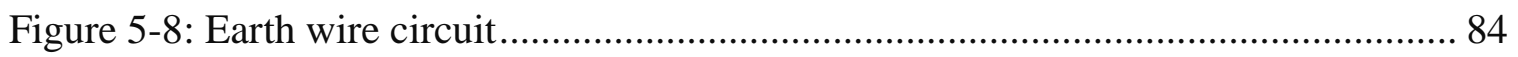

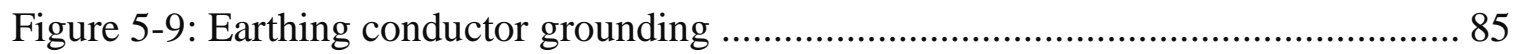

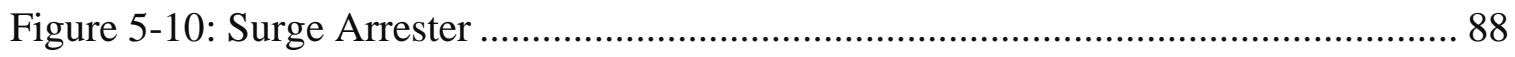

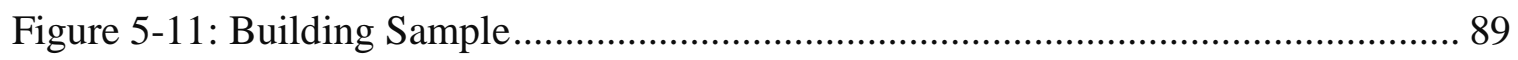

Figure 5-12: LP angle and radius of rolling sphere ................................................. 93

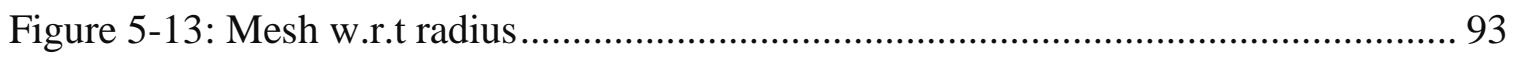

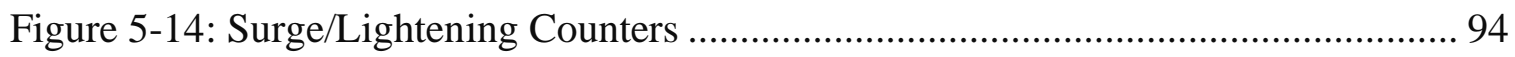

\section{List of Tables}

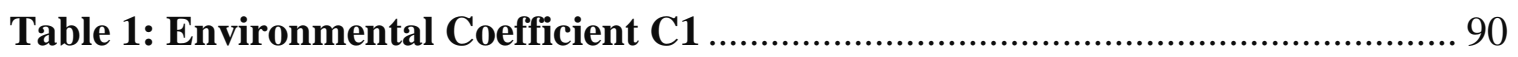

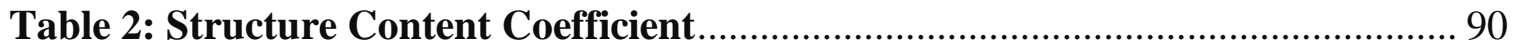

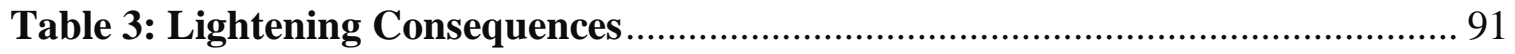

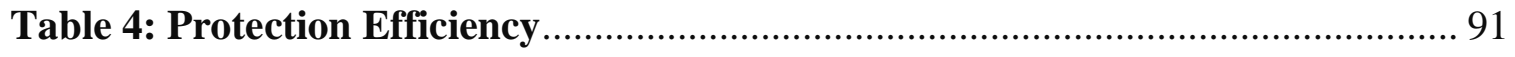




\section{INTRODUCTION AND LITERATURE REVIEW}

\subsection{Introduction:}

The Solar energy is a viable source of generating electricity, photovoltaic is the direct conversion of the solar energy into electricity. It can be used in number of applications. Solar Energy is very useful where the climatic conditions are appropriate. This source of renewable energy is a feasible and sustainable source of energy generation in the regions where Sun is incident on the surface for 6 to 10 hours [1]. This project is about installing an off-grid Hybrid PV system in a house or building. Though, the capital cost is high, but operation and maintenance charges of the PV system are very low. System installation and component selection is very critical in this project as it would affect the cost analysis and may prolong the payback period and make the project financially infeasible as well as alternative to the conventional sources of the energy which are affecting the environment. The simple hybrid PV system is shown in the figure 1-1 [2].

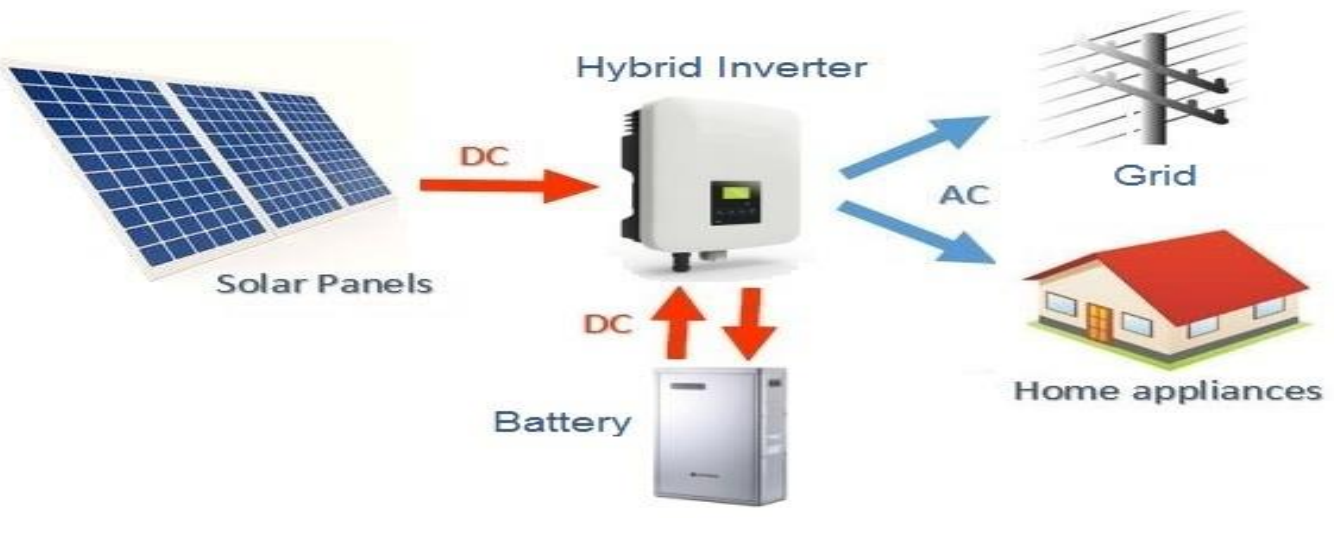

Figure 1-1 Basic Hybrid PV System

\subsection{Introduction to Photovoltaic Systems}

The Solar PV system has number of components when installed together produces electricity. Components should be selected according to the load requirements and applications [3]. Following are the components used in the fully functional system:

- PV Module

- Solar Charge Controller (PWM \& MPPT) 
- Inverter

- Battery Bank

- Wiring \& Frame

- $\quad$ Load (Home Appliances)

- Monitoring Device

PV module is the major component of the PV system, it is made from the semiconductor (Si), which converts sunlight to electricity. Photovoltaic effect causes semi-conducting materials to absorb photons of light and release electrons. Each Band gap in the material has a potential difference of $1 \mathrm{eV}$. Each PV cell is connected to form array of PV module. The output of Silicon PV cell is $0.5 \mathrm{~V}$ [3] The most common types are amorphous-Si, mono-crystalline and poly-crystalline. Amorphous Silicon has high final yield but the crystalline modules are efficient and high-capacity factor. The energy when not in use for load is stored in the battery bank of specific requirement and will be used in night or days of autonomy. Lithium-Ion are the most expensive due to high energy density [4]. Solar panels are made of different materials as shown in fig 1-2 [5]

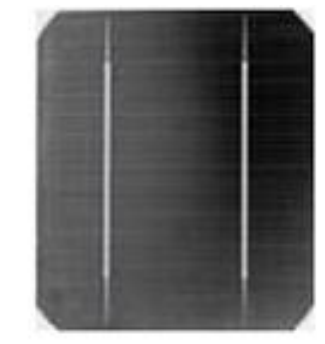

mono crystalline

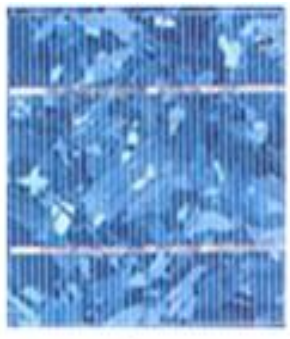

poly crystalline

Figure 1-2: Different Kinds of PV Cells

The batteries material is also important in storage of electricity. As the material will be able to store more charge the battery last longer. In this regard the best option is lithiumion battery. This relative comparison is shown in the figure 1-3 [6] as follows as. 


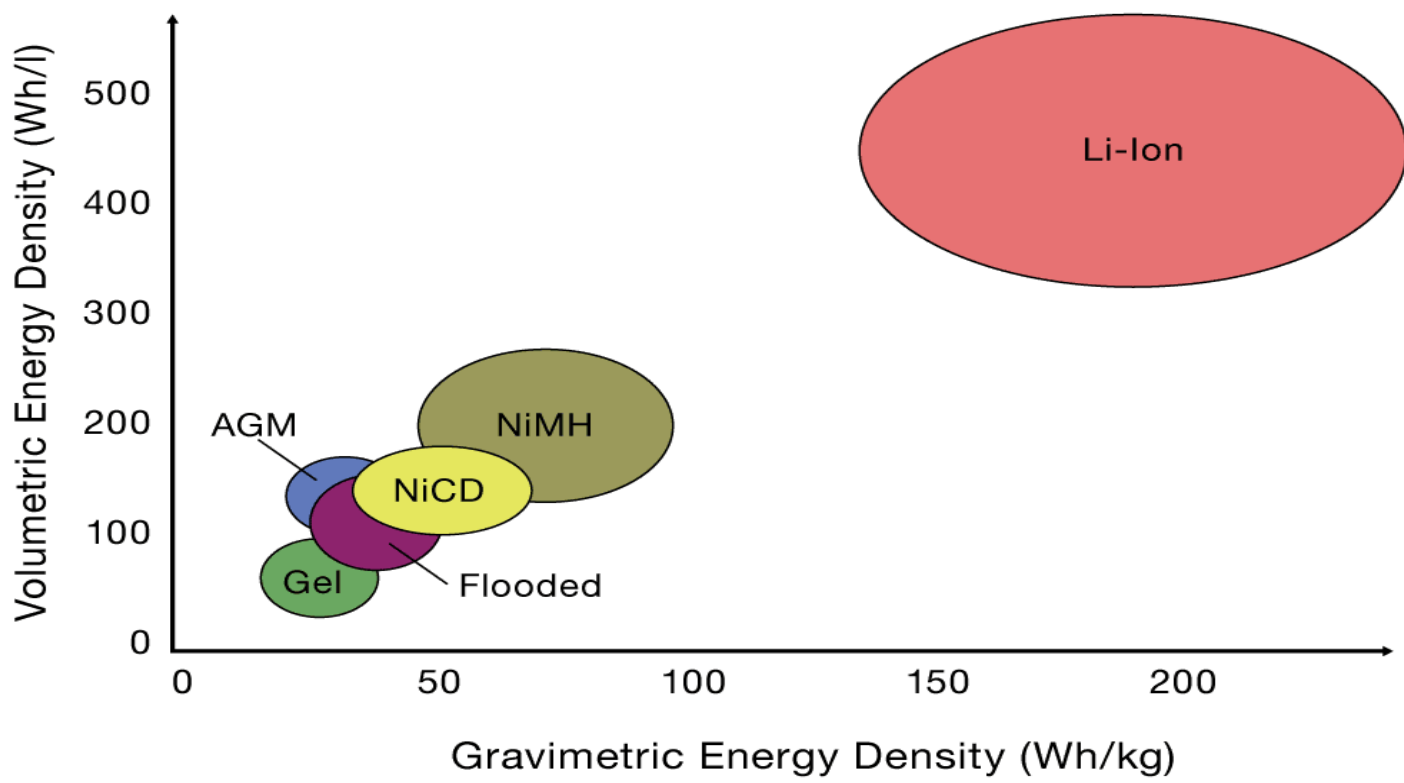

Figure 1-3: Battery Density Comparison

Solar charge controllers can be MPPT. It regulates the voltage and current to the battery and cuts off the power supply when the batteries are fully charged due to which life of batteries is increased. MPPT is the only way to regulate grid connected modules for battery charging.

Inverter converts $\mathrm{DC}$ current into the $\mathrm{AC}$ current for running $\mathrm{AC}$ home appliances. There are different types of inverters which are:

- Stand-Alone Inverters

- Grid-tie Inverters

- Battery Backup Inverters

- Hybrid Inverters

Each inverter has its own function, Stand-Alone Inverter is used in isolated system and not connected to the utility grid and simplest of all kinds. Grid-Tie Inverters shut down when there is a power loss from the grid. Hybrid Inverters are the most expensive and smart 
inverters which manages load according to the requirements and distributes among PV module, battery and grid [7]. These inverters are also used in the net-metering where excess electricity is sent back to the grid and money is saved for the consumer. Net metering is a technique of Electricity-billing that benefits green energy system owners with Solar System, Wind Turbines installed at their homes, for the electricity units they add to the grid. If a consumer of energy has a PV solar system on the home's rooftop, it can generate excess electricity than the house power requirements. Net-metering is the process of making the electricity meter run negative to provide a credit against excess electricity consumer has produced, $20-40 \%$ of a solar energy system's output ever goes into the grid. Exported solar electricity serves nearby customer's loads. This can be shown in fig. 1-4 [4]

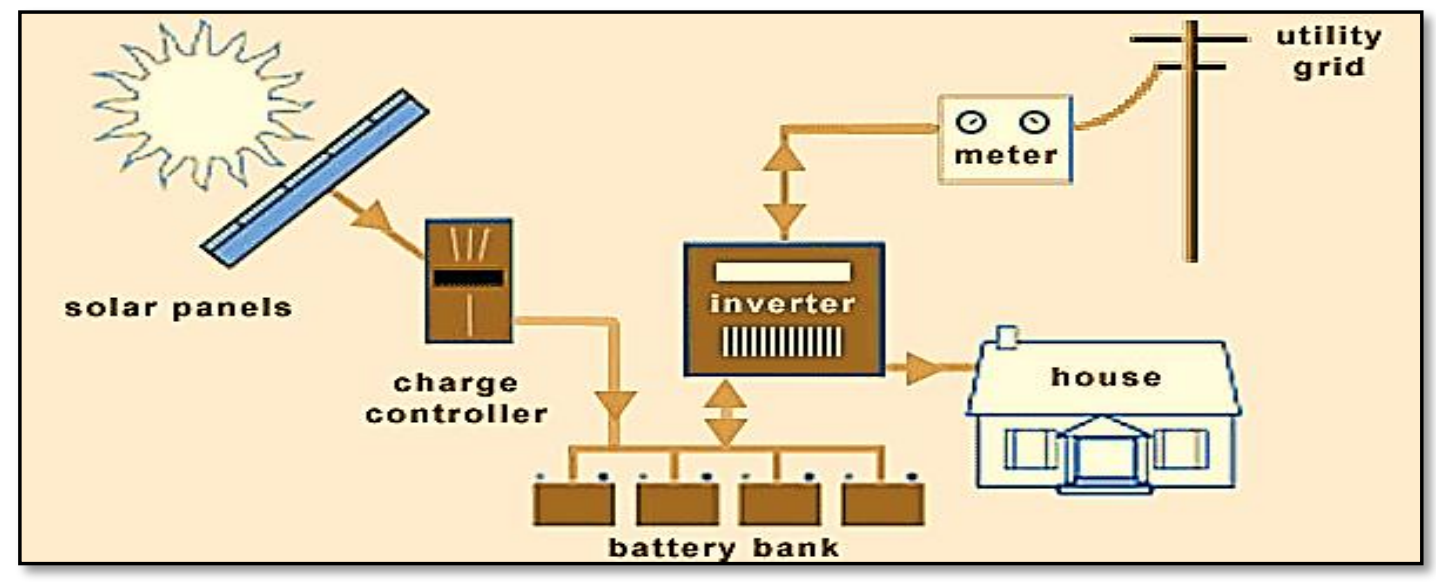

Figure 1-4: Net Metering PV System House

\subsection{Procedure for System Design:}

Following are the detailed steps in the procedure of the PV System Design [9]:

1. The electrical devices are itemized along with their power ratings and number of hours in operation in a day. Average Energy Demand is calculated in Watt-hour per day. This is multiplied with the correction factor in order to incur any losses in the system which is usually 1.3. This is done to avoid the under-sizing of the system.

Total Energy $=$ Energy Demand $*$ Correction Factor 
2. After the total load requirement of the house or building is known, next step is to size the PV modules array, PV panels must be connected in series in order to maximize output. Average sun hour per day of the region and VDC of the system must be known in order to select and size the PV panels. Peak Power is calculated by dividing the corrected energy load requirement with the sun hours. The total current will be calculated by using Peak Power and Voltage of the panels usually varies from 12 to $48 \mathrm{~V}$. Total number of the panels is calculated using two methods, first one is to divide the peak power by power of one module. Second one is much more reliable as it takes in account both the current and voltage. Number of Panels are calculated using the following relation in both the methods [9]:

$$
\begin{aligned}
N & =\frac{\text { Peak Power }}{\text { Rated Power of one Module }} \\
N_{P} & =\frac{\text { Total Modules Current }}{\text { Rated Current of One Module }} \\
N_{S} & =\frac{\text { System DC Voltage }}{\text { Module Rated Voltage }} \\
N & =N_{S} * N_{P}
\end{aligned}
$$

3. Third step is to size the energy storage [8] system which will be useful in the times when Sun energy will not available. Total Energy demand will be divided by number of factors as such as DoD, efficiency and voltage of the system. The resulted output is multiplied by the Days of autonomy which is the number of days system will run without sun-energy. The result is Ampere-hour capacity of the battery-bank. Number of Batteries will be calculated by dividing the total capacity by rating of single battery being selected. The relation are as follows [9]

Battery Capacity $=\frac{\text { Energy Demand } * \text { Days Autonomy }}{\text { Efficiency } * D O D * \text { Voltage }}$ Ah

4. For series PWM Charge controller, the sizing depends on the total short-circuit current which is delivered to the controller and series or parallel configuration. Capacity of controller is calculated from the total short circuit current and correction factor. MPPT Controller is designed on the basis of Open circuit voltage, for instance, for the $110 \mathrm{~W}$ panel, 5 of them in series $\left(V_{O C}=20.7 \mathrm{~V}\right)$ would yield 
103.5V at 7.6A into the MPPT Controller, but the latter would convert that down to $45.8 \mathrm{~A}$ at $12 \mathrm{~V}$. The factor of safety is employed to make sure that the regulator handles maximum current produced by the array [9].

$$
I=I_{S C} * N_{p} * F S
$$

5. To size the inverter, actual power rating of all the home appliances is added and an inverter from suitable manufacturer depending on the rating of $3 \mathrm{kVA}, 5 \mathrm{kVA}, 10$ $\mathrm{kVA}$ and $20 \mathrm{kVA}$ is selected as per requirements.

The below is the diagram of process [9]

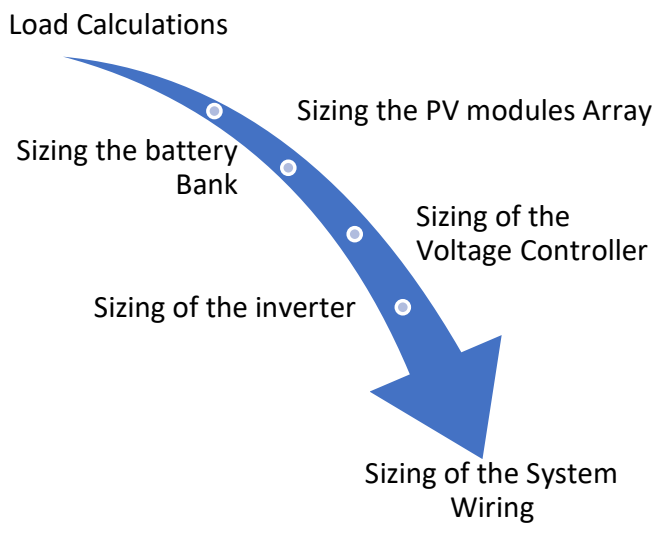

Figure 1-5: Solar Designing Steps

\subsection{Literature Review:}

P. Kaur et.al [1] proposed a DC solution for off grid homes. They reduced the battery bank size by 2.5 percent and also reduced the cost of power by half. They have used $48 \mathrm{~V} \mathrm{DC}$ as system voltage and used this same voltage for both the battery bank and consumption line. The AC voltage is put in optional for this system. Thus, they improved the existing DC models. Additionally, they used blue tooth interface and operated thus proposed a method in which you can remotely access the solar in range of the blue tooth. 
Kitson, $\mathbf{J}$ et al. [3] developed a model using various renewable resources for the off grid and near off grid commodities. They combined all of them to provide the off-grid power DC power solution. They used homer for the system designing and the Simulink for dynamic modelling. Wide range of the data has been collected for this purpose and organized in proper manner.

Sajeeb. H et.al [10] proposed a nano scale off grid solar model. They used this for making a separate system to domestic and household use and for the agricultural purpose separately. They applied it for the rural and remote areas. The scale could be both house hold and domestic

Nasir M. et. al [11] studied the photovoltaic solar home and standalone system. They aggregated the power using the multiple solar house system. The modified IV loop is studied and the MATLAB is used in the dynamic modelling of the system.

Sharma et.al [12] conducted research on modelling and simulation of the off grid solar system using photovoltaics. They used battery storage, local load PV and wind a component for their system.

Ramachandran et.al [13] purposed an inverter less central management system for off grid and nearly off grid systems. They integrated the main power and the solar line in such a way that normally the system will provide the power but in case the power is low than it will manage the load with the transmission lines and thus there will be no interruption.

Singh et. al [14] made a hybrid energy model. He then computed and simulated this model on the homer pro. This hybrid model consists of multiple energy sources such as biomass fuel gas, fuel cells and solar. This power for each of the energy source $5 \mathrm{~kW}$. the levelized cost per unit achieved is $15 \mathrm{Rs} / \mathrm{kWh}$ and per day production reached $100 \mathrm{kWh}$. He uses standard homer mechanism all data was collected and fed to homer and computed and simulated to find the optimum results.

Rousis et.al [15] conducted a research in which they developed a model for hybrid energy. There model consist of PV array, DC generator and both AC and DC load, Simulation is done on the homer pro. Multiple option has been used and out of the them most feasible 
one was selected as per homer optimization. Additionally, they have calculated CO2 emission to the environment and also calculated the fuel consumption.

Madziga et.al [16] performed experiment with multiple options. they component they have used are PV array, Diesel generator and the battery bank. They have used three combinations. PV with generator, PV with battery bank and PV, generator and battery bank. Each of the case is simulated and compared. They have also changed the PV power value as $1,0.8,0.6$ and $0.4 \mathrm{~kW}$. They have also varied the battery bank size. Another major improvement is the calculation of the emission and fuel during this power supply. They also estimated that cost of battery bank is $26 \%$ of total cost. Thus, whole study for each case is presented.

Esmail et.al [17] developed a model in which they used they combined PV and wind. They used homer for the simulation and results verified that $78 \%$ of the total consumption was PV supported and $22 \%$ was wind supported. And the dynamics modeling done on MATLAB.

Al-Shamani and Najah [9] developed a standard stand-alone system for a normal household application. They also developed and performed calculation regarding full sizing of the solar plant and all of the components involved in it.

Tahir et. al [18] conducted a detailed research on the solar condition of Pakistan. The electricity condition is examined and alternative resources in the Pakistan. Also; they have conducted research on the solar potential in Pakistan. The solar irradiation, power with respect to each region of Pakistan and explained potential in terms of data of each region. Ali et. al [19] conducted a research in which they studied the rooftop PV systems. In their study, they analyzed seven different structure of solar at different location. Then they examined the results on the basis of different factors such as efficiency, yield etc. they used PV syst software for the system designing and simulation. They did this in Dubai, UAE. S S kumar [20] write a review about net metering. In study he discussed the net metering in details. He described the mechanism to do the net metering, the factors influencing and other factors. 
Li, Matthew et. al [21] studied the lithium-ion batteries in detail. Under the research they researched the developmental stages of the lithium batteries, their construction. The material properties such as material porosity and current. They also explained the current properties and storage capacity of the lithium-ion batteries

\subsection{Objectives of the Research:}

The usage of solar energy is increasing day by day both in terms of demand and usage. Our aim is to provide the most useful solar solution while maintaining the novelty. So, we will be designing a solar system for a house-hold application. We will design off grid system with DC load along battery bank. The off-grid application is considered because we want the system to be independent of the grid so that it can be used at any time. Also, we are considering battery bank so that excess of energy could be stored. Then dynamic modelling of the system will show actual output waveform.

\subsection{Thesis Outlines:}

Following are the research outlies that we follow throughout the thesis.

- First chapter is related to the introduction to Solar PV and the system. We have discussed the term involved method to produce it. Literature review is also discussed in the chapter related to what is done previously on the off grid solar, battery banks and PV panels.

- Second chapter is related to actual designing of the system. We have described all of the parameters of the designing and explained them. Then each step of process is explained thoroughly. Then actual system PV, battery bank and charge controller is designed by selecting specific model and according to actual loading and consumption. All of this sizing is done. 
- Chapter 3 is related to actual system designing on homer software. We have designed three system which were designed by changing the parameters. Each of the designed output graph and the figure are presented in the chapter.

- Chapter 4 is related to dynamic modelling on the system on the MATLAB to show the actual output of the system. We have discussed the $\mathrm{P}$ and $\mathrm{O}$ algorithm and boost converter. We have shown resultant output.

- In chapter 5 we have discussed the safety precaution for the AC and DC load and safety instrument used in the system installation

\section{SITE SELECTION \& SYSTEM SIZING}

\subsection{Site Selection}

The site selection and sizing are the most important step in the solar system design. It is the main area where the PV array is mounted that can be used to capture the light. The site should be selected keeping in mind the few things. Shading analysis is important. There should not be shadow or any hindrance that can minimize the radiation [16]. Site should be such so that panels should be fully exposed to sunlight. In that way the panel will get maximum sunlight. Then comes the sun hours and we should be careful to look what is sunlight duration in that area. Usually, the area with 4 peak hours is considered as ideal. Another factor is tilt angle. Usually, it varies with region but we can optimize it by using pyranometer and inclinometer. The location that we have chosen for our project is located at $31^{\circ} 30^{\prime} 15.4^{\prime \prime} \mathrm{N} 74^{\circ} 16^{\prime} 48.1^{\prime \prime} \mathrm{E}$. This site is located in the region of Lahore. The actual location from google can be shown in the figure 2-1 [22] 


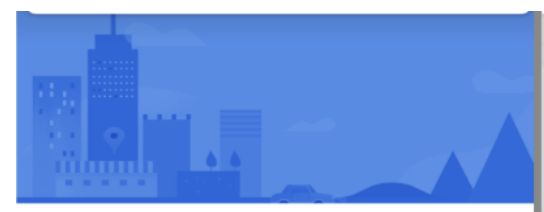

$31^{\circ} 30^{\prime} 15.4^{\prime \prime} \mathrm{N} 74^{\circ} 16^{\prime} 48.1^{\prime \prime} \mathrm{E}$ $31.504278,74.280028$

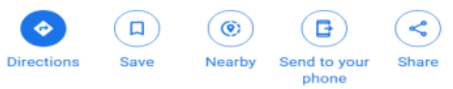

.: G73J+P2 Lahore

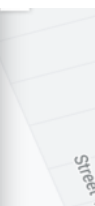

音

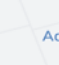

Admire

jeanswear
othing store

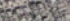

sistilite:

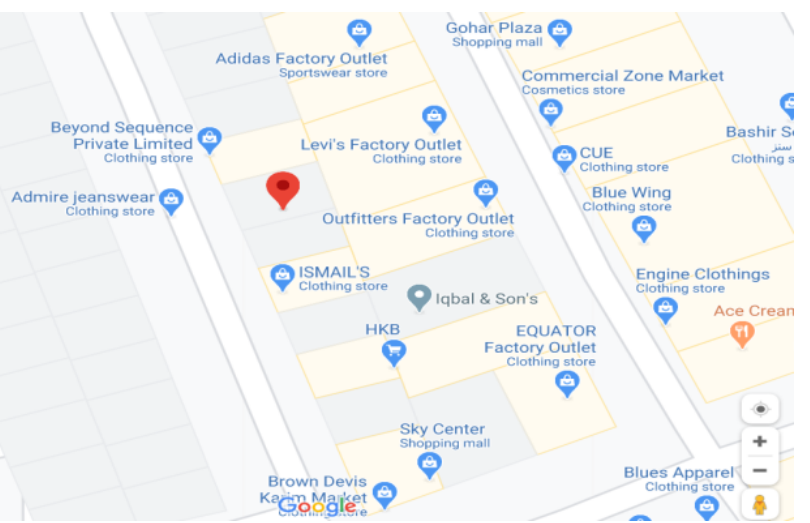

Figure 2-1:: Site location from google map

Throughout the year the temperature is varying. The GPS coordinates of Pakistan are $30.3753^{\circ} \mathrm{N}, 69.3451^{\circ} \mathrm{E}$. The geographical position of Pakistan is such that it has variety of the seasons [23] Generally, 4 seasons are observed.

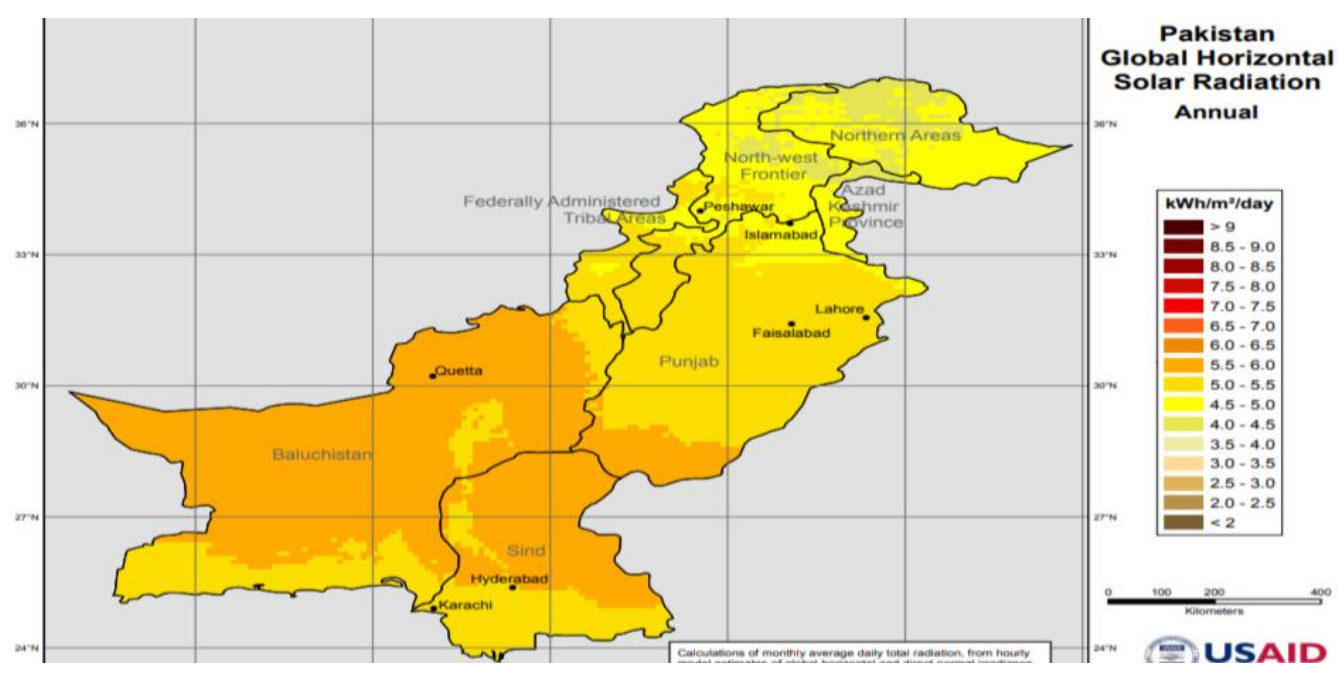

Figure 2-1: Global radiation map of Pakistan

Lahore is the one of the regions where the radiation is high in number so this can lead us to ideal place for selection of off-grid PV solar system. In Lahore, similar to Pakistan the 
radiations are at peak during may, june and july. Thus solar radiations are also at peaks during these months [24]. this can be shown in figure 2-3.

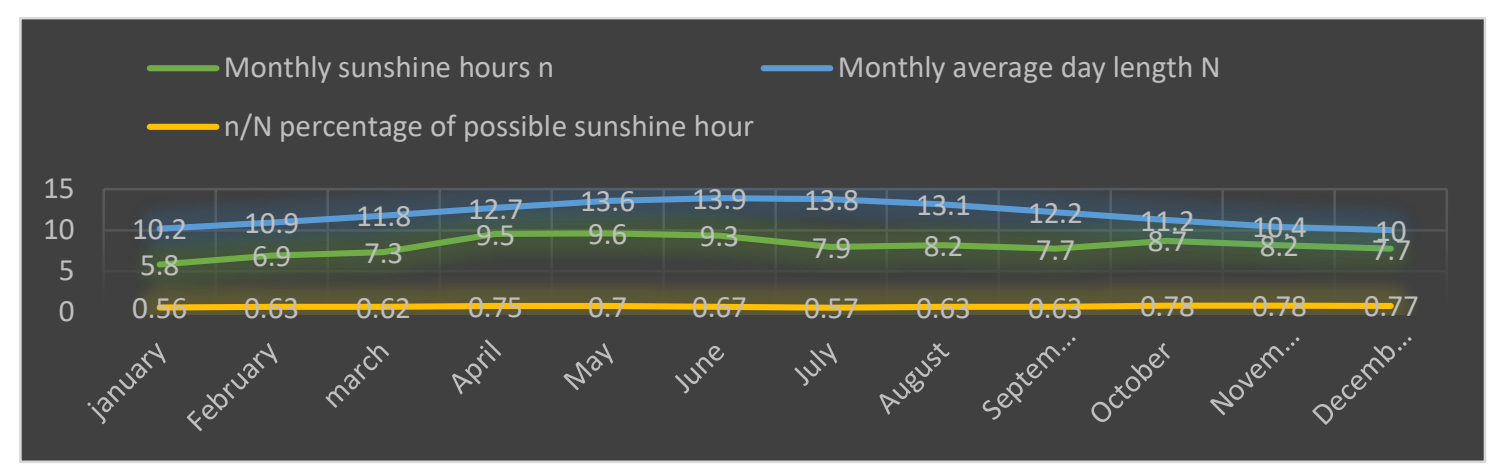

Figure 2-2: Global solar radiations in Lahore

This is due to very limited fossil fuel resources and poor economy, which restrains the import of fossil fuels on a large scale. To overcome energy shortage, Pakistan needs to develop its indigenous energy resources like hydropower, solar and wind. Pakistan lies in an area of one of the highest solar insolation in the world. The location of Pakistan makes it unquestionably the best. This energy source is widely distributed and abundantly available in the country. The mean global irradiation falling on horizontal surface in Pakistan is about 200-250 watt per $\mathrm{m}^{2}$ in a day with about 1500-3000 sunshine hours in a year. The south-western province of Baluchistan is particularly rich in solar energy. It has an average daily global insolation of $19-20 \mathrm{MJ} / \mathrm{m}^{2}$ day $\left(1.93-2.03 \mathrm{MWh}\right.$ per $\mathrm{m}^{2}$ in a year) with annual mean sunshine duration of 8-8.5h [24]. Such conditions are ideal for photovoltaic (PV) and other solar energy applications. The Energy Information Administration describes the daily solar energy potential for Pakistan as $5.3 \mathrm{KWh}$ per $\mathrm{m}^{2}$. The overall radiations through the year are suitable as obvious from the figure 2-4 [25]. 


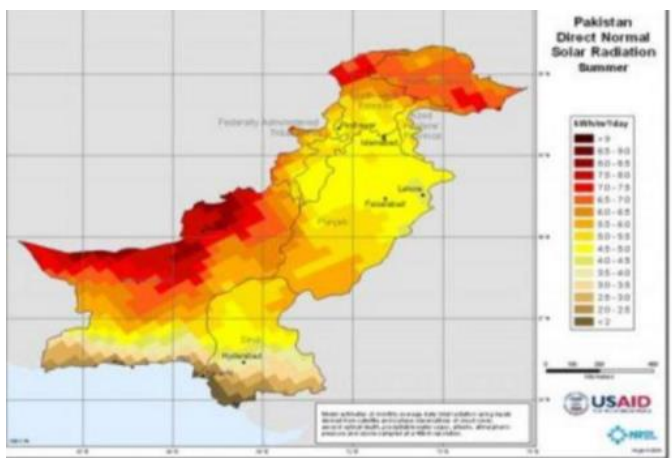

Direct Normal Solar Radiation for Summer (June, July, August)

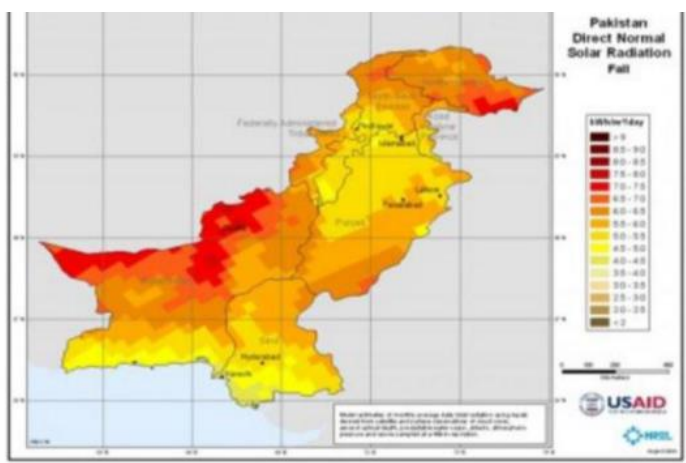

Direct Normal Solar Radiation for Fall (September, October, November)

Figure 2-3: Solar map for June to November

It is obvious from the above figure the region of Pakistan and color scheme particularly indicate the corresponding temperature. In Pakistan actually the main season for the hot weather are the June to September and so during these days the temperature is so hot and high and solar work on it maximum power and so we can get huge power from the sun and this thing aid the idea of solar installation. As shown on figure 2 and 5 the overall radiation throughout the year with interval of three months [25].

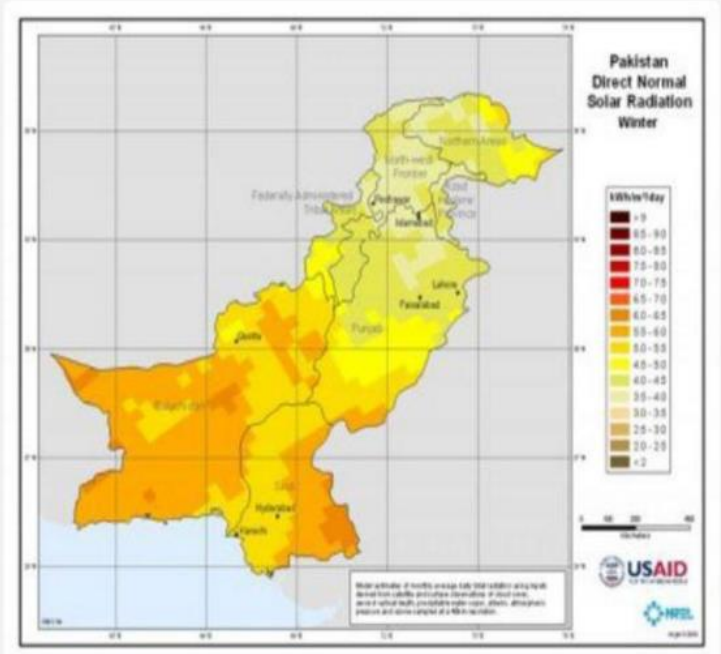

Direct Normal Solar Radiation for Winter (December, January, February)

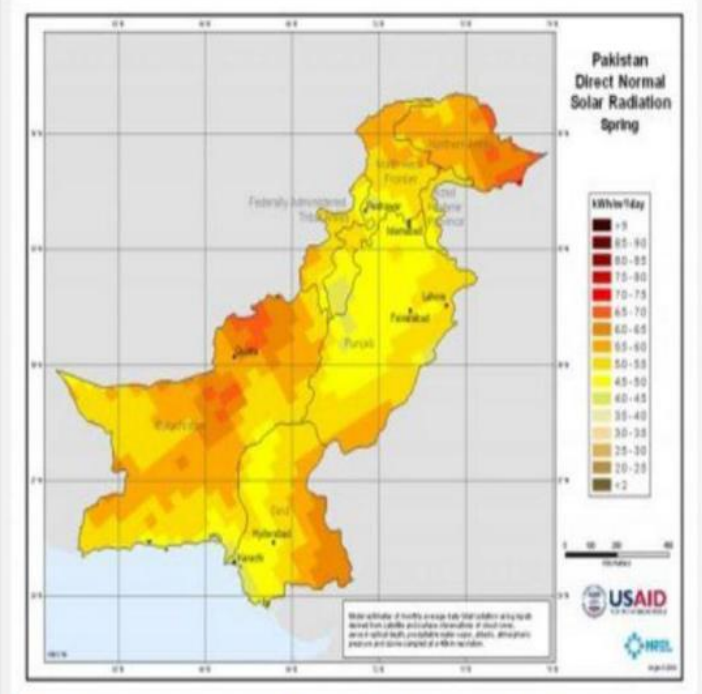

Direct Normal Solar Radiation for Spring (March, April, May)

Figure 2-4: Annual Direct Normal Solar Radiation

Pakistan covers $796,095 \mathrm{~km}^{2}$ of land between latitudes $24^{\circ}$ and $36^{\circ}$ north and longitudes 
$61^{\circ}$ and $76^{\circ}$ east. Country is facing serious energy problems. Every day, the country receives an average of about $19 \mathrm{MJ} / \mathrm{m}^{2}$ of solar energy. This source can be utilized as an excellent alternative to fossil fuels especially in remote areas where access to fossil fuel is very difficult and there is no access to electricity. A daily average of global irradiation falling on horizontal surface is about $200-250 \mathrm{~W} / \mathrm{m}^{2}$. This amounts to about $6840-8280$ $\mathrm{MJ} / \mathrm{m}^{2}$ in a year [24].

\subsection{Basic System Sizing}

The important and most critical step is off-grid designing. Whenever someone require to install a solar electric system the first question to be asked is whether they want on grid or off grid design. In case of on grid designing; the energy for the user consumption is provided through the PV panels and surplus amount is sent to the grid. Whereas in the case of off-grid designing the electricity is stored in the separate system called as battery bank. The solar with off grid is not dependent on the sun but for the on-grid matter how much small or large there is always some critical requirement of the Alternating current which can be possible with the grid. We must have to know all the aspects of the solar designing while we are designing the off-grid system. First of all, we discussed the typical schematic diagram of the off-grid system shown in the figure 2-6 below [26]. 


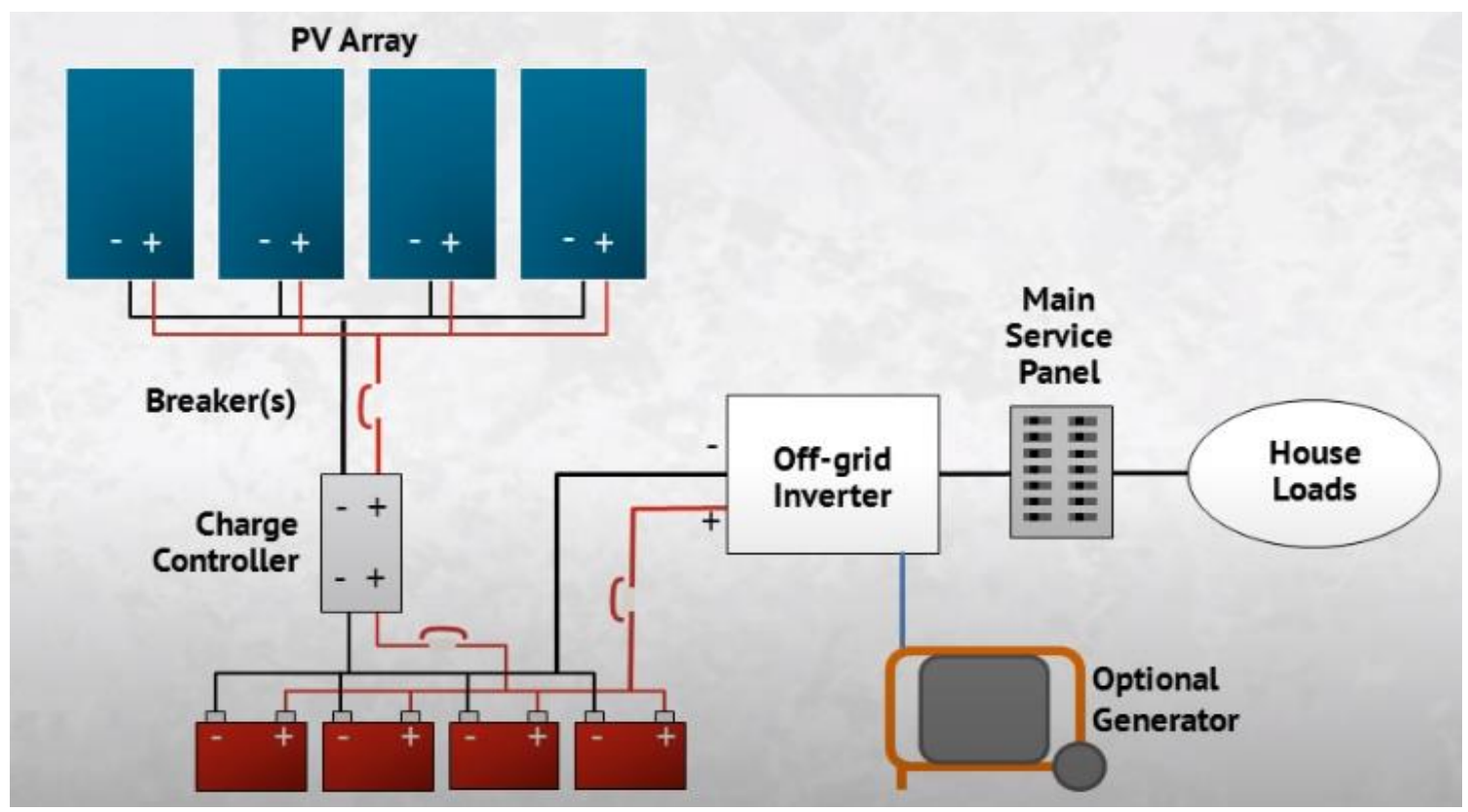

Figure 2-5: Off-grid solar system schematic diagram

PV array is basically our solar panel plates consisting of photo voltaic cells. They capture the solar radiations and photo voltaic action generates a current of moving electrons. They are mounted outside on the ground at certain angle. This electronic charge is the amplified by the charge controller. It modifies the current as per requirement of the system and then send it to storage battery. Then an off-grid converter/inverter is mounted that convert DC into AC because PV cell and dry batteries provides DC current while most of our house hold appliances and industry machinery operate on AC. So, inverter serves this purpose. Then this inverted current goes into switching panel where its supply to different location can be controlled and monitored. A back-up generator is provided to the inverter. This generator is for any instantaneous load. For instance, if you need to operate a grinding machine that consumes extra power. Now our system is not designed for this load. Hence, we will use additional power supplied by the generator. That's all is the phenomena of how off-grid solar system works. 


\subsubsection{Designing parameters}

In solar off-grid designing following steps [9][13].

i- $\quad$ Analyzing load and usage capacity.

ii- Designing battery bank

iii- $\quad$ Solar PV array designing

iv- Charge controller sizing

V- Inverter selection.

Now let us discuss each aspect in detail

\subsubsection{Analyzing the load and daily usage}

The first and foremost step is load calculation. We have to point out each and every load that will be include in the system. Calculate all of the appliances and instruments and note them separately. We have to design the system on load that is used for normal days. An anomaly should be noted separately. By anomaly we mean some extra load or power consumption. For instance, if you are designing the system for normal office days. In these days there will not be any abrupt load. But if you need a repair and maintenance or for any other purpose if we need additional load then we must add some additional source in order to support that additional power so we should provide power continuously. Calculate each of the AC source and DC source. Enlist each of the item with their separate specs. Tabulate them and use calculator or manual calculation to find detail watt. Check the labels of each items. The details of each of the item is usually mentioned on them. Usually the power, current or voltage is given. We can easily estimate missing values by taking their standard value against each appliance. Unit of energy consumed is $\mathrm{kWh}$. If one-watt power is consumed in one hour then energy consumption is one $\mathrm{kWh}$. For DC appliances same formula is applicable. Power for some item are difficult to find and in some case the appliances are energy star labelled. This label indicates the energy 
consumption per year in kWh [26]. Now in that case we divide that value by 365 and thus we get consumption in one day. Also, in some case wattage or no other information is provided on the appliance and thus it is crucial to find the value and so an instrument used called watt-meter [27]. This can be shown in the figure 12. This meter is plugged into that particular device of which rating we are about to find and it give average wattage per hour consumption of the electricity.

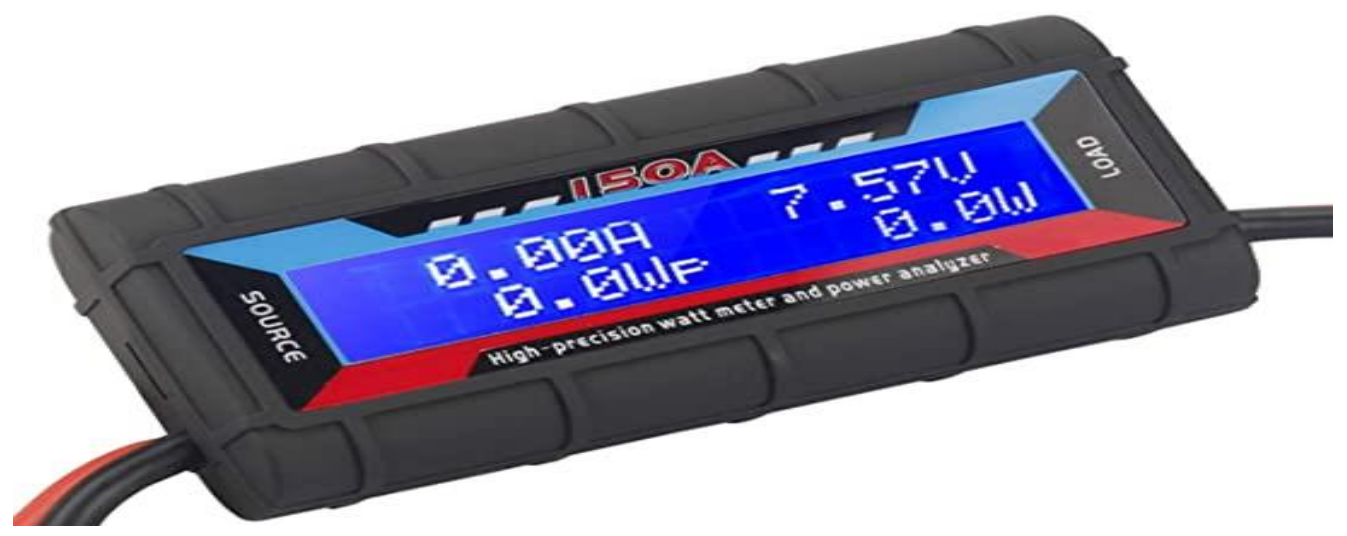

Figure 2-6: Watt meter principle

The appliance load is calculated and tabulated as below .

\begin{tabular}{|l|r|r|r|r|r|}
\hline Item & $\begin{array}{l}\text { Power } \\
\text { (W) }\end{array}$ & $\begin{array}{l}\text { Qty } \\
\text { (n) }\end{array}$ & $\begin{array}{l}\text { Number of } \\
\text { Hours (h) }\end{array}$ & $\begin{array}{l}\text { Energy Wh } \\
\text { W x n x h }\end{array}$ \\
\hline Tube Lights & 60 & 2 & 6 & 0.720 \\
\hline Energy savers & 32 & 4 & 6 & .7680 \\
\hline Fan & 80 & 1 & 9 & 0.720 \\
\hline Fridge & 180 & 1 & 9 & 1.620 \\
\hline Air-Conditioner & 1000 & 1 & 4 & 4.000 \\
\hline Total Power & & & & & $7820 \mathrm{Wh}=7.82 \mathrm{kWh}$
\end{tabular}

Figure 2-7: Daily Load Calculation

The watt meter is common electricity meter that is installed outside our home but for 
small scale application, the meters are also available. Now after calculating all of the watt and considering all of appliances the table can be generated as follows.

\subsubsection{Designing the battery bank}

The battery bank is the main component to store electricity. Now there are certain point in this regard that need to be addressed.

First, we need to consider that what voltage and current; the battery bank made. It may be $12 \mathrm{~V}, 24 \mathrm{~V}$ or $48 \mathrm{~V}$ and the amperes are produced accordingly per design. Now the formula is product of voltage and current. Power $\mathrm{P}(\mathrm{W})=$ Voltage $\mathrm{V}(\mathrm{v}) \times$ current I (amp). Now here below is the table to illustrate how to calculate the capacity of battery bank [26]

\subsubsection{Step in order to calculate:}

\section{STEP 1: DETERMINE AVERAGE DAILY WATT-HOUR}

We will calculate for both AC and DC collectively. However in case of DC only, AC can be omitted.

$(($ Avg AC Wh consumed/inverter efficiency $)+$ DC Average Wh $)=$ Avg-daily watt hours

\section{STEP 2: BATTERY BANK CAPACITY (WATT-HOUR)}

(Average daily $\mathrm{Wh} \times$ Days of autonomy* $\times$ battery T multiplier**) $/$ discharge limit $=$ battery bank capacity Wh

* day when there is no sun

** that corresponds to change of battery capacitance with change in temperature 
STEP 3: DETERMINING BATTERY BANK CAPACITY IN (AH)

Battery bank capacity in Wh / System voltage = battery bank capacity in Ah

\section{STEP 4: FIND NUMBER OF SERIES STRING \& NO. OF BATTERIES IN EACH} STRING

Battery bank capacity (Ah) / maximum no of parallel strings = minimum battery capacity DC system voltage $/$ battery voltage $=$ batteries in each string .

Battery bank capacity in Wh / System voltage = battery bank capacity in Ah

Now we will calculate the battery bank. The energy consumption per day $=7.82 \mathrm{kWh}$ $=7820 \mathrm{Wh}$

Size of battery bank = (energy cons. per day in Wh x days of autonomy $) /($ DoD x system voltage $\mathrm{x}$ battery efficiency)[66] $=(7820 \times 3.5) /(0.34 \times 48 \times 0.85)[67]=1980 \mathrm{Ah}$

Now battery that we are using is $12 \mathrm{~V}$ and $190 \mathrm{Ah}[66]$

number of batteries required $=1980 / 190=11$

no of batteries $=11$

number of batteries in series $=48 \mathrm{~V} / 12 \mathrm{~V}=4$

number of parallel strings $=11 / 4$

Thus, we have 3 string in parallel

\subsubsection{Array sizing/ Designing:}

Now another important part of the solar design is PV array. They capture the sunlight and uses it to make DC current. There are some terminologies that need to be defined while discussing PV. Insolation: it is the number of hours when sun intensity is equal to standard test condition. And there are certain maps that are available for any particular sites regarding insolation [26] 
While designing the array keep this thing in the mind that we have to look for the worstcase scenario i.e., winter. Now we must also account for inefficiencies. The main factor that reduces the efficiency are dust, debris and shadowing are some factor that can reduce it. So now we will provide step by step calculation for the array sizing [11]

\section{STEP 1: DETERMINING PV ARRAY SIZE DEPENDING IN LOAD}

(Avg daily Wh $\times$ system efficiency) / Worst case sun hours* $=$ Minimum size $(\mathrm{W})$

*worst case sun hours are those where the sun does not rise e.g. a cloudy day

\section{STEP 2: DETERMINE TOTAL NUM. OF MODULES NEEDED FOR ARRAY}

Minimum array power $(\mathrm{W}) /$ Module size $(\mathrm{W})=$ No. of modules

\section{STEP 3: DETERMINING NO OF MODULE IN EACH STRING + NO. OF MODULES NEEDED}

System voltage $/$ Module voltage $=$ No. of modules per string

Total No. of modules/ modules per series string= No. of parallel strings

Calculate design PV panel for our system

Total power required $=7.82 \mathrm{kWh}$

Total plant rating $=$ power $/$ days of autonomy $=7.82 / 3.5 \mathrm{hr}$

$$
=2.2342 \mathrm{~kW} \text { approx. }
$$

Loss factor $=1.25$

Power plant $=1.25 \times 2.2342=2.7928 \mathrm{~kW}$

Panel required $=$ total power $/$ power of single $\mathrm{PV}$ panel

$$
=2.7928 / 0.325=8.5=9
$$

No of modules in series $=1$

Number of modules in parallel $=9$ 


\subsubsection{Charge controller sizing:}

Charge controller is another main component in the solar system. It varies the charge and voltage according to the requirement. Mainly there are two type of charge controller. Pulse width modulation (PWM) and maximum power point tracking (MPPT) [26]. We will discuss critical points.

\begin{tabular}{|l|l|l|}
\hline Sr. No. & Pulse width modulation (PWM) & Maximum power point tracking (MPPT) \\
\hline $1-$ & $\begin{array}{l}\text { Pulse has direct connection from } \\
\text { solar panel to battery. } \\
\text { Voltage of panel is pulled down } \\
\text { to battery voltage }\end{array}$ & $\begin{array}{l}\text { It convert voltage input to battery voltage } \\
\text { When voltage drop it it increases the } \\
\text { current }\end{array}$ \\
\hline
\end{tabular}

Main steps while designing the charge controller are as follows as

\section{STEP 1: DETERMINE TOTAL WATTAGE OF ARRAY}

Wattage of panels $/$ no. of panels in array $=$ total array wattage

\section{STEP 2: DETERMINE CHARGE CONTROLLER OUTPUT AMPS}

Total array wattage $/$ battery bank nominal voltage $=$ current 


\section{DC SYSTEM DESIGN AND OUTPUT}

As far as designing of solar PV system is concerned then there are certain ways in which we can design the system. We are mainly concerned with three configurations; Battery back-up PV system, DC generator along PV panels, Stand-alone system.

\subsection{Homer Software}

One of the essential steps in solar grid designing involved software designing. Several commercial packages are available for the solar design and simulation. We have chosen the homer because it is more convenient and accessible in terms of interaction between developer designers and field engineer. We have high value of customization in the homer. It was developed by Homer energy LLC in 2009 [28]. Mainly two types of packages are available in the homer for the desktop use. One is homer pro and other is homer grid. Homer pro is mainly used for the micro-grid and distributed energy resources. If there is small scaled energy analysis is required that is coupled with multiple energy resources then we sue the homer pro. While for grid and main commercialized energy supply we use homer grid. Current version of homer pro is 3.13.8. released on March $18^{\text {th }} 2020$ [28].

\subsection{Components of the homer:}

homer software can be easily downloaded from

https://www.homerenergy.com/products/pro [28] After installation we can see several components that can be explained further.

\subsubsection{Location:}

First thing in analysis is location selection. Homer has built in option for the map or

location selection. As per our project we have given the coordinates of and so Homer will 
automatically locate the site as shown in the figure 3-1 [29].

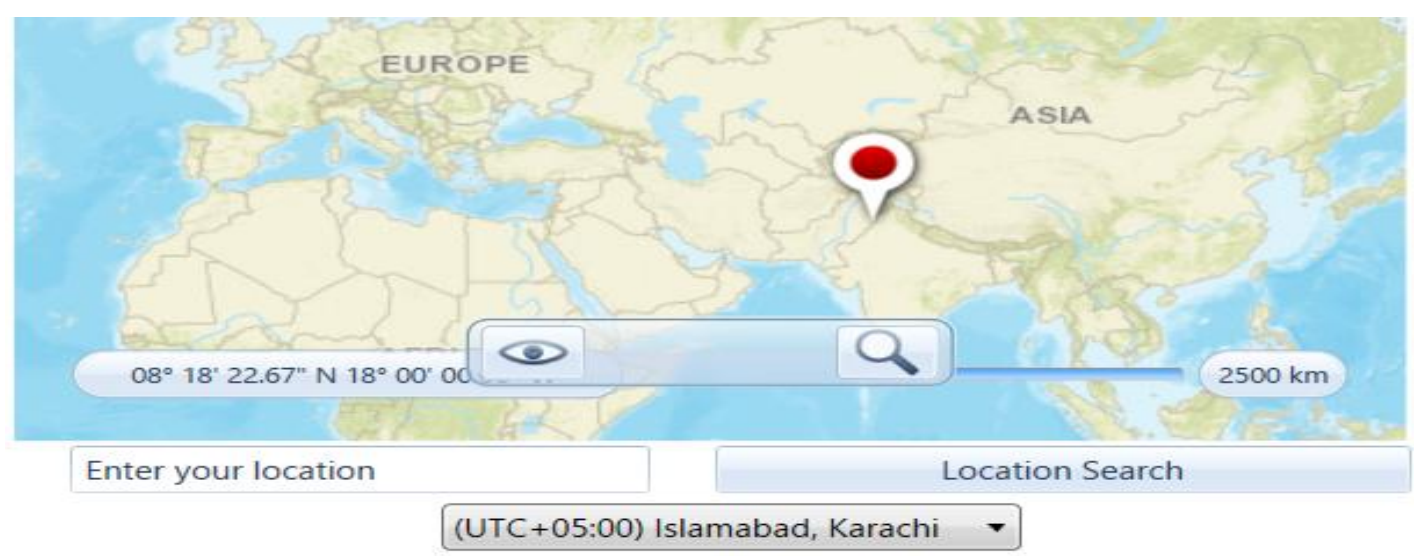

Figure 3-1: Site Location on homer

\begin{tabular}{|c|c|}
\hline Resour & \\
\hline \multicolumn{2}{|l|}{ Solar } \\
\hline & $\begin{array}{l}\text { National Renewable Energy Lab } \\
\text { National Solar Radiation Database }\end{array}$ \\
\hline 网 & NASA Surface meteorology and Solar Energy \\
\hline$\square$ & Global horizontal radiation, monthly averaged values over 22 year period (July 1983 - June 2005). \\
\hline \multicolumn{2}{|r|}{ Temperature } \\
\hline$n$ & NASA Surface meteorology and Solar Energy \\
\hline$\square$ & Air temperature, monthly averaged values over 22 year period (July 1983 - June 2005) \\
\hline \multicolumn{2}{|r|}{ Wind } \\
\hline$\square$ & $\begin{array}{l}\text { NASA Surface meteorology and Solar Energy } \\
\text { Wind speed at 50m above the surface of the earth for terrain similar to airports, monthly averaged values over } 10 \text { year period (July } \\
1983 \text { - June 1993) }\end{array}$ \\
\hline
\end{tabular}

Figure 3-2: Resources Tab

\subsubsection{Resources}

After loading the site location there is an option for the resources. The resources are basically global horizontal irradiance, temperature profile etc. they are basically available for every site. When we load the resources, it will show the different resource and we can 
easily download that.

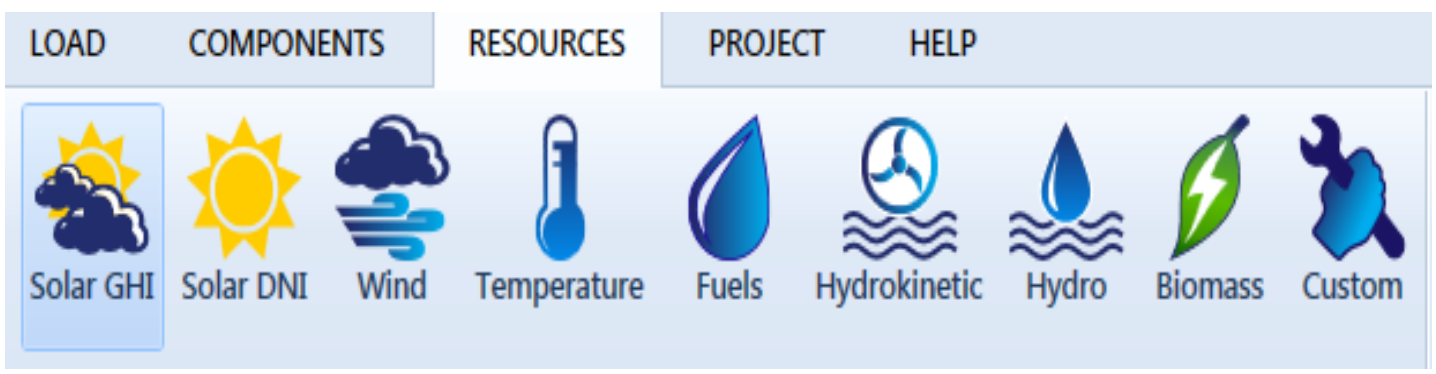

Figure 3-3: Resources template

It is then automatically fed. This can be shown in the figure 3-2 [30]. In the figure 3-3 [30], there are other resources. Their usage varies with the requirement. The last tab is custom; is the one resource that you want to add by yourself. We have downloaded temperature and solar irradiance data and is automatically loaded.

\subsubsection{Electric load:}

The next thing is the load. By the load we mean electric load that is consumed at particular site.in the electric we have to include all of the load. When we have to put the load there are various option available in that software. Firstly, there is built in temperature profiles. In that case we have to specify the month and peak month. Once we specify the peak month it will automatically load the electric load profile. It can be shown in figure 3-4 [31] 


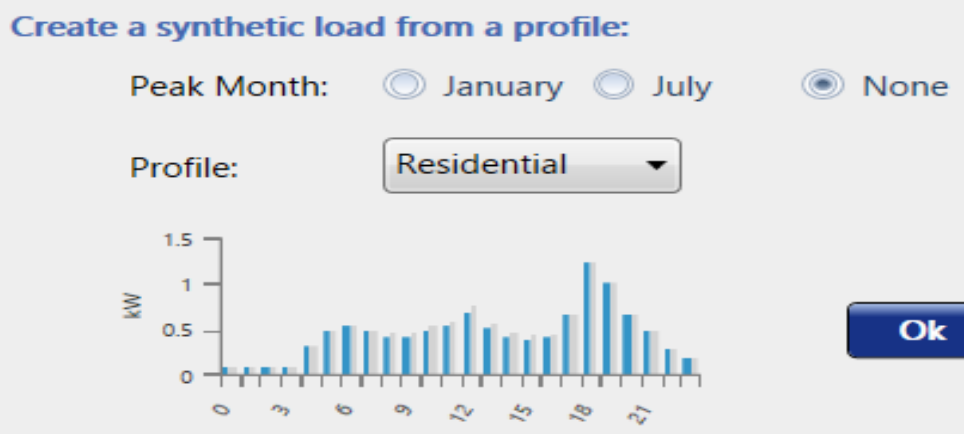

Figure 3-4: Synthetic load

profile can be commercial or residential or community. This is built in synthetic load shown in figure 16. Another way is importing file custom made. We can also import file that is custom built by user as per requirement. According to the homer guidelines there are mainly 6 types of formats are given according to which we can input the load data. For that we need specified format provided by homer software.

\subsubsection{Format of file:}

Six formats are given by homer are as follows. Two column formats in which date time (in $24 \mathrm{~h}$ format) are entered in one column and load in $\mathrm{kWh}$ in another column. Three column formats in which date time and load are given in separate column. Third one is green button format in which entries are meter number, date, start time, duration, value, edit code, flow direction and TOU. The largest one is forth, which is utility API in which entries are very large in number shown in figure. We have option 5 in which day by row is given it has data of each day in 24 hours [32]. All of the data requires to be entered must be in CSV format so that it could be easily readable by the software. For our calculations we have used day by row format that is shown as in the figure 3-5 [32] below. 


\begin{tabular}{|c|c|c|c|c|c|c|c|c|c|}
\hline & $0: 00$ & 1:00 & 2:00 & $3: 00$ & 4:00 & $5: 00$ & $6: 00$ & 7:00 & $8: 00$ \\
\hline $1 / 1 / 2014$ & 507 & 425 & 288 & 478 & 559 & 660 & 897 & 47 & 58 \\
\hline $1 / 2 / 2014$ & 600 & 201 & 698 & 264 & 174 & 318 & 477 & 523 & 170 \\
\hline $1 / 3 / 2014$ & 438 & 266 & 290 & 428 & 332 & 436 & 223 & 695 & 590 \\
\hline $1 / 4 / 2014$ & 456 & 123 & 534 & 747 & 969 & 393 & 349 & 627 & 945 \\
\hline $1 / 5 / 2014$ & 816 & 702 & 610 & 899 & 269 & 401 & 63 & 830 & 50 \\
\hline $1 / 6 / 2014$ & 646 & 973 & 690 & 711 & 701 & 638 & 145 & 302 & 769 \\
\hline $1 / 7 / 2014$ & 168 & 222 & 70 & 505 & 552 & 718 & 324 & 705 & 787 \\
\hline $1 / 8 / 2014$ & 778 & 809 & 857 & 910 & 534 & 813 & 432 & 118 & 169 \\
\hline $1 / 9 / 2014$ & 796 & 767 & 467 & 272 & 987 & 329 & 546 & 856 & 24 \\
\hline $1 / 10 / 2014$ & 238 & 477 & 748 & 986 & 660 & 183 & 166 & 530 & 729 \\
\hline $1 / 11 / 2014$ & 971 & 484 & 403 & 686 & 905 & 818 & 132 & 551 & 758 \\
\hline $1 / 12 / 2014$ & 846 & 799 & 472 & 185 & 815 & 328 & 571 & 756 & 444 \\
\hline $1 / 13 / 2014$ & 192 & 295 & 555 & 570 & 132 & 673 & 213 & 572 & 424 \\
\hline $1 / 14 / 2014$ & 265 & 770 & 143 & 577 & 783 & 745 & 735 & 774 & 430 \\
\hline $1 / 15 / 2014$ & 955 & 694 & 207 & 842 & 469 & 73 & 467 & 616 & 379 \\
\hline $1 / 16 / 2014$ & 341 & 243 & 766 & 481 & 799 & 34 & 383 & 531 & 130 \\
\hline $1 / 17 / 2014$ & 885 & 78 & 300 & 815 & 814 & 460 & 133 & 646 & 61 \\
\hline $1 / 18 / 2014$ & 949 & 17 & 290 & 411 & 192 & 297 & 108 & 808 & 288 \\
\hline
\end{tabular}

Figure 3-5: Load Format (24 hour)

We can see that in the figure each day of year is given and against each there is 24 hours reading of the load consumption in $\mathrm{kWh}$. The yellow column is day of the year and the horizontal yellow row on the top is hour of the day which is going to be 24 . Thus, the file is created that will consumed in software. 


\subsubsection{Components}

The important step in the process is component. These are the component that are all included in the solar system. Main thing for our concern is PV panels, generator, diesel etc. The components tab is given on the top as follows as figure 3-6 [33].

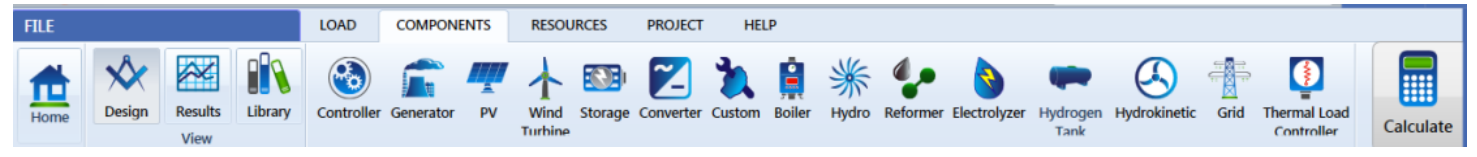

Figure 3-6: Components Tab

\subsubsection{PV panels}

PV panels are given in the directory of the components. The PV panels have all of the directory given in it. These panels have all of the information provided along with it. It has all of the spec. that are necessary for the PV panels. While selecting the PV panels we can have variety of option. All of brands are given in our PV catalog so that we

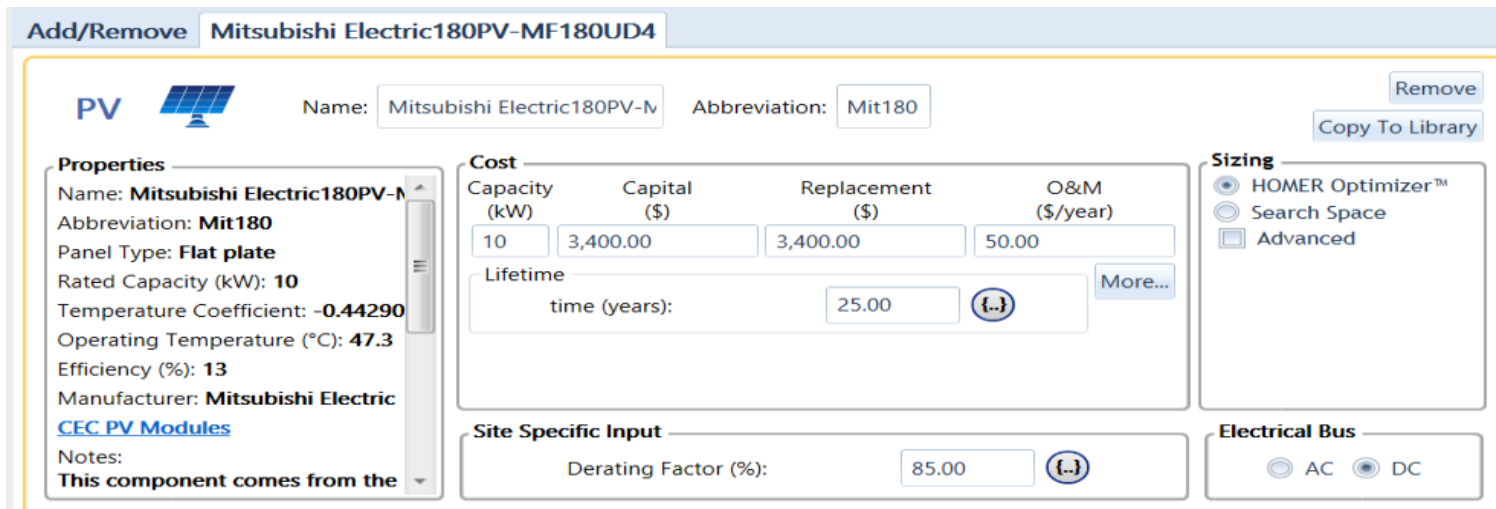

Figure 3-7: Sample PV setup Tab

can easily select the panel from the list. The sample PV tab is shown in figure 3-7 [34]. if you specify the brand then it is feasible otherwise we can provide generic flat plate in which it will automatically pick optimized plate which is optimized as per our requirement. It is also connected to $\mathrm{AC}$ bus or DC bus. But for our requirement. We can see in the figure that all of the specifications for the particular panel is given in the 
information so we don't need to put the data any plate except the name. there is an option for sizing. In this option we have choice either we assign the sizing values to choose between different option or use homer optimizer. Homer will optimize the sytem as per provided load.

\subsubsection{Battery}

next important component is battery. Now battery is also a crucial component in the PV system. If we consider off grid or battery bank we need to have batteries provided in our system. So for the battery tab is shown in the figure 3-8 [35].

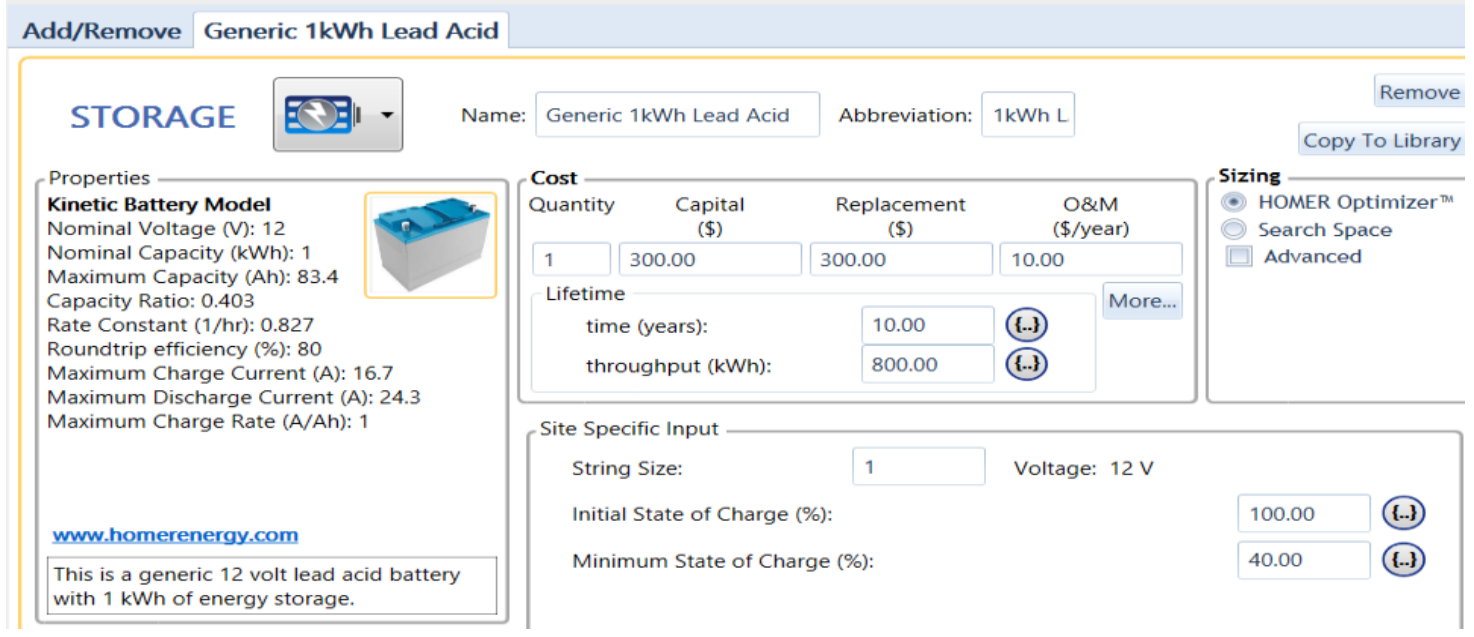

Figure 3-8:Sample Storage (battery)

Similar to above case the battery tab has various options. Either you can select it by brand or you can specify your own. First of all, there are brands of battery mentioned from which you can select or you can specify generic battery type. As defined in chapter 2 we have defined state of charge and other things, we can fix value of each of them. We can specify initial, replacement as well as maintenance amount for each of the battery select. We can also select multiple batteries we can also add it with proper specification. There is bracket given specifically against some option that indicates the sensitivity analysis. 
For the battery there is also option of lead storage, dry battery of cell. Once you specify the battery this will be added to simulation part.

Similarly, we have another component available in the bar that can be used as according to requirement. For instance, consider generator that we have used in one of our simulation. We require a DC generator so we used DC generator and bus is DC. Also, because our use is DC, we haven't used inverter but for the most case we require AC at the output so we use the inverter. This inverter can also be modified accordingly. As per figure 30 we can use multiple energy sources as per our need but we have to specify as sources differ with case. After putting all of the data we have completed the file. Our circuit of schematic diagram is also shown on the left side. We can see that in the bottom there is a ribbon they are parameter like sensitivity analysis rate etc. after completing all of the component then there is calculate button on the right side. it will simulate and gives us result which can be interpreted later.

\subsection{Actual project}

Actual Project location is as shown in figure 3-9 [22]

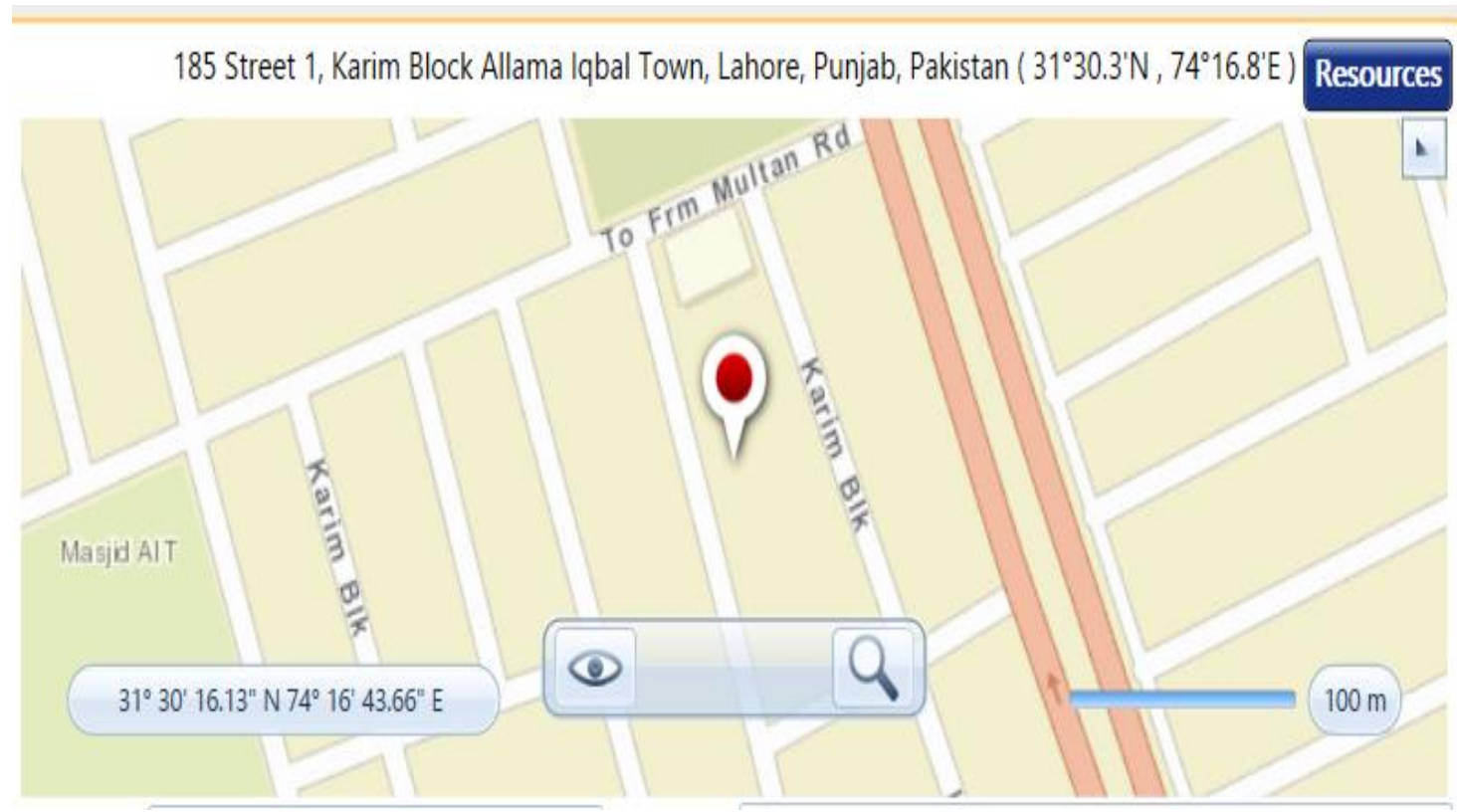

Figure 3-9: Project location 


\subsubsection{Location}

Location cordinates for our project are $31^{\circ} 30^{\prime} 12.15^{\prime \prime} \mathrm{N} 74^{\circ} 16^{\prime} 53.1^{\prime \prime E}$. this site is located in Lahore's Kareem market [22]. In chapter 2 we the geographic and weather condition of the site. When we go through the resources, we can find the solar and temperature data for the site such as GHI and temperature. It will automatically be loaded to the database.

\subsubsection{Electric load}

the next step is electric load feeding. We have used actual bill of the site. Then we have found $\mathrm{kWh}$ and plot the consumption against the year. In the figure 22 we have plotted the energy consumption throughout the year. In this pot we have each day energy plotted hourly. We can see that maximum 2 units are consumed per hour. There is more consumption in summer and less consumption in winter that witness that peak months are of summer (may, June, July). If we look closely, we can see that in month of July, there is anomalous behavior (less concentration of spikes). This is because in that month no or relatively less amount of energy is consumed as shown in fig 3-10. The middle of the 
load is low because the load file that we have taken has very low consumption during this month. So that is why the load is too low here.

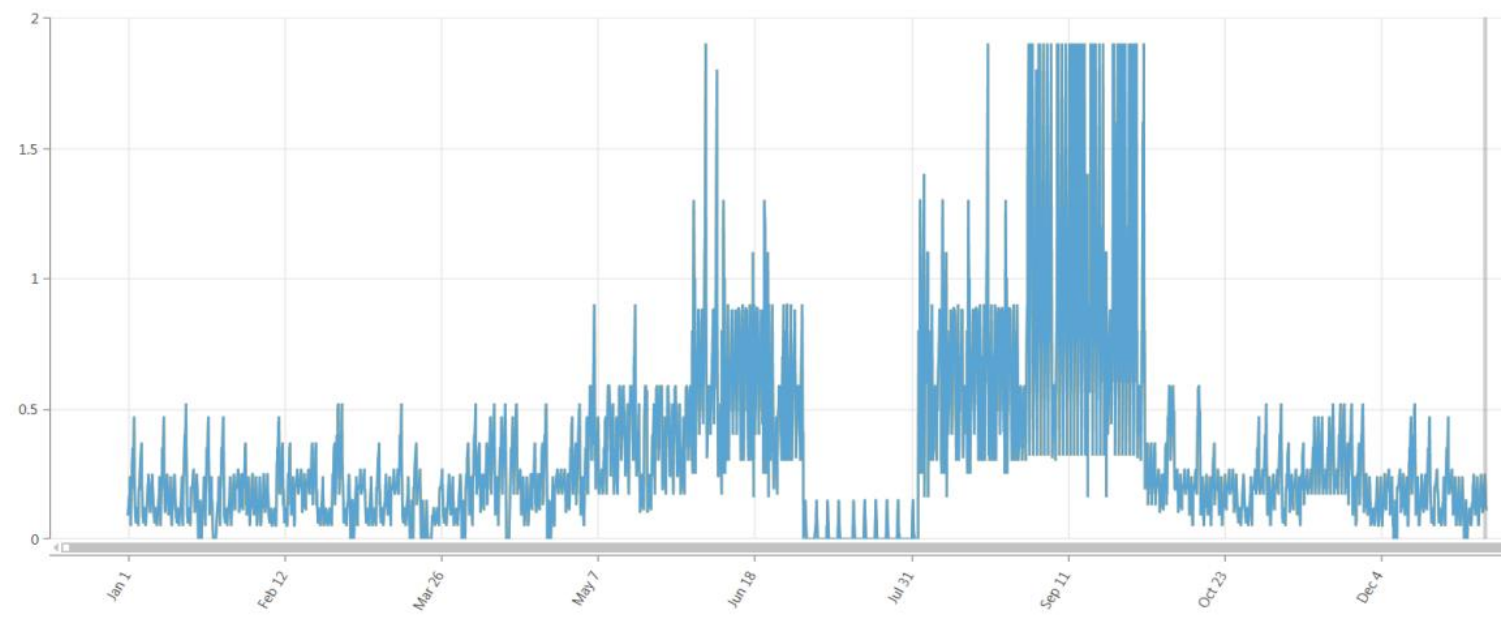

Figure 3-10: Energy Plot throughout the year

Energy plot of the homer for the individual month in shown fig 3-11. we can see that load consumption increase during the mid of month as major rise in graph occur in the middle.

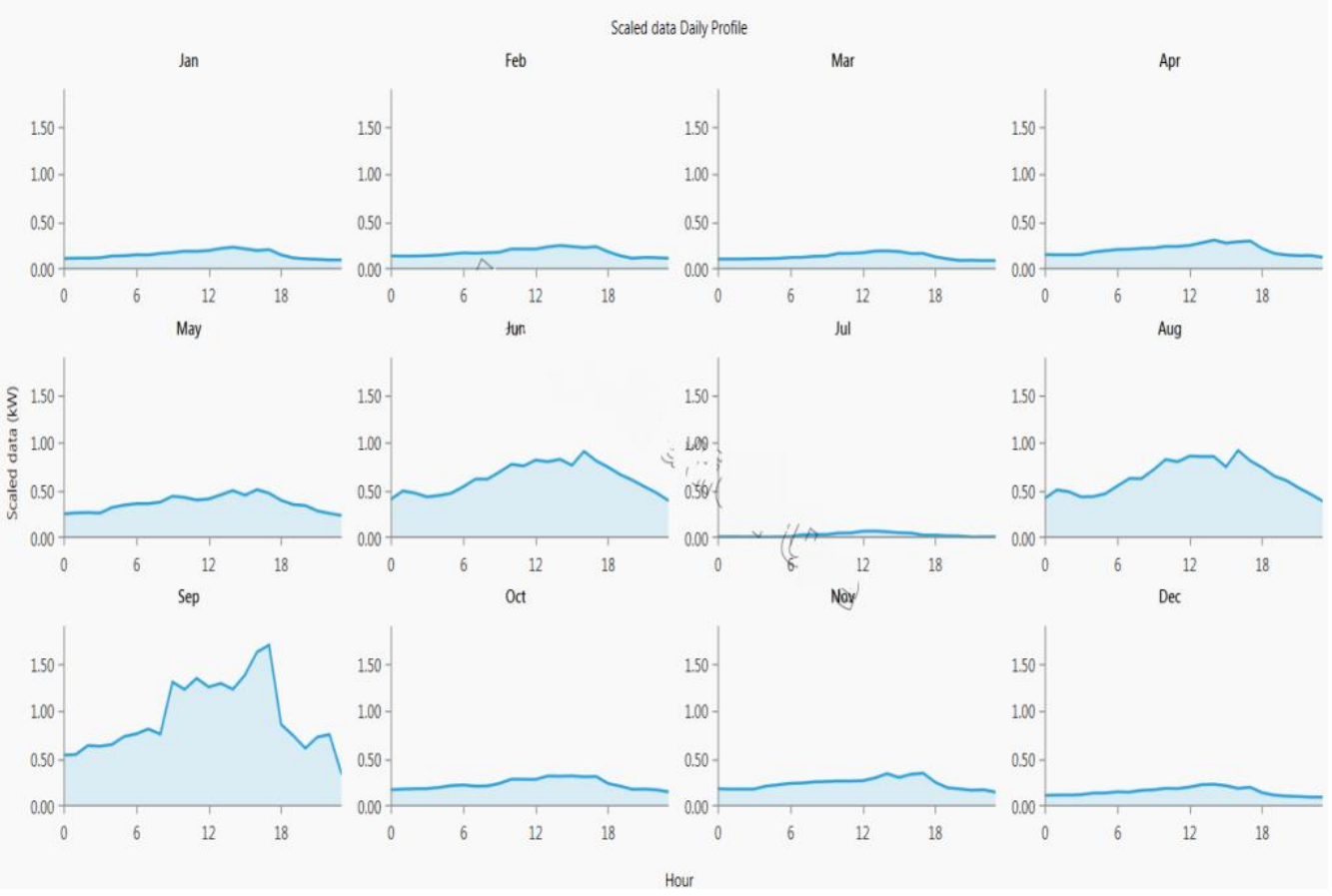

Figure 3-11:scaled daily profile 
Now even we look at the data closely we can see that our major consumption is in during the mid-hours of the day. Another graph generated by homer will elaborate this as shown in the figure 24 homer generated this profile based upon the file that we input. As explained earlier we have generated day by row profile. This profile has entries of all-day w.r.t 24 hours calculated over 365 days and so total values will be $365 \times 24=8760$. All of these values are $\mathrm{kWh}$. For generating this file, we first distributed monthly reading randomly over a month (30/31 days) and then distributed each day value over 24 hours.

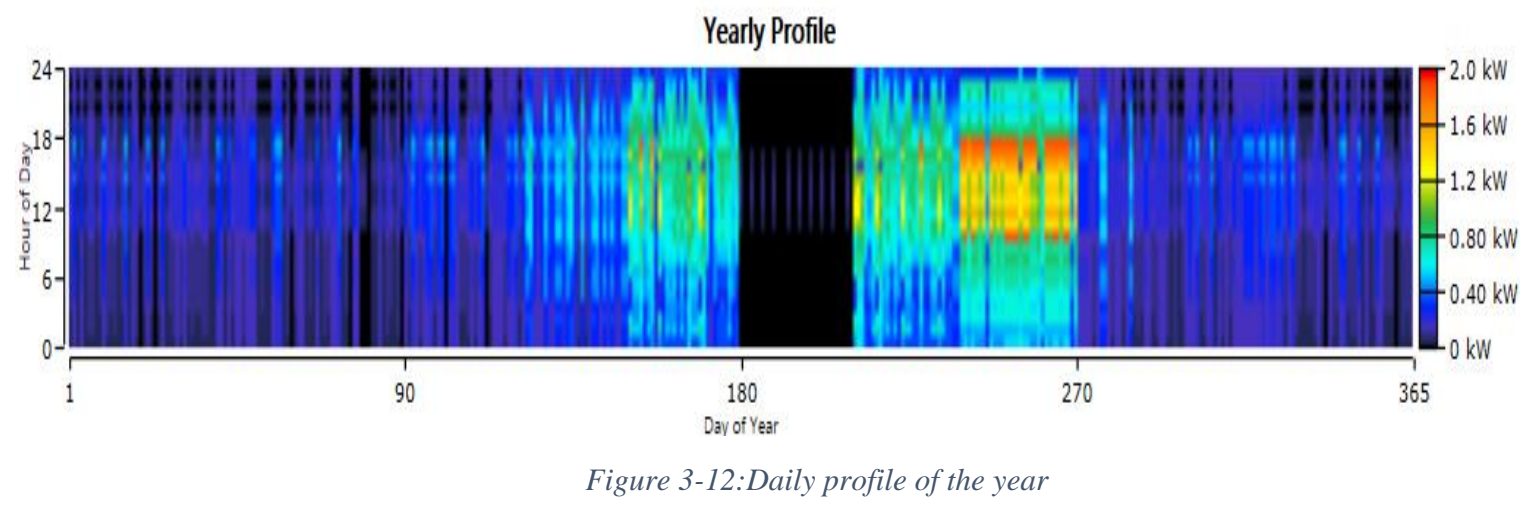

In this figure we can see that our value of energy mainly increased mainly between 6am to $6 \mathrm{pm}$. This is usual time where the sun is present. In region like Pakistan, we have more sun during this period of time as so this graph is depicting. Secondly the July is shown with dark region which indicates that during this month the consumption is very less. While all values are loaded, a good electric load is generated.

\subsection{Cases Under consideration}

we will vary the components in the system and change the configuration to get different results. These selected 4 configurations are as follows as.

a. PV system, battery backup and load

b. PV system with DC generator and load 
c. DC generator, PV, battery bank and load

\subsubsection{PV system with battery backup:}

Firstly, we have used this system. In this system we have introduced a PV array and battery backup. We have given the PV detail; battery details and load details and homer have done the calculation which are as follows as

\subsubsection{System Architecture for simulation 1:}

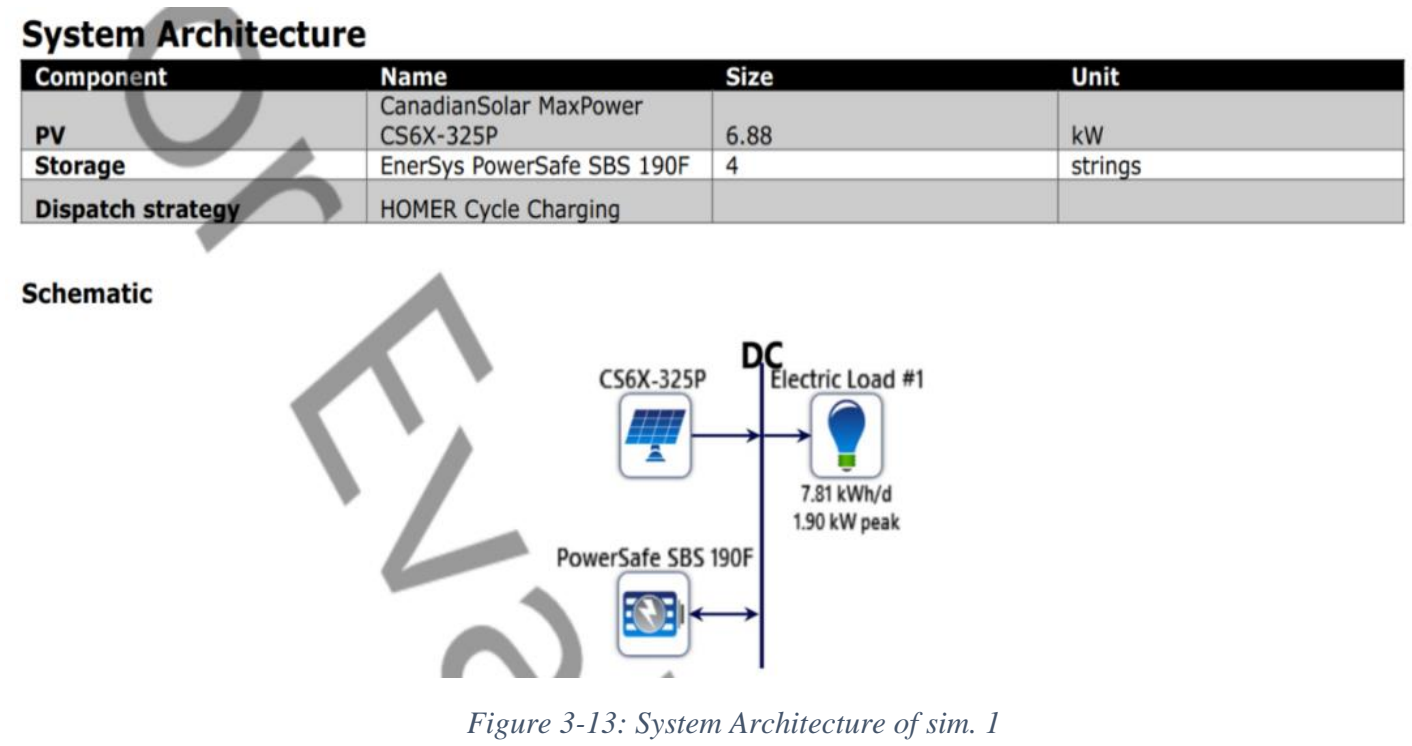

As we have used DC so all the applications are DC based. Abbreviation are written on the top. Here source are panels and battery and load is electric load 1. Cost summary analysis for the system is given in the figure below. The solar plates used are Canadian solar with 325 watts, the battery used is 190 A battery and the load is $7.81 \mathrm{kWh}$ DC load. This load is the calculated from daily comsumption. With this arrangement we have only to use the 16 batteries with 4 strings of 4 batteries and solar panel wattage equal 6.88 kWs. The charging would be cycle charging. 


\subsubsection{Cost Summary for Simulation 1:}
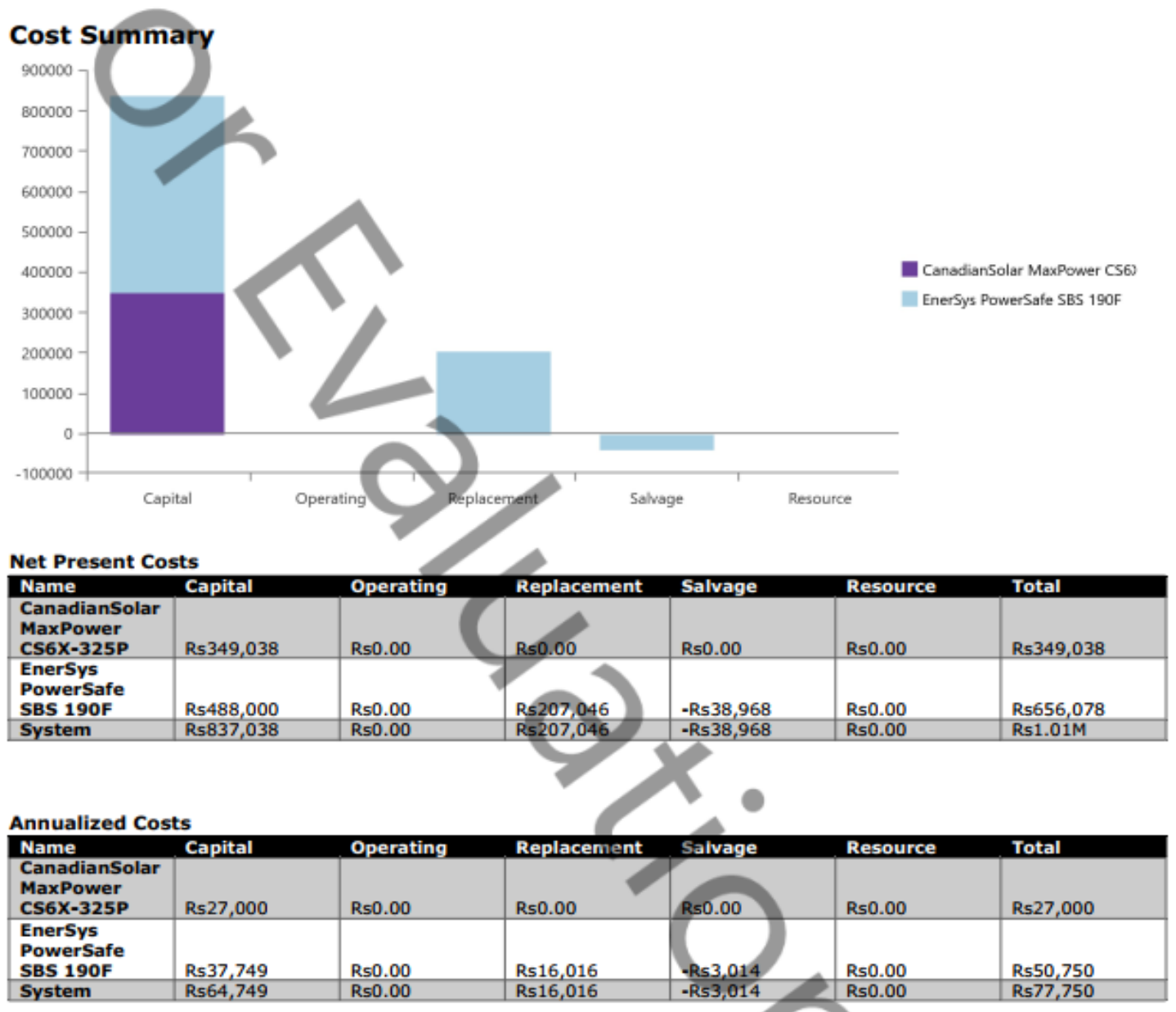

Figure 3-14: Cost Summary for Sim. 1

Now we as compared to all of our analysis this standalone is the most feasible and lowcost option. We can see that our total cost will be under 0.9 million rupees. The operating cost is not considered owing to some reasons. Firstly, the batteries are dry batteries. The other types of batteries require the distilled water which is mainly dilute sulphuric acid. But in case of dry battery there is no need of this. But the batteries with time get hot and accumulate heat but this can be reduced by proper ventilation. Secondly the solar panel we used are not so much. They are merely in 24 to 26 panels. The problem that mainly 
arises in large scale solar plants is that the dust and debris pollute the panel. If this is on small scale it is removed on regular interval with rain and fast blowing air. But on the large scale the only rain is not sufficient and we have to setup a system for the proper cleaning of the panels. And hence we have to spent some money in order to setup cleaning system. But in our case the panel are only 22 and the cleaning will be done will rain or air. We can also see other value such as salvage values and total values and they are over the all years.

\subsubsection{Cash Flow:}

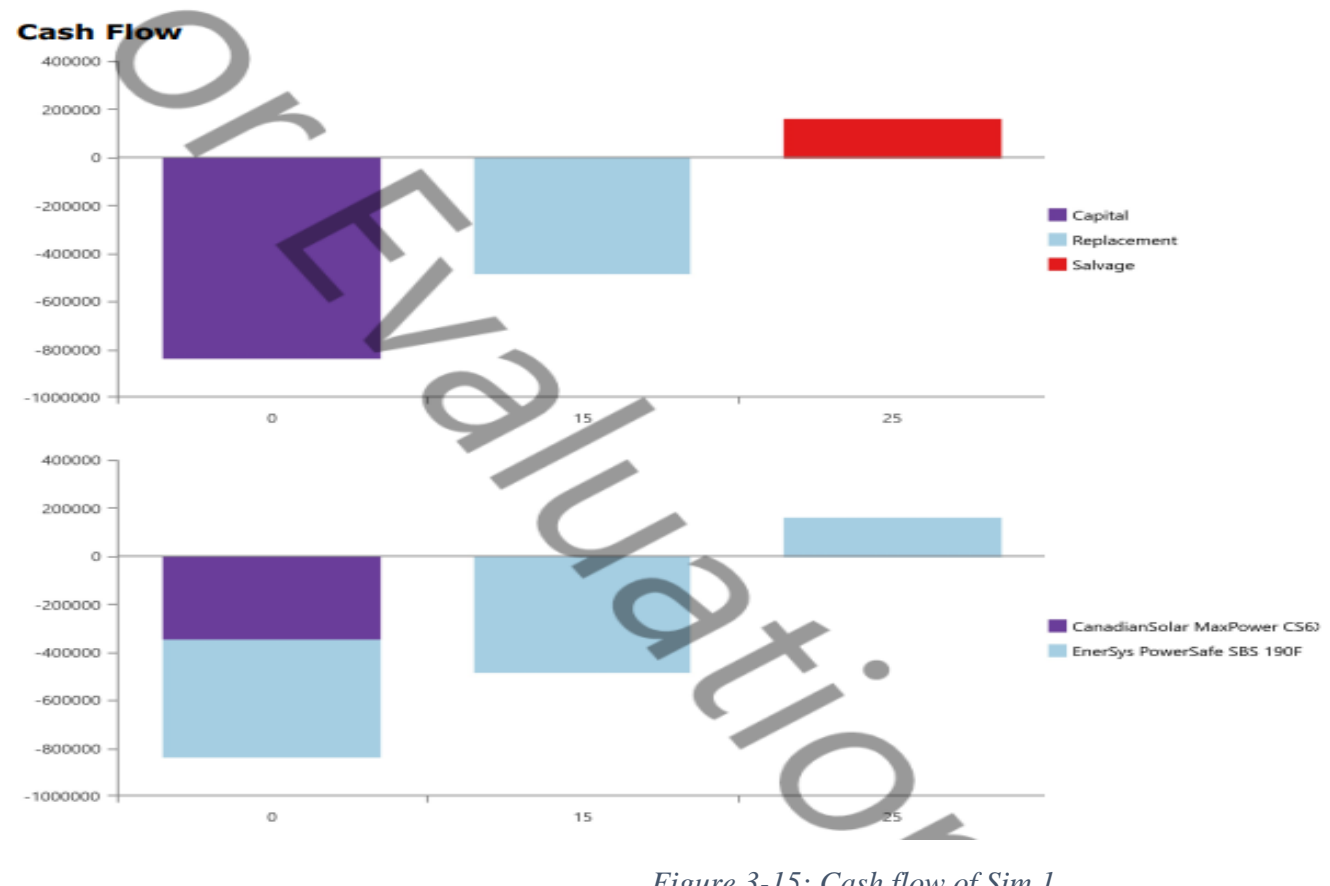

Figure 3-15: Cash flow of Sim.1 
The cash flow of the system is shown in above figure 3-15 the salvage vaue is obtained at $25^{\text {th }}$ year. Similar to $2^{\text {nd }}$ figure in which the enersys value is recoverd in last five years.

\subsubsection{Electrical Summary of Simulation 1:}

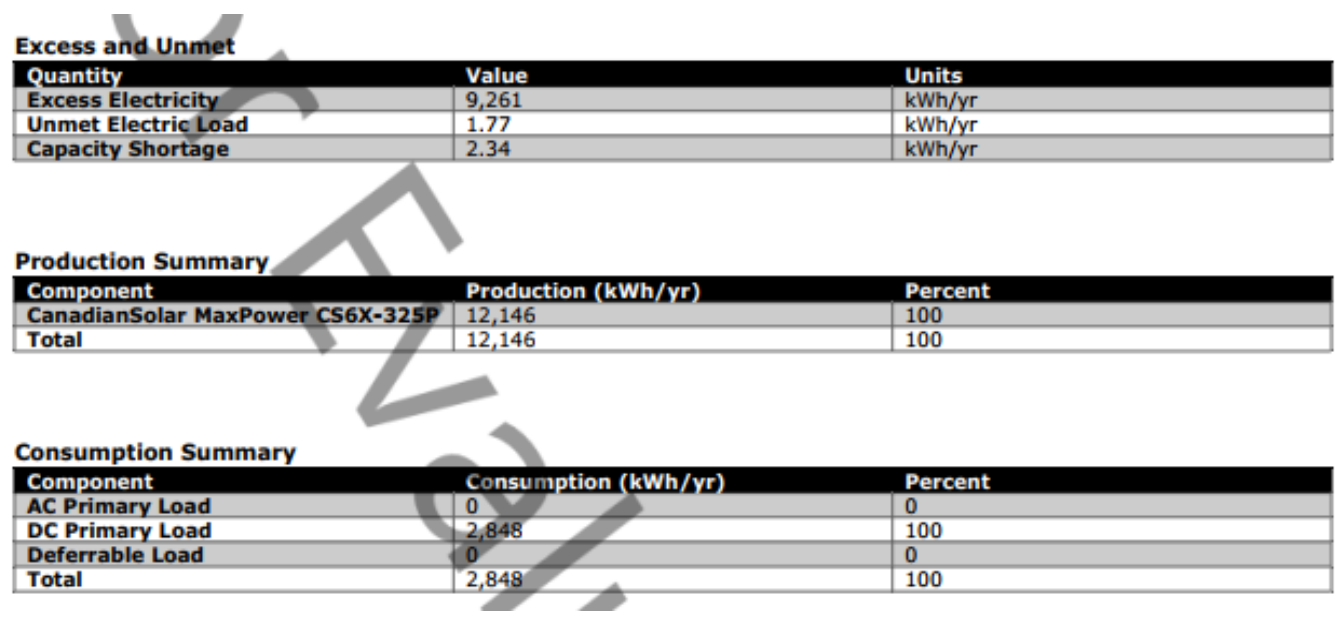

Figure 3-16: Electrical summary sim.1

The electric summary of this system is also shown in the figure 3-16. this summary indicates the electricity value in term of $\mathrm{kWh}$ produced per year. All of the consumption is $\mathrm{DC}$ as we have no AC consumption. The values are the quantitative and indictive measure of the system electricity consumption. 


\subsubsection{PV panel details:}

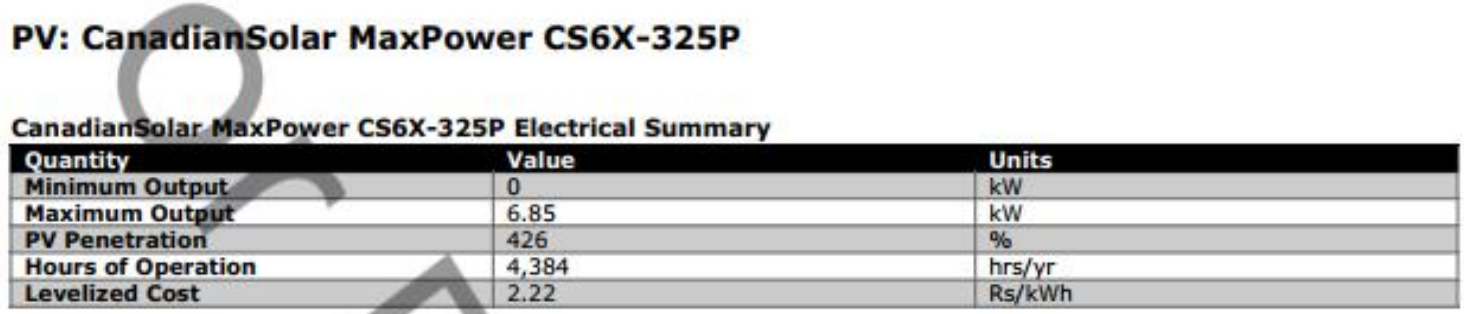

\begin{tabular}{|c|c|c|}
\hline Quantity & Value & Units \\
\hline Rated Capacity & 6.88 & $\mathrm{~kW}$ \\
\hline Mean Output & 1.39 & $\mathrm{~kW}$ \\
\hline Capacity Factor & 20.2 & $\%$ \\
\hline Total Production & 12,146 & $\mathrm{kWh} / \mathrm{yr}$ \\
\hline
\end{tabular}

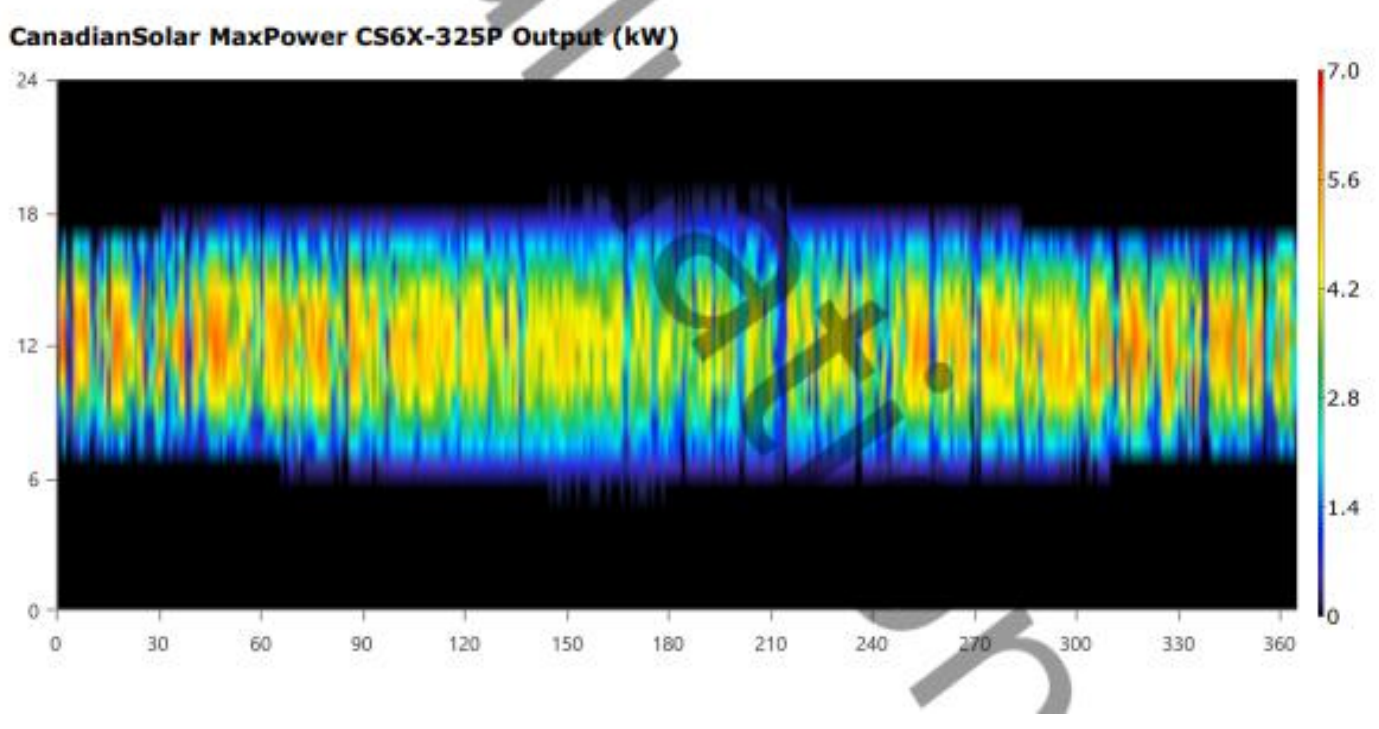

Figure 3-17: PV panel electrical summary Sim.1

The figure 3-17 indicates the solar PV panel output. First, we have to discuss the graph of the output. The solar or other output mainly depends on the solar. As solar is more in summer and dilated, solar is more in that timing. They dark area are mainly those where the solar is below a certain threshold. Another factor that contributes in the solar production is the load. As we can clearly see the fringes in the lines in the pattern. This is due to our load. As load varies so our consumption also reduced. The tables indicate the 
value of the solar energy produced. We can see that levelized cost of the electricity unit is 2.22 rupees per $\mathrm{kW}$ which is fairly low.

\subsubsection{Battery Bank for Simulation 1:}

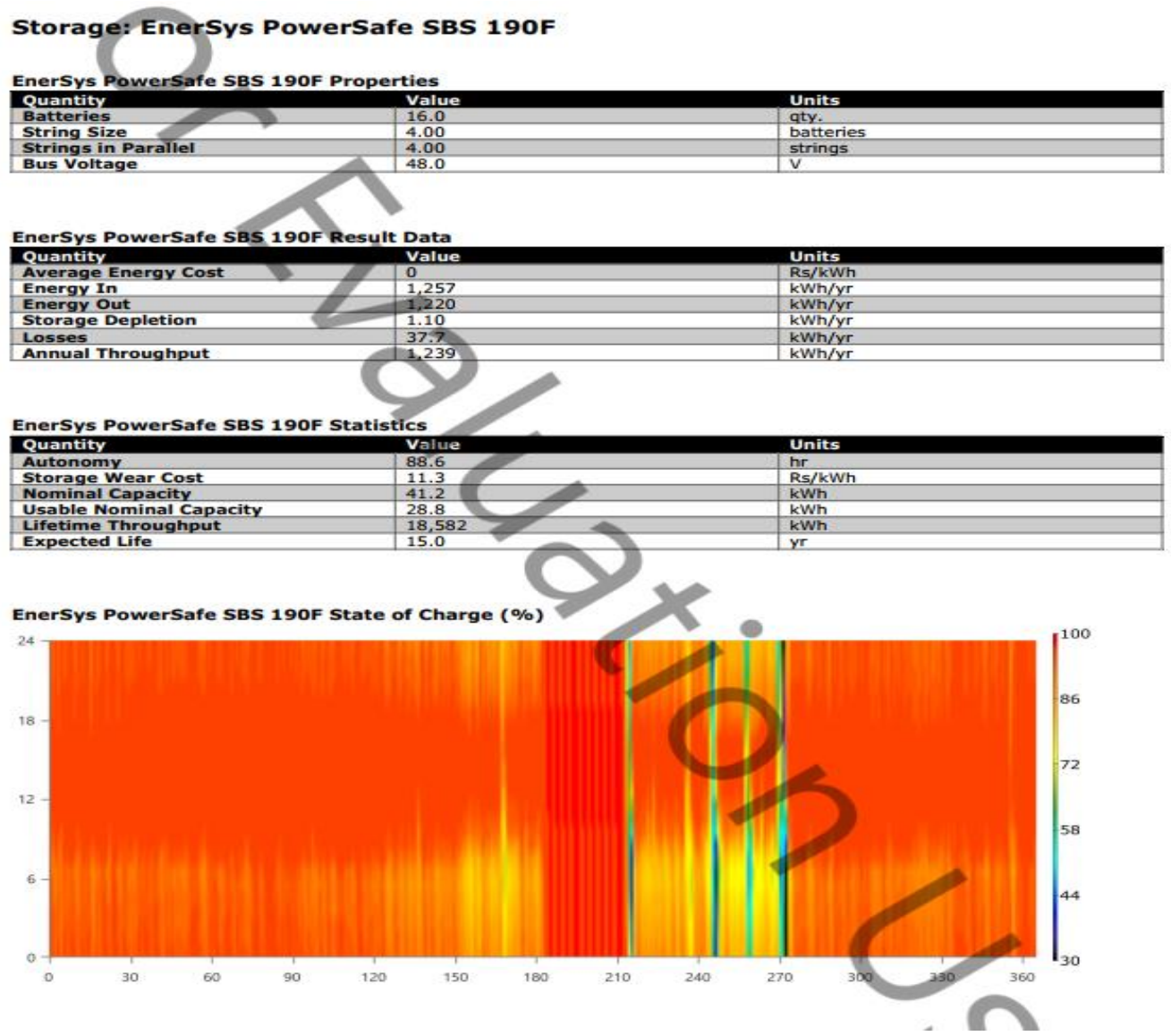

Figure 3-18:Battery bank sim.1

the figure 30 indicates the battery bank condition. We can see that most of the time the state of charge is $100 \%$. This is because most of the time the battery remains full and our consumption is not so high. Very few lines in the center shows the lower range of charge. They are actually the months of the year when the consumption is high as compared to rest of year. 
Thus, this is the first system that we have used as standalone for our need. We have used as for our research purpose. we have also used other system with different arrangement of the equipment that are discussed below.

\subsubsection{PV system and DC generator backup.}

In this system we have used battery bank with DC generator and battery bank.

\subsubsection{System Architecture for simulation 2:}

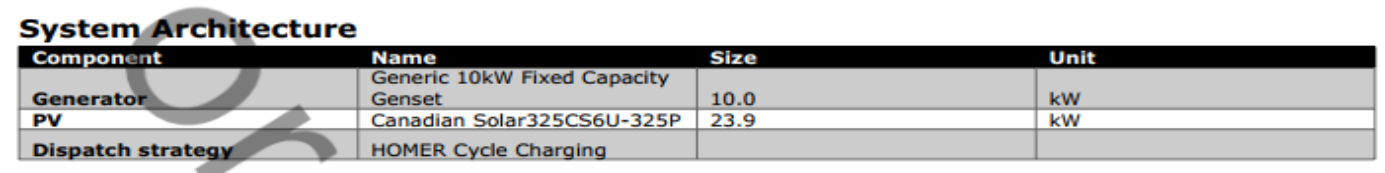

Schematic

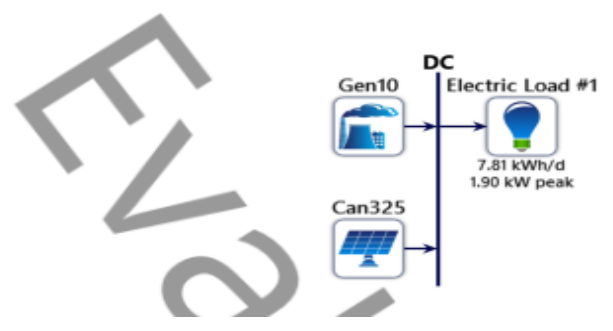

Figure 3-19: System Architecture sim.2

In this system we have used a 10-kw dc generator by Ricardo and the PV panel system of Canadian solar. The generator is $10 \mathrm{~kW} \mathrm{DC} \mathrm{constant} \mathrm{power.} \mathrm{This} \mathrm{simulation} \mathrm{is} \mathrm{another}$ arrangement out of the three which we have selected to study. 


\subsubsection{Cost Summary for Simulation 2:}

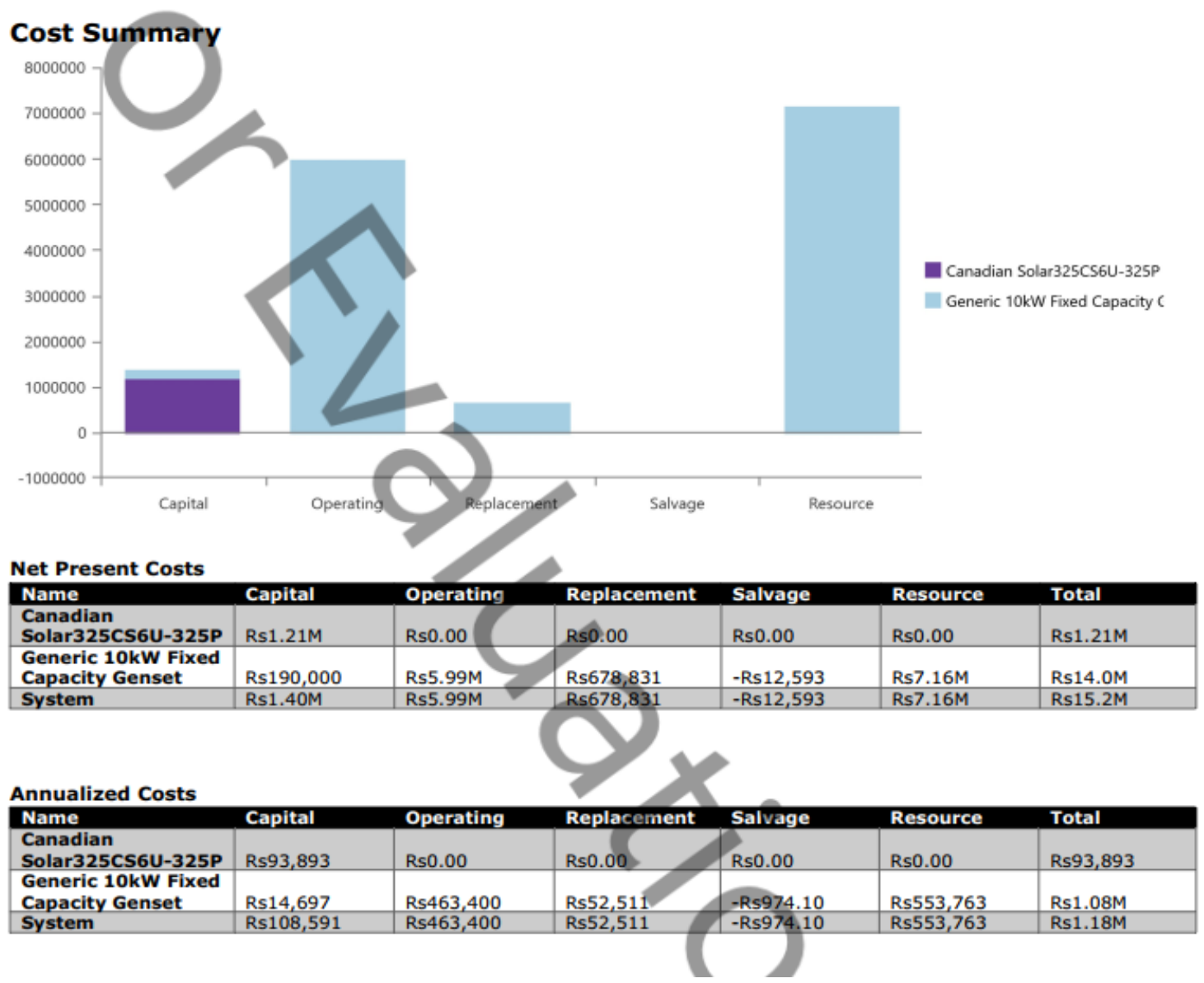

Figure 3-20: cost analysis Sim 2

Now in this case the operation cost is also involved because generator will consume fuel and will also require some maintenance so the annual cost also there and this amount will also be added up in the final value. 


\subsubsection{Cash Flow for Simulation 2:}

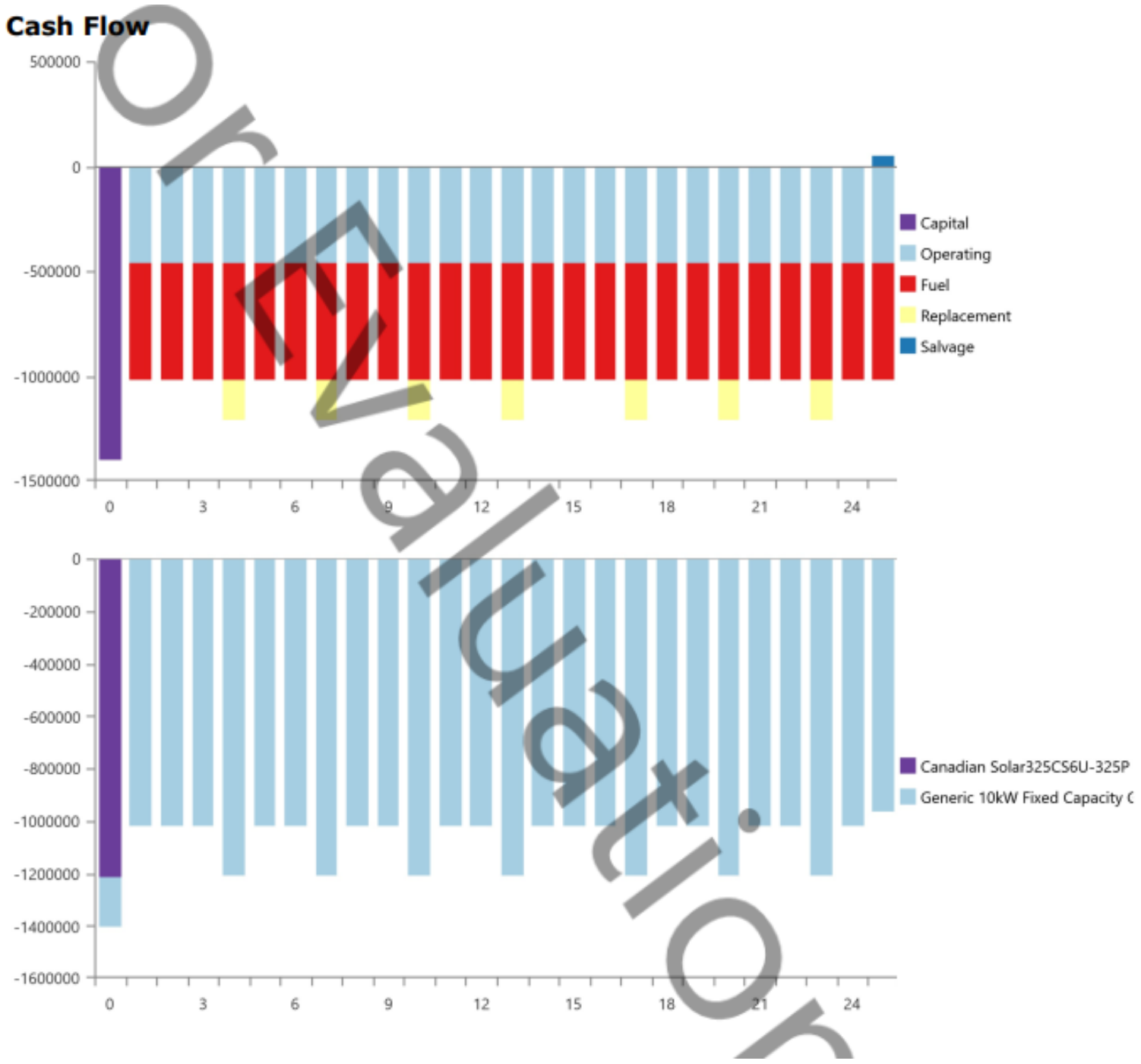

Figure 3-21: Cash flow sim 2

The figure above indicates the cash flow of the system. In this case we have both operation cost and fuel cost so each year these values will be added up and thus the system will become costly. The coloring scheme indicates each price separately. In the other figure we can see that solar will only cost initial and rest of time the cost will be of the generator in term of fuel and maintenance. 


\subsubsection{Electrical summary of simulation 2:}

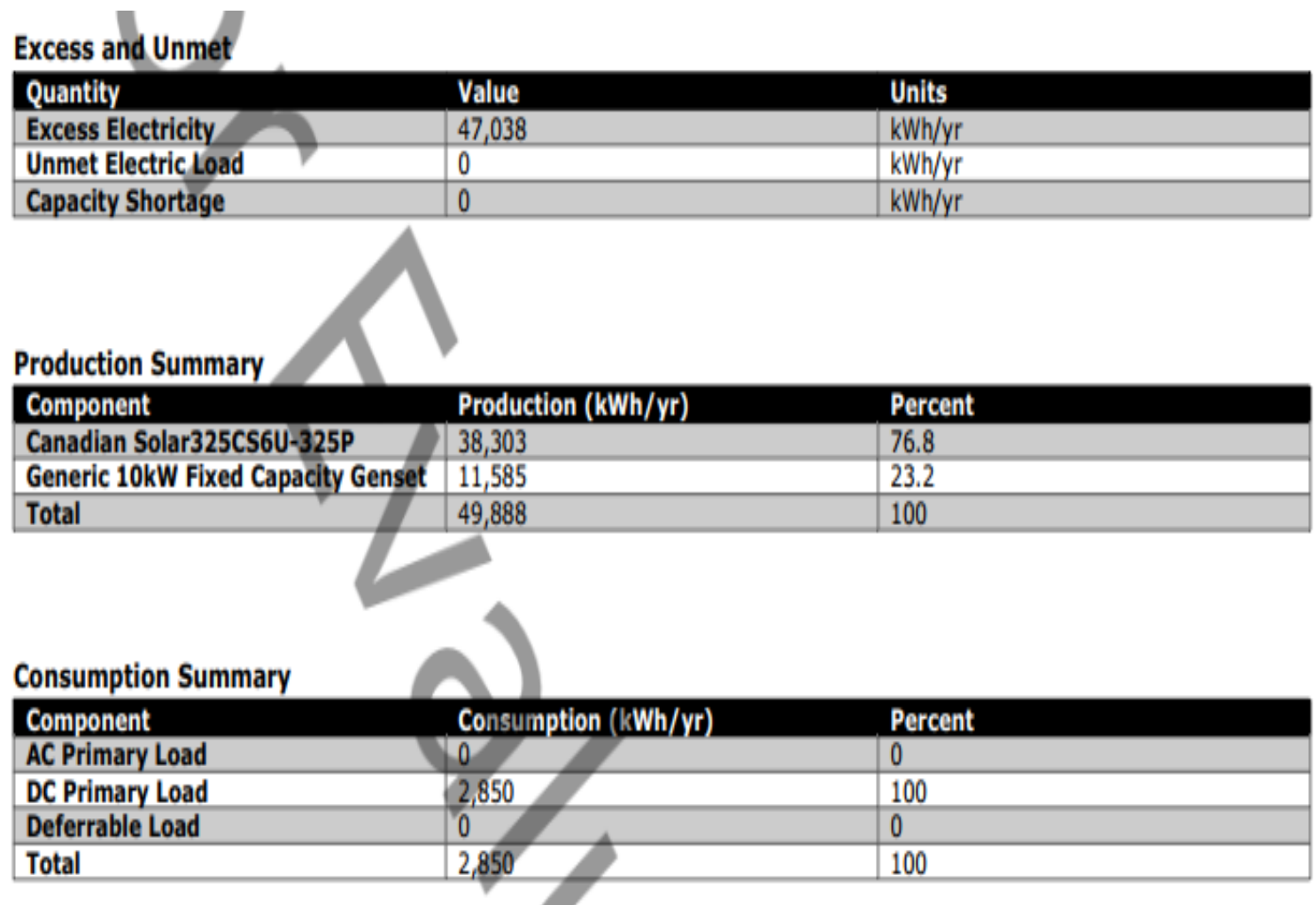

Figure 3-22: Electric summary sim.2

The electrical summary indicates that more than $75 \%$ of the electricity requirement are fulfilled by the Canadian solar. Though solar is not available during all days, yet must take one thing in our consideration that our main load occurs during the day time and so solar is also available during the day time. The generator plays it role during night time when there is no solar. 


\subsubsection{Generator $10 \mathrm{~kW}$ generic:}

Generic 10kW Fixed Capacity Genset Electrical Summary

\begin{tabular}{|l|l|l|}
\hline Quantity & Units \\
\hline Electrical Production & 11,585 & $\mathrm{kWh} / \mathrm{yr}$ \\
\hline Mean Electrical Output & 2.50 & $\mathrm{~kW}$ \\
\hline Minimum Electrical Output & 2.50 & $\mathrm{~kW}$ \\
\hline Maximum Electrical Output & 2.50 & $\mathrm{~kW}$ \\
\hline
\end{tabular}

Generic 10kW Fixed Capacity Genset Fuel Summary

\begin{tabular}{|l|l|l|}
\hline Quantity & Value & Units \\
\hline Fuel Consumption & 5,538 & $\mathrm{~L}$ \\
\hline Specific Fuel Consumption & 0.478 & $\mathrm{~L} / \mathrm{kWh}$ \\
\hline Fuel Energy Input & 54,490 & $\mathrm{kWh} / \mathrm{yr}$ \\
\hline Mean Electrical Efficiency & 21.3 & $\%$ \\
\hline
\end{tabular}
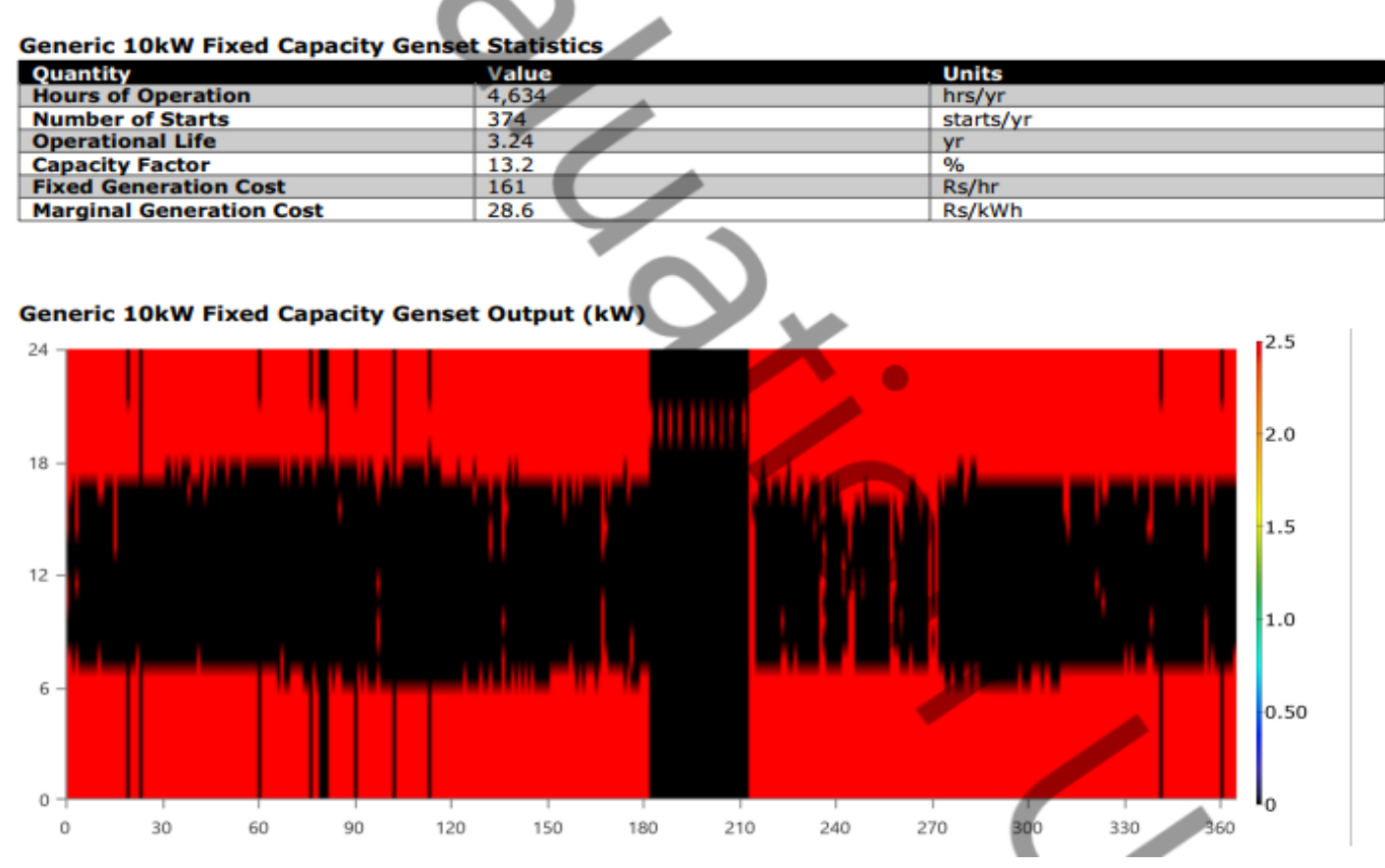

Figure 3-23: Generator Summary sim.2

The generator output shows that during the day no generator is used so most of the area is dark. But we can also see that during the night generator will come into play and will start production. 


\subsubsection{Fuel Summary for Simulation 2:}

\begin{tabular}{|c|c|c|}
\hline Quantity & Value & Units \\
\hline Total fuel consumes & 5,538 & $\mathrm{~L}$ \\
\hline Avg fuel per day & 15.2 & L/day \\
\hline Avg fuel per hour & 0.632 & L/hour \\
\hline
\end{tabular}

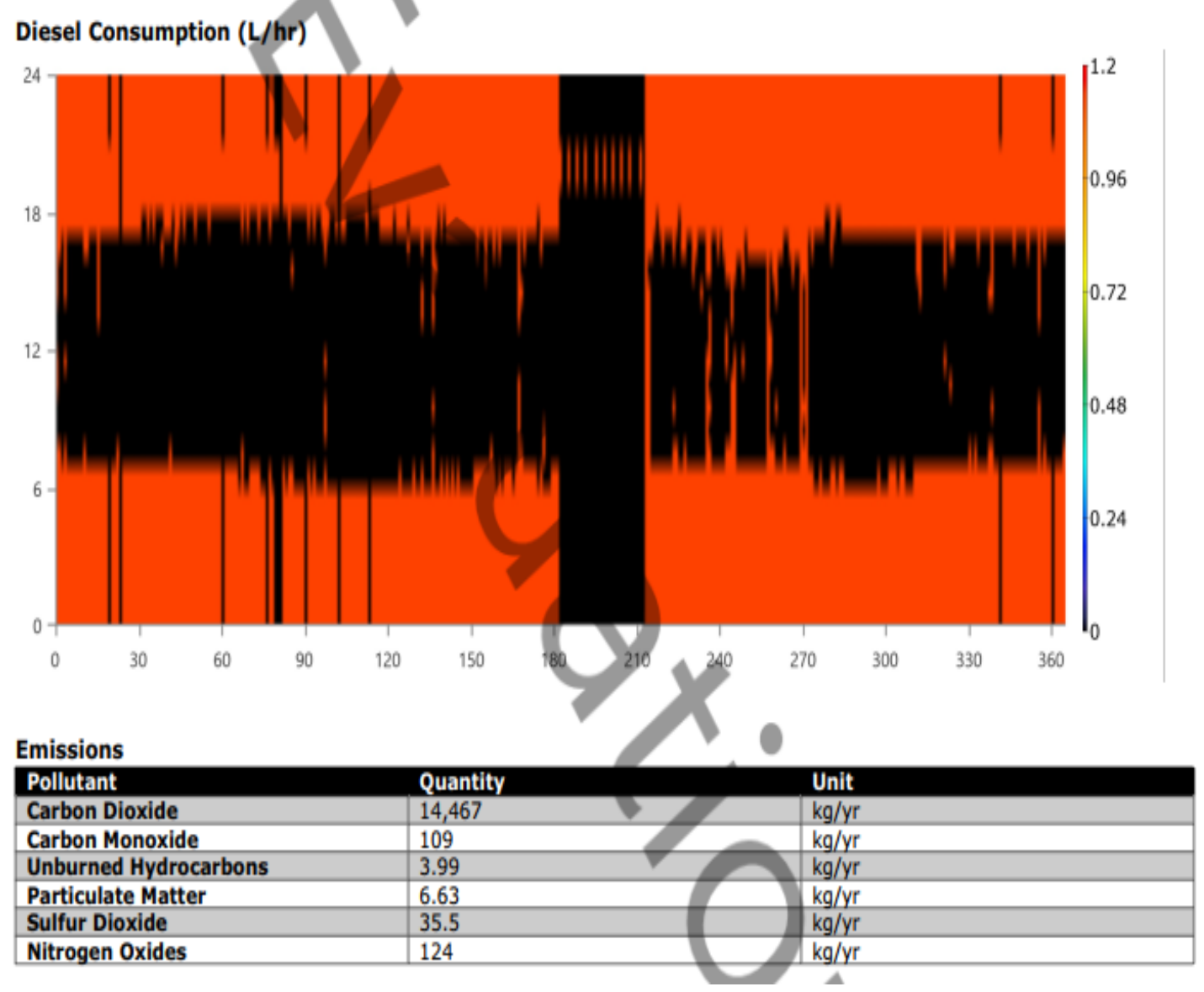

Figure 3-24: Fuel Summary Sim.2

The fuel summary is similar to the generator consumption. The emission and exhaust gases details are also mention that we have to cater for removing the pollutant from environment. 


\subsubsection{PV panels, DC generator and Battery bank combined}

In third simulation we have used DC generator with PV panels, battery bank and provided the load

\subsubsection{System Architecture:}

\begin{tabular}{|c|c|c|c|}
\hline Component & Name & Size & Unit \\
\hline & $\begin{array}{l}\text { Generic 10kW Fixed Capacity } \\
\text { Genset }\end{array}$ & 10.0 & $\mathrm{~kW}$ \\
\hline PV & Canadian Solar325CS6U-325P & 4.40 & $\mathrm{~kW}$ \\
\hline Storage & Enersys PowerSafe SBS $190 \mathrm{~F}$ & 2 & strings \\
\hline Dispatch st: & HOMER Cycle Charging & & \\
\hline
\end{tabular}

Schematic

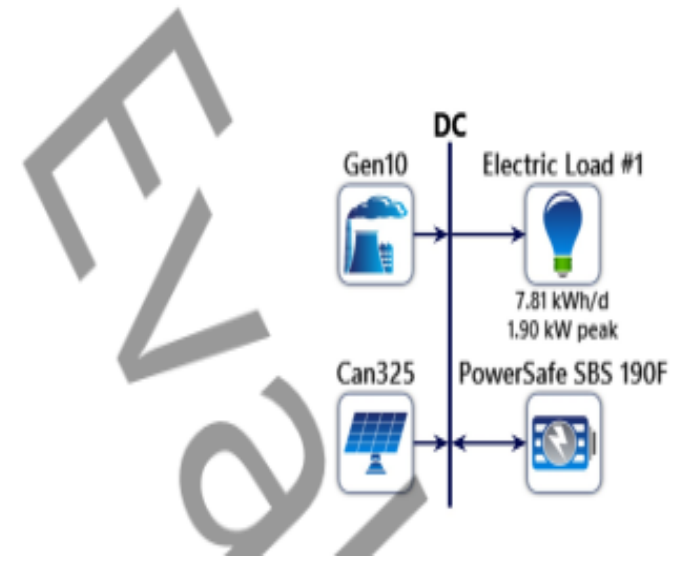

Figure 3-25: Schematic diagram for sim 3

In third simulation we have used the PV panels of Canadian solar, the Dc generator and the battery bank of EnerSys SBS. the load is our load consumption which is our daily load. The system has maximum component attached to it. Now for this system the battery bank will consist of 2 string of 4 batteries. Solar PV panels will be 14 and generator will be of $10 \mathrm{~kW}$. These all appliances are DC applicable. 


\subsubsection{Cost Summary for simulation 3:}

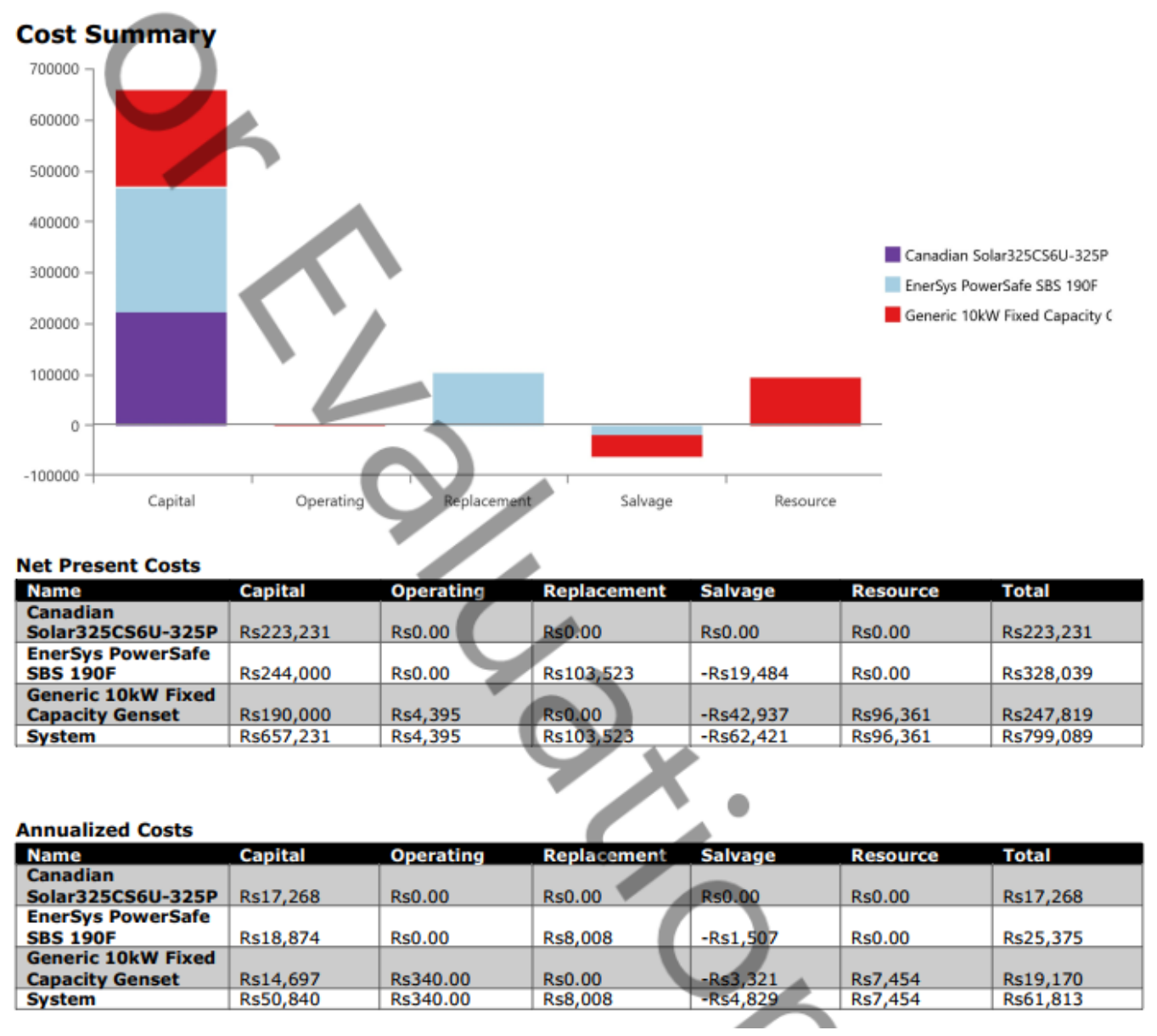

Figure 3-26: Cost summary sim.3

The cost of the system is 657 thousand. In this case all of three items are present with so we have 2 items in salvage. 


\subsubsection{Cash Flow for Simulation 3:}

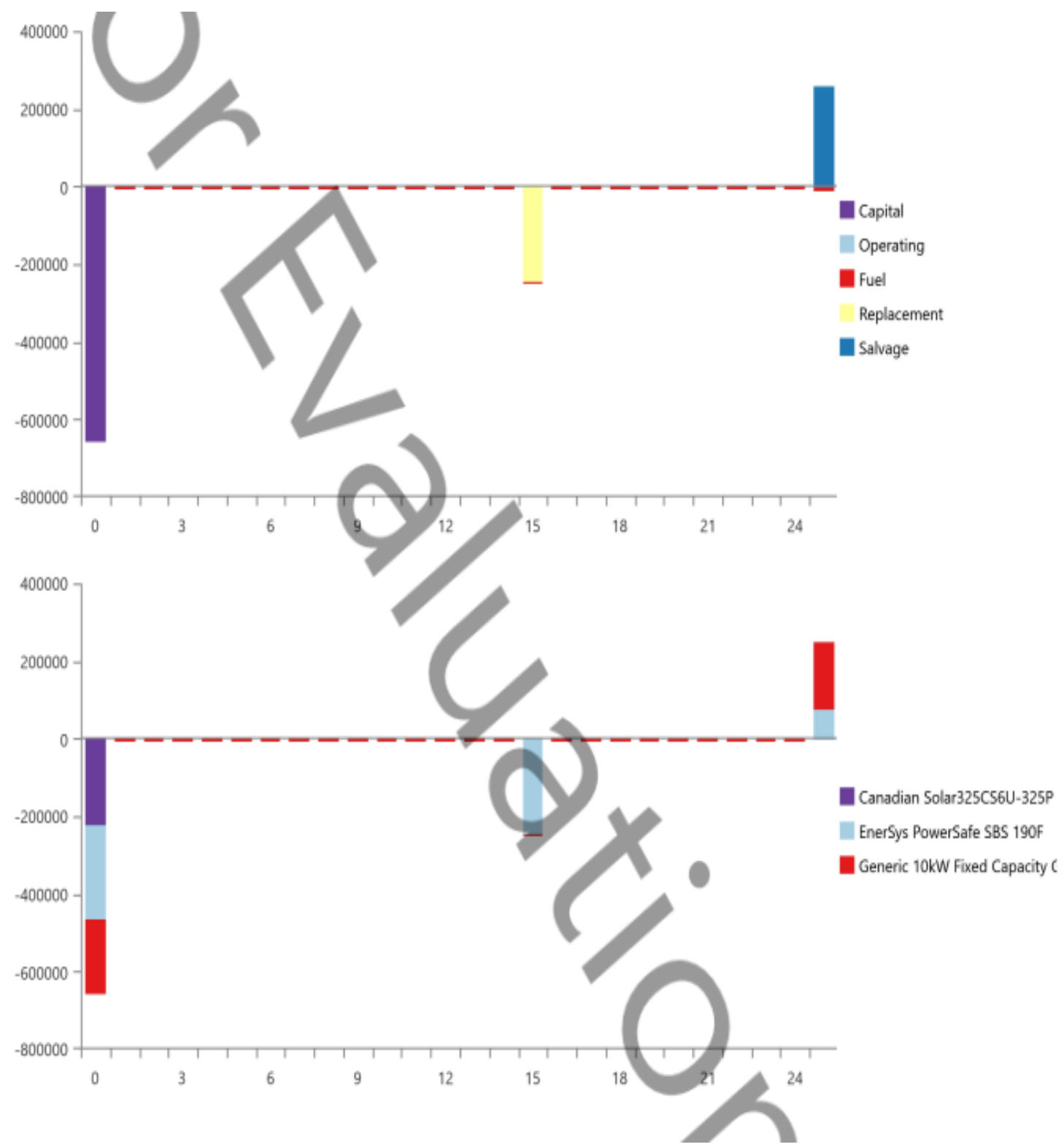

Figure 3-27: cash flow sim 3 


\subsubsection{Electrical Summary for Simulation 3:}

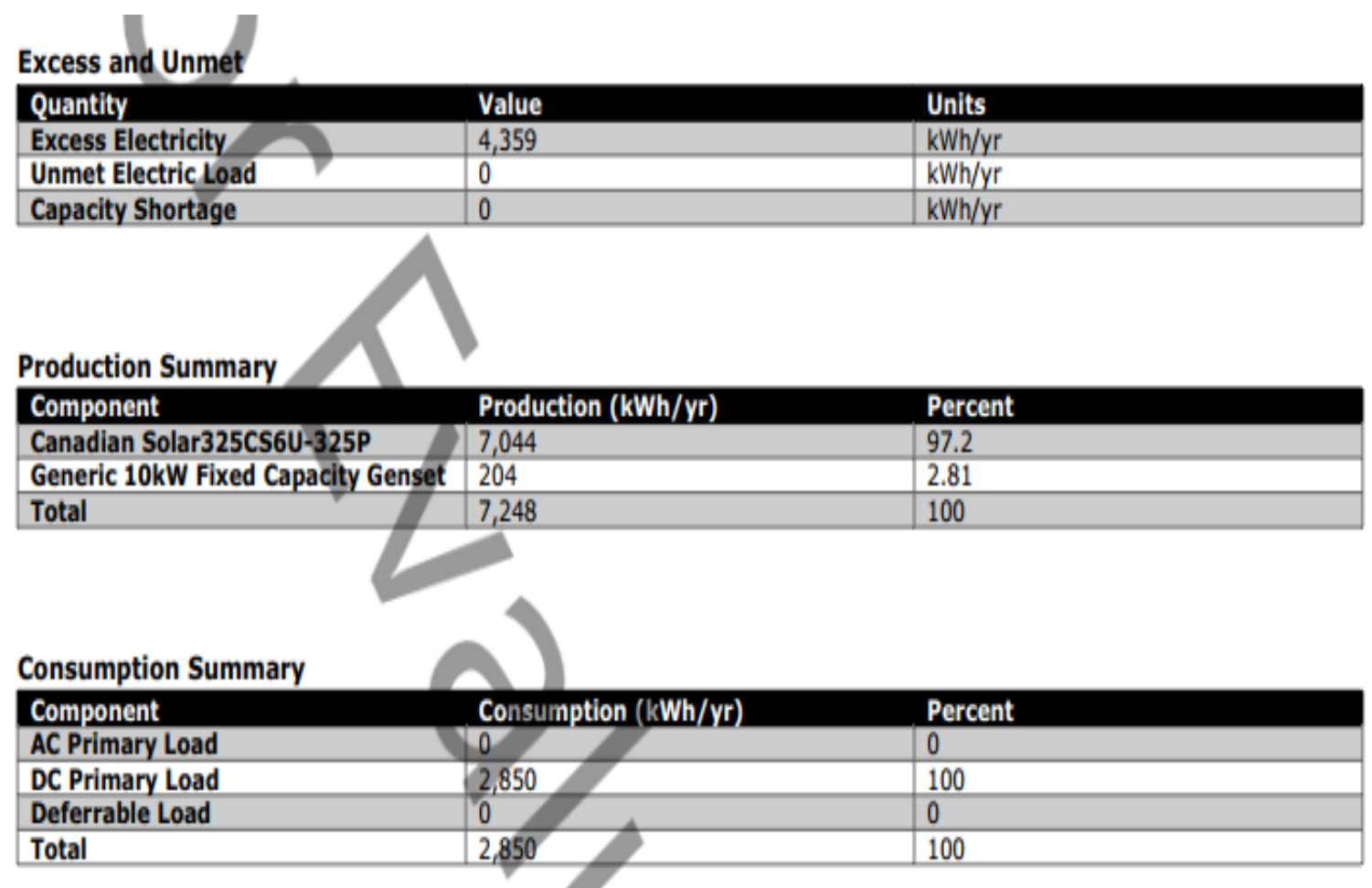

Figure 3-28: Electrical summary sim. 3

We can see that electrical summary indicates that power consumption is shared by the solar and generator. Solar power is 97.2 percent of total and 2.81 percent is shared by the DC generator. In this case the solar power percentage is increased as compared to the previous case. This is because the battery bank will store the energy and will use it at the time of consumption. In this case generator is minimum used so the cost has reduced significantly. 


\subsubsection{PV for simulation 3:}

Canadian Solar325CS6U-325P Electrical Summary

\begin{tabular}{|l|l|l|}
\hline Quantity & Value & Units \\
\hline Minimum Output & 0 & $\mathrm{~kW}$ \\
\hline Maximum Output & 4.20 & $\mathrm{~kW}$ \\
\hline PV Penetration & 247 & $\%$ \\
\hline Hours of Operation & 4,384 & $\mathrm{hrs} / \mathrm{yr}$ \\
\hline Levelized Cost & 2.45 & $\mathrm{Rs} / \mathrm{kWh}$ \\
\hline
\end{tabular}

\section{Canadian Solar325CS6U-325P Statistics}

\begin{tabular}{|l|l|l|}
\hline Quantity & Value & Units \\
\hline Rated Capacity & 4.40 & $\mathrm{~kW}$ \\
\hline Mean Output & 0.804 & $\mathrm{~kW}$ \\
\hline Mean Output & 19.3 & $\mathrm{kWh} / \mathrm{d}$ \\
\hline Capacity Factor & 18.3 & $\%$ \\
\hline Total Production & $\mathbf{7 . 0 4 4}$ & $\mathrm{kWh} / \mathrm{yr}$ \\
\hline
\end{tabular}

\section{Canadian Solar325CS6U-325P Output (kW)}

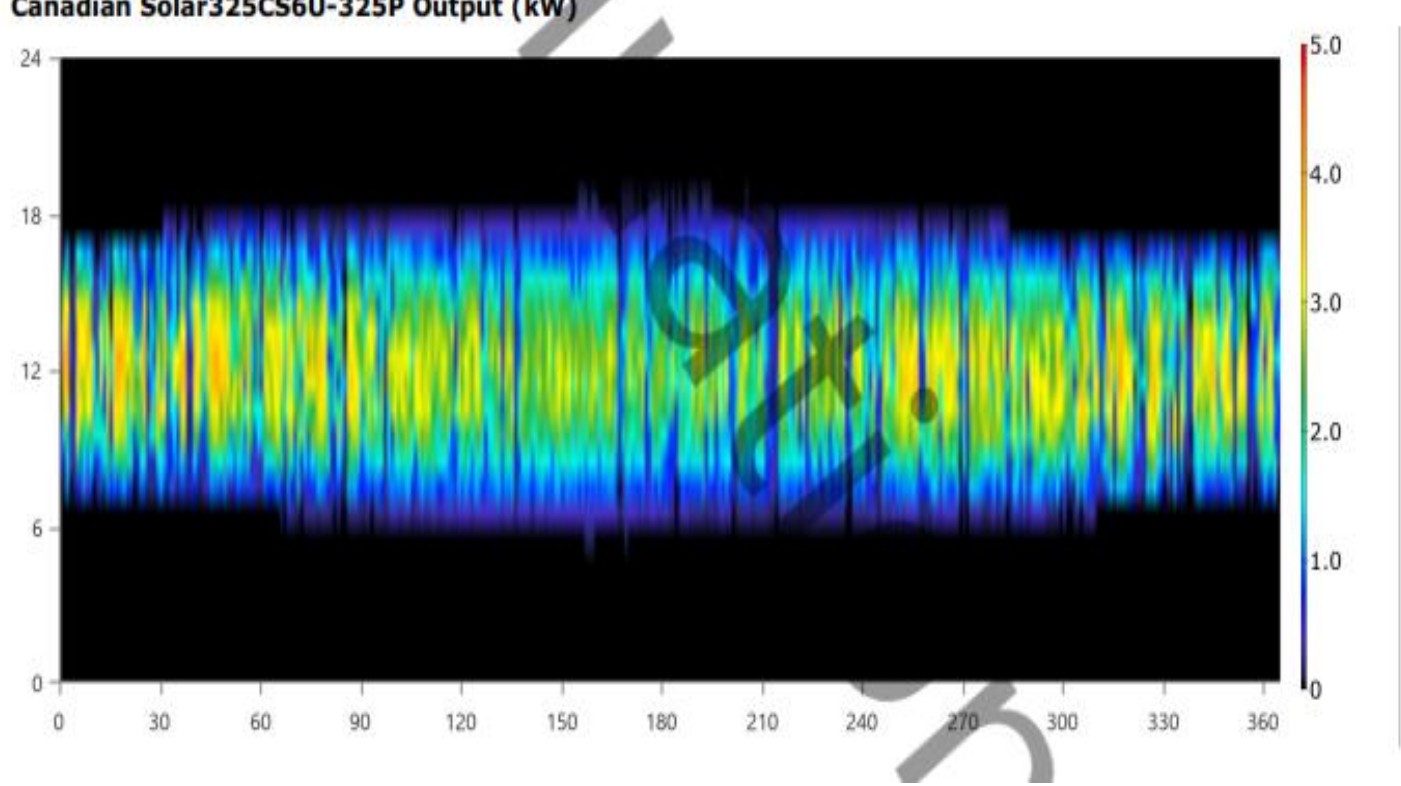

Figure 3-29: PV panel details Sim.3

Now in this can we have seen that solar has almost same profile as that of the the first but the levelized cost is 2.45 rupees per $\mathrm{kWh}$ which is slightly higher than the first case. 


\subsubsection{DC generator for simulation 3:}

Generic 10kW Fixed Capacity Genset Electrical Summary

\begin{tabular}{|l|l|l|}
\hline Quantity & Value & Units \\
\hline Electrical Production & 204 & $\mathrm{kWh} / \mathrm{yr}$ \\
\hline Mean Electrical Output & 5.99 & $\mathrm{~kW}$ \\
\hline Minimum Electrical Output & 2.50 & $\mathrm{~kW}$ \\
\hline Maximum Electrical Output & 9.71 & $\mathrm{~kW}$ \\
\hline
\end{tabular}

Generic 10kW Fixed Capacity Genset Fuel Summary

\begin{tabular}{|l|l|l|}
\hline Quantity & Value & Units \\
\hline Fuel Consumption & 74.5 & $\mathrm{~L}$ \\
\hline Specific Fuel Consumption & 0.366 & $\mathrm{~L} / \mathrm{kWh}$ \\
\hline Fuel Energy Input & 733 & $\mathrm{kWh} / \mathrm{yr}$ \\
\hline Mean Electrical Efficiency & 27.8 & $\%$ \\
\hline
\end{tabular}

Generic 10kW Fixed Capacity Genset Statistics

\begin{tabular}{|l|l|l|}
\hline Quantity & Value & Units \\
\hline Hours of Operation & 34.0 & $\mathrm{hrs} / \mathrm{yr}$ \\
\hline Number of Starts & 17.0 & $\mathrm{starts} / \mathrm{yr}$ \\
\hline Operational Life & 441 & $\mathrm{yr}$ \\
\hline Capacity Factor & 0.232 & $\%$ \\
\hline Fixed Generation Cost & 70.7 & $\mathrm{Rs} / \mathrm{hr}$ \\
\hline Marginal Generation Cost & 28.6 & $\mathrm{Rs} / \mathrm{kWh}$ \\
\hline
\end{tabular}

Generic 10kW Fixed Capacity Genset Output (kW)

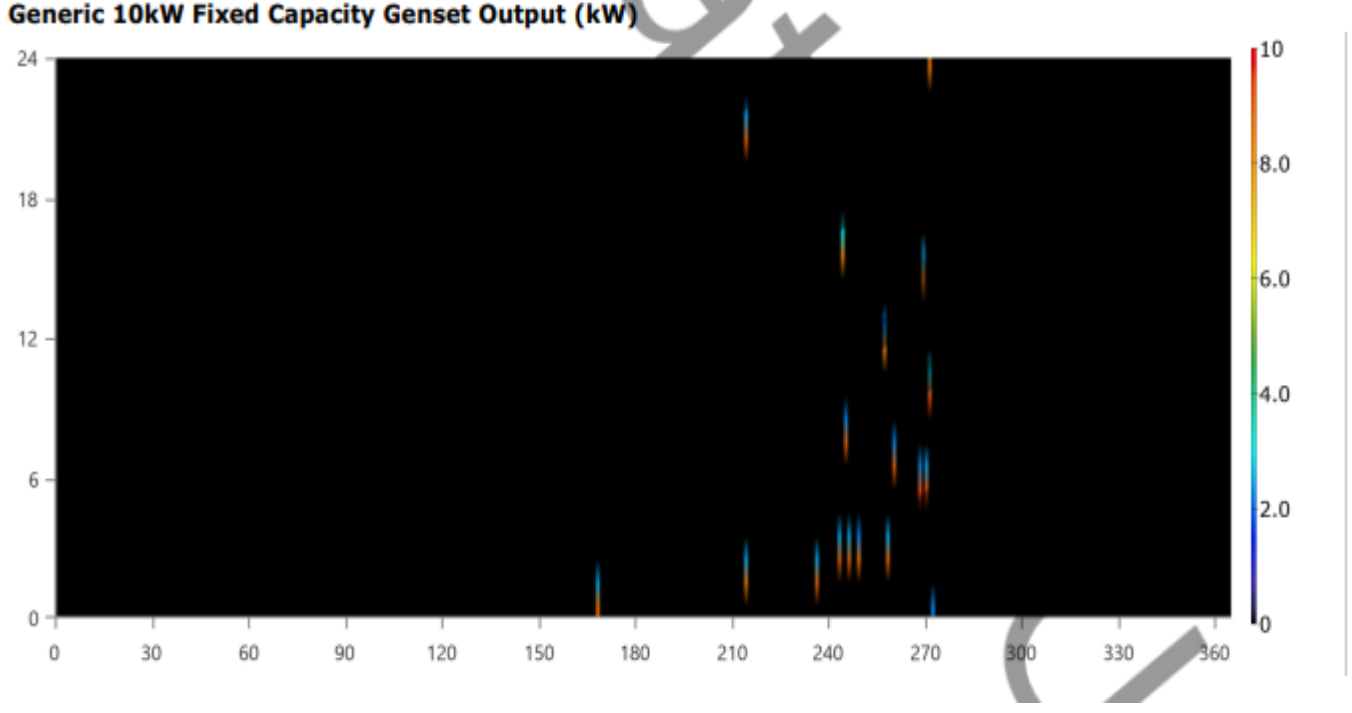

Figure 3-30: Generator details Sim.3 


\subsubsection{Fuel Summary for Simulation 3:}

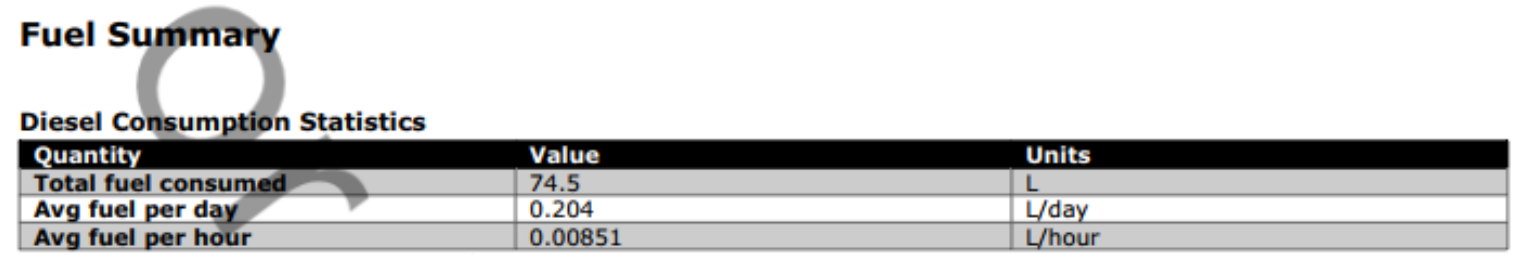

\section{Diesel Consumption (L/hr)}

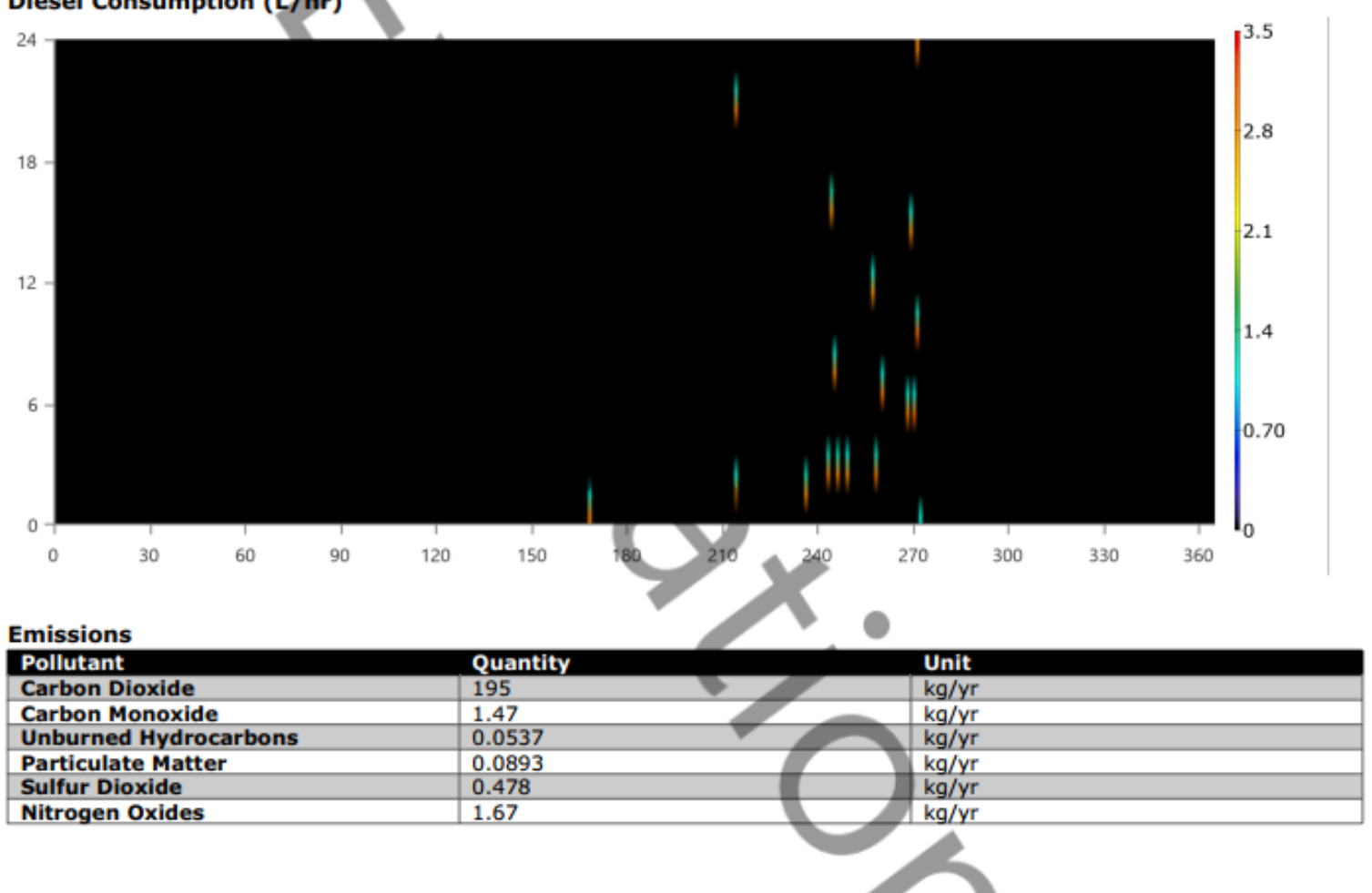

Figure 3-31: Fuel summary sim.3

From the generator output and fuel summary, it is cleared that generator is used minimally and hence the fuel is also consumed very less that is why cost is less for this. Consequently, the emission from the generator are also very less. 


\subsubsection{Battery bank for simulation 3:}

\section{Storage: EnerSys PowerSafe SBS 190F}

EnerSys PowerSafe SBS 190F Properties

\begin{tabular}{|l|l|l|}
\hline Quantity & Value & Units \\
\hline Batteries & 8.00 & qty. \\
\hline String Size & 4.00 & batteries \\
\hline Strings in Parallel & 2.00 & strings \\
\hline Bus Voltage & 48.0 & V \\
\hline
\end{tabular}

EnerSys PowerSafe SBS 190F Result Data

\begin{tabular}{|l|l|l|}
\hline Quantity & Value & Units \\
\hline Average Energy Cost & 1.03 & $\mathrm{Rs} / \mathrm{kWh}$ \\
\hline Energy In & 1,342 & $\mathrm{kWh} / \mathrm{yr}$ \\
\hline Energy Out & 1,303 & $\mathrm{kWh} / \mathrm{yr}$ \\
\hline Storage Depletion & 1.11 & $\mathrm{kWh} / \mathrm{yr}$ \\
\hline Losses & 40.3 & $\mathrm{kWh} / \mathrm{yr}$ \\
\hline Annual Throughput & 1,323 & $\mathrm{kWh} / \mathrm{yr}$ \\
\hline
\end{tabular}

EnerSys PowerSafe SBS 190F Statistics

\begin{tabular}{|l|l|l|}
\hline Quantity & Value & Units \\
\hline Autonomy & 44.3 & $\mathrm{hr}$ \\
\hline Storage Wear Cost & 11.3 & $\mathrm{Rs} / \mathrm{kWh}$ \\
\hline Nominal Capacity & 20.6 & $\mathrm{kWh}$ \\
\hline Usable Nominal Capacity & 14.4 & $\mathrm{kWh}$ \\
\hline Lifetime Throughput & 19,840 & $\mathrm{kWh}$ \\
\hline Expected Life & 15.0 & $\mathrm{yr}$ \\
\hline
\end{tabular}

Expected Life

EnerSys PowerSafe SBS 190F State of Charge (\%)

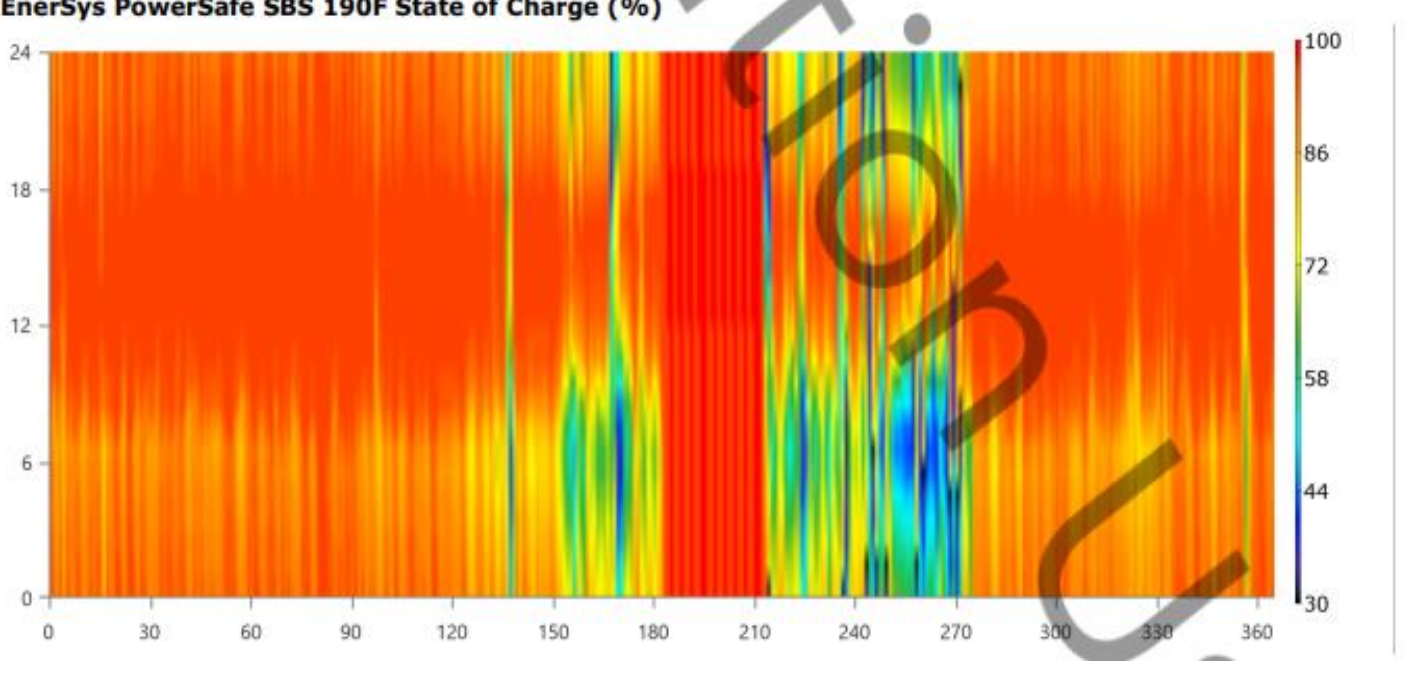

Figure 3-32: Battery bank result sim.3 


\section{DYNAMIC MODELLING OF THE DESIGNED SYSTEM}

We have done calculations on the homer but for the calculation and energy optimization. For getting the output wave form of the system we have made such a system in the MATLAB and then we have simulated it to get actual waveform.

In the Simulink either we have built in equipment with the specs that we can load or we can manually enter the load as according to our changed requirement. The technical specification of the solar panel are as follows as

\subsection{Canadian Solar 325 CS specification [36]}

- Nominal Max. Power (Pmax): 325W

- Opt. Operating Voltage (Vmp): 37.0V

- Opt. Operating Current (Imp): 8.78A

- Open Circuit Voltage (Voc): 45.5V

- $\quad$ Short Circuit Current (Isc): 9.34A

- Module Efficiency: 16.72\%.

- Operating Temperature: $-40^{\circ} \mathrm{C} \sim+85^{\circ} \mathrm{C}$

- Max. System Voltage: 1000V (IEC)/(UL)

- Module: Fire Performance Type 1 (UL 1703) or CLASS C (IEC 61730)

- Max. Series Fuse Rating: 15 A

- Application Classification: Class A

- Power Tolerance: $0 \sim+5 \mathrm{~W}$

Similarly, we also have to input the technical specification of the battery for our battery bank. In our case the batteries we have used is Enersys SBS $190 \mathrm{~F}$ technical specification are given below as.

\subsection{Enersys Power safe SBS 190 F [38]}

- Nominal Voltage : $12 \mathrm{~V}$

- Nominal Capacity(kWh): 2.57 
- Maximum capacity (Ah):214

- Capacity ratio: 0.489

- Rate constant(1/hr): 0.972

- Maximum charge current (A) :190

- Maximum charge $\operatorname{rate}(\mathrm{A} / \mathrm{Ah}): 1$

\subsection{Components of Circuit diagram:}

Now we have to define the method for Simulink use. The main component for the system is solar panel. This is closed loop system. We have introduced $325 \mathrm{~W}$ solar panel the input to the panel is irradiance and temperature, which we input to the system. The solar panels are 22 in number. The battery bank has 4 string of 4 batteries. We have to give the detail of the power and bank then we have to check the output value at the end. The output can be displayed on the oscilloscope. For adding the boost converter, we have subdivided into inductor resistor and transistor. There is also properties table in which we can add their properties as according to our requirement. The result obtained can vary by varying the inputs. Value of voltage are changed accordingly in order to check that the output is stable or not. There are options available in the Matlab. You can either make your own block diagram or you can load someone from math work or sample file are also 
available. [38]. The sample P \& O diagram for our circuit is shown in figure below 39]

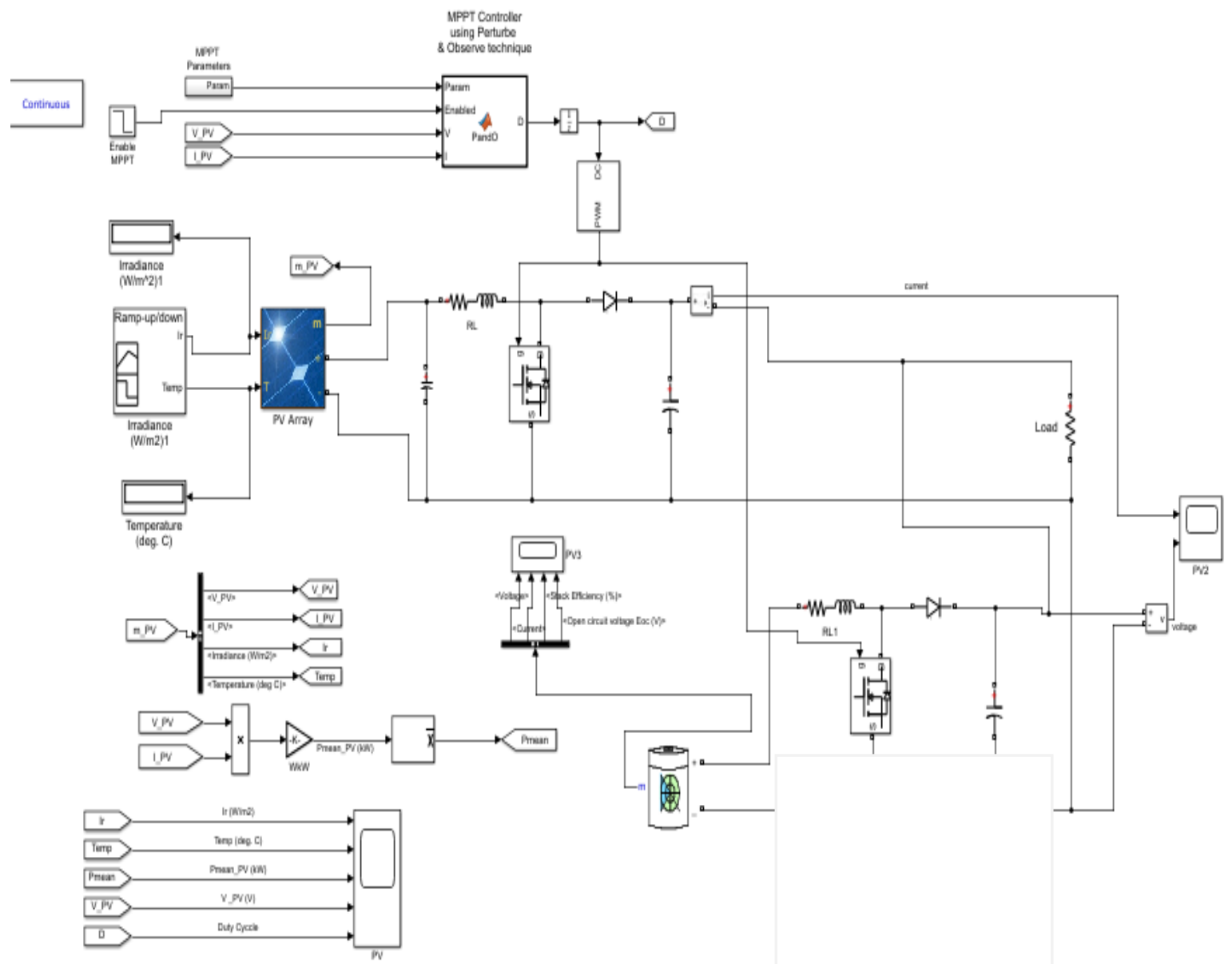

Figure 4-1: Simulink 1

\subsection{Boost Converter:}

Another thing that we have used in the system is boost converter or step up converter. It is used for conversion of low voltage in to relatively high voltage with quite simple circuitry [40] The boost converter boosts up small voltage signal. The simple of the boost 
converter diagram is shown in the figure 4-2 [41]

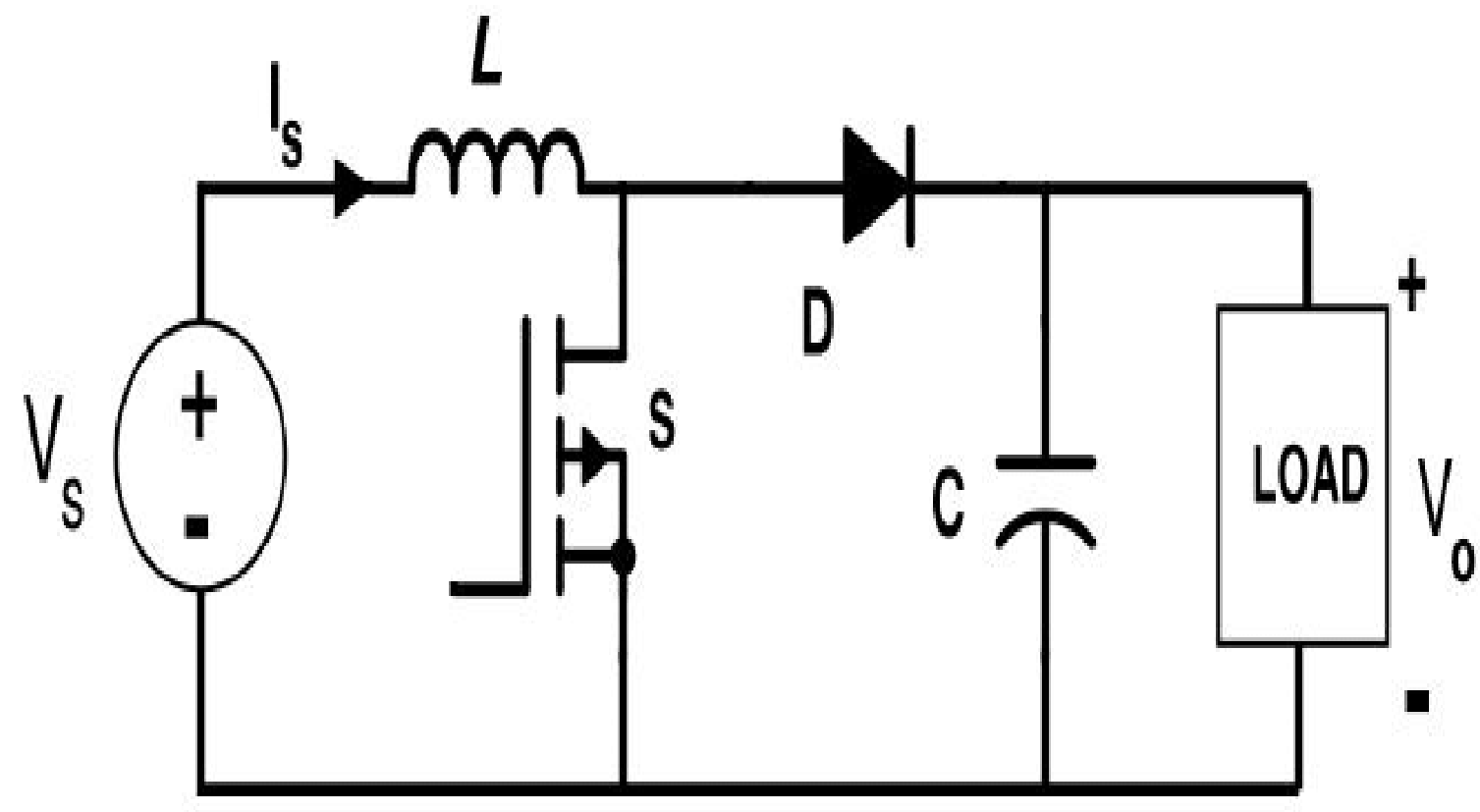

Figure 4-2: Boost Converter Diagram

If we look closely the converter is right after the panel. When the current passes through the inductor, a magnetic force is produced around it. This magnetic field has a push or itself voltage. The boost converter that very property to level up the voltage level. The transistor in the circuit acts as the switch and it do the switching multiple times as much as possible. Because the switch turning on and off is so fast, the inductors magnetic field never fully collapses, so when the switch is opened again this causes a higher voltage on the inductor as it adds to the magnetic field [42]. Now we have a capacitor in the circuit, every time the voltage signal is pushed it passes the semiconductor and is stored in the capacitor. The semiconductor acts as barrier to stop the current going backward. 


\subsection{Maximum Power point tracking (MPPT):}

we have used maximum power point tracking strategy in order to capture the maximum power out of solar. This can be shown in the figure 47 below [44]. This shows the process path and procedure for the maximum point power tracker [43].

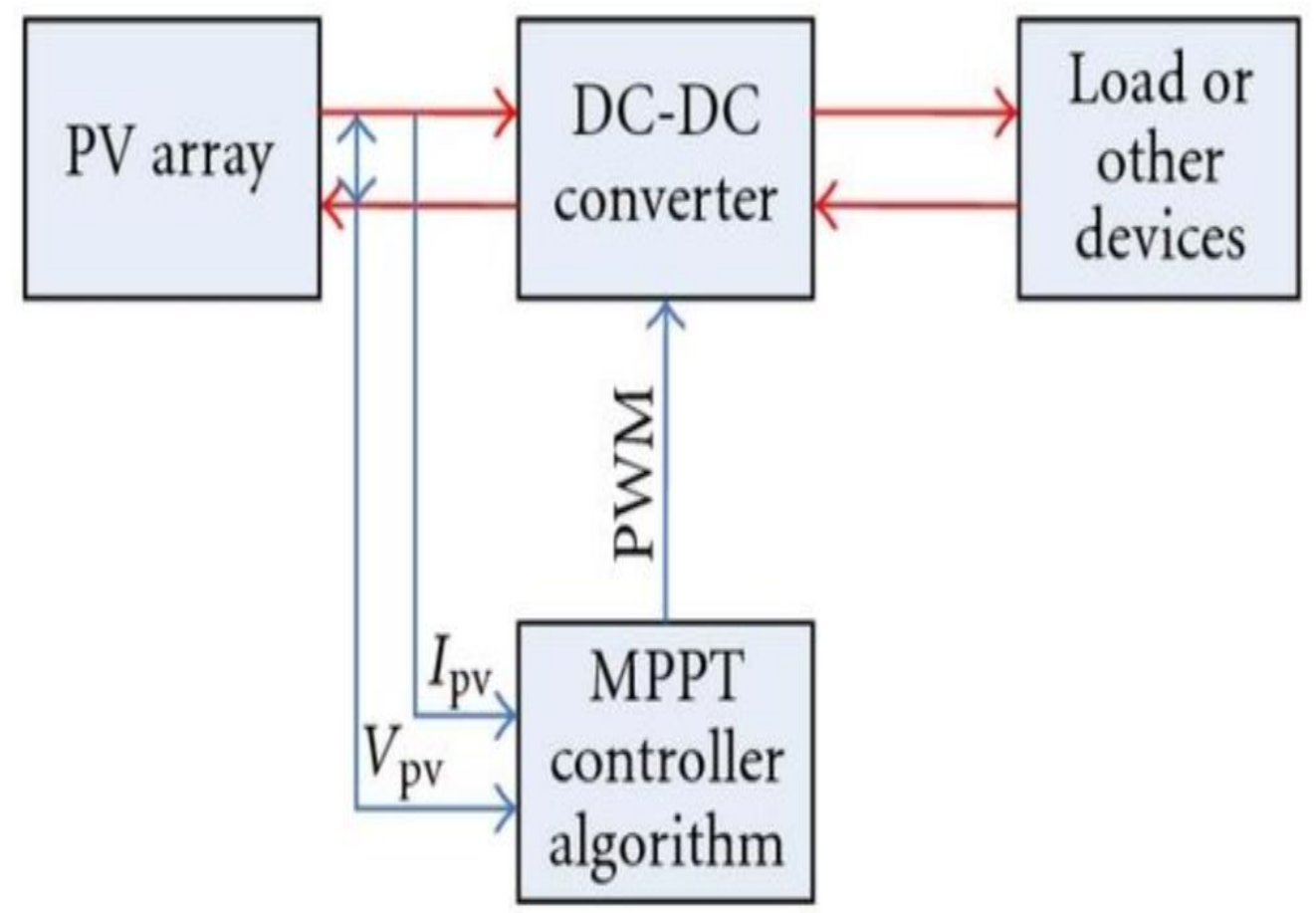

Figure 4-3: MPPT design

\subsection{Reason for MPPT design:}

The solar voltage is obtained capturing the sun light. As the sun is always moving so we have variable power at every moment and so we have to make algorithms to capture the maximum power. These algorithms require maximum requires power around maximum power point. this method can find power without the change in original value. The behavior of the current and voltage for a solar panel can be shown in the following 
figure 48 [45].

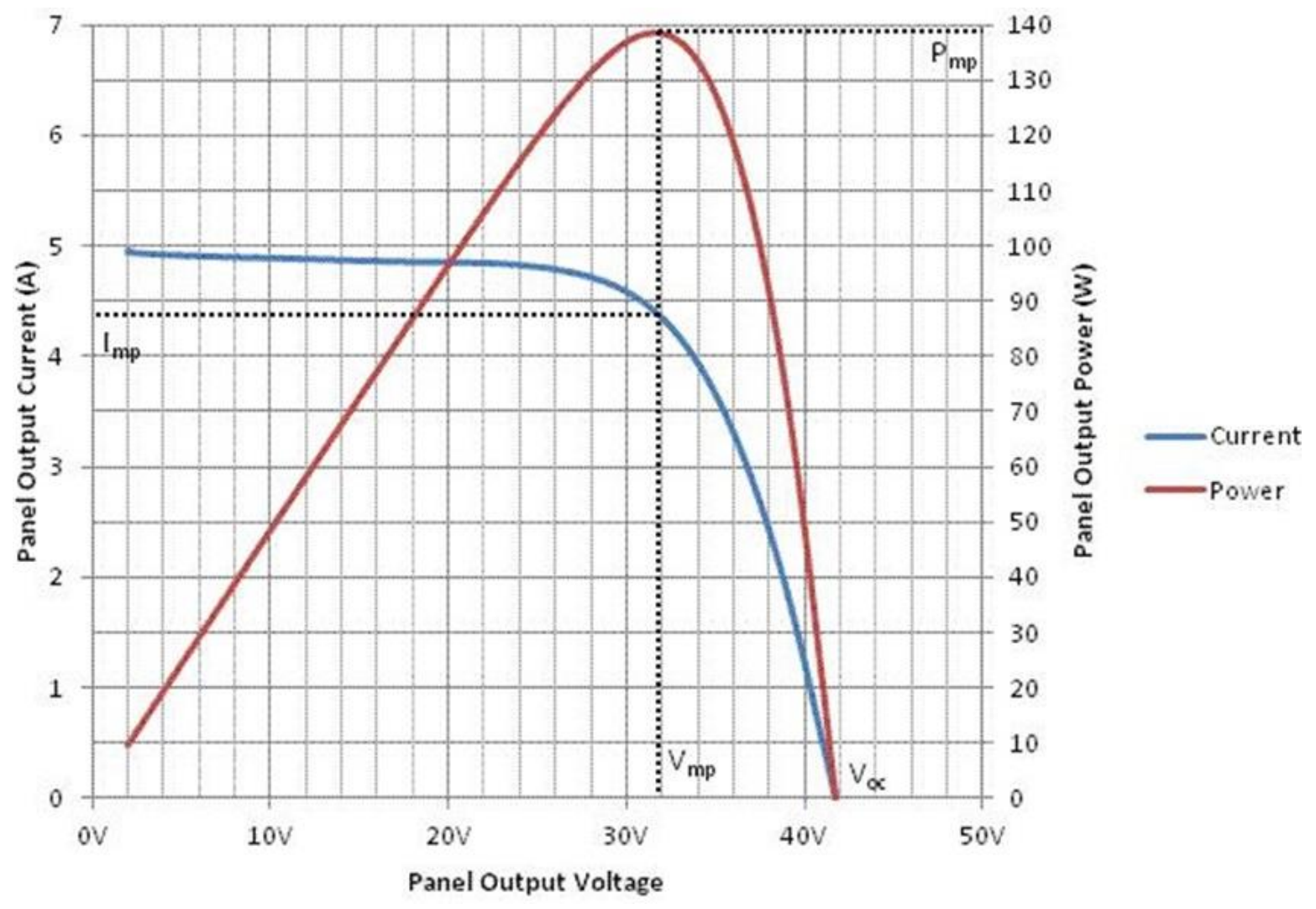

Figure 4-4: Solar PV panel Output waveform

. At first it rises and then it reaches a maximum value and then its value gradually decrease and eventually becomes zero. The dome or peak of the graph is the maximum power point. Actually, for every point except the peak the voltage is rising [43]. And with rise in voltage the current also increase. The power is product of current and voltage. The differential at any point before peak is greater than zero and right after the peak point is negative. However, at the peak point the value of power is maximum and there will no further increment in this. This will be the point of 
maximum power as shown in the figure 49[46]

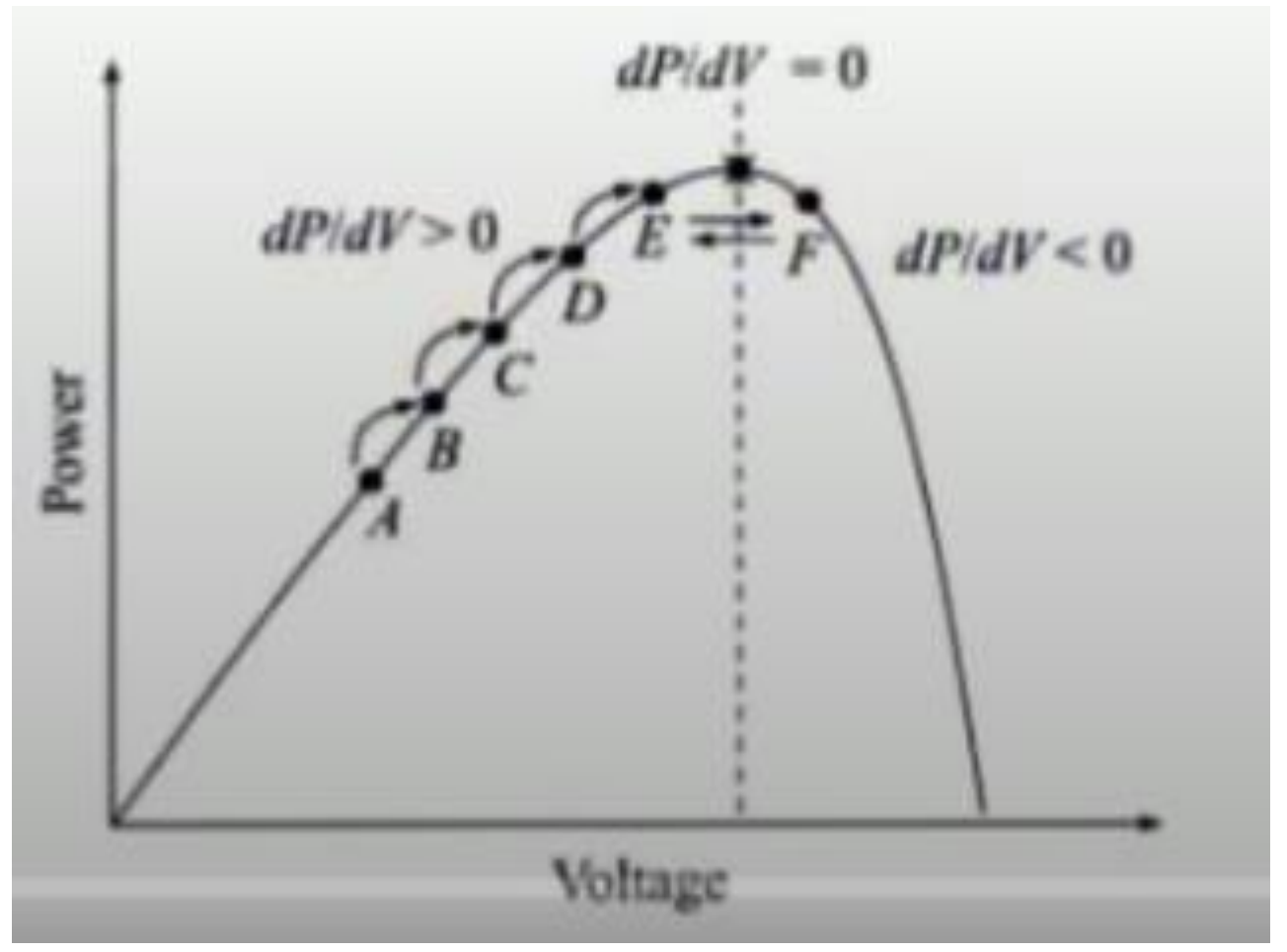

Figure 4-5: MPPT graph

\subsection{Mathematical Derivation:}

The mathematical calculation involved in incremental conductance in perturb and observed method is as follows as [47] it compares the value if the voltages as $\mathrm{I} / \mathrm{V}=\mathrm{dI} / \mathrm{dV}$ where the $\mathrm{I} / \mathrm{V}$ is the instantaneous conductance and $\mathrm{dI} / \mathrm{dV}$ is incremental conductance. It has condition that it at maximum point the change in power wrt voltage is zero $\mathrm{dP} / \mathrm{dV}=0$

Now power $=\mathrm{P}=\mathrm{VI}$

And hence according to chain rule $\mathrm{dP} / \mathrm{dV}=\mathrm{d}(\mathrm{V} . \mathrm{I}) / \mathrm{dV}$

$$
=\mathrm{I} . \mathrm{dV} / \mathrm{dV}+\mathrm{V} \mathrm{dI} / \mathrm{dV}
$$




$$
=\mathrm{I}+\mathrm{V} \mathrm{d} \mathrm{I} / \mathrm{dV}
$$

MPP is reached when $\mathrm{dP} / \mathrm{dV}=0$

So $0=\mathrm{I}+\mathrm{V} \mathrm{dI} / \mathrm{dV}$

$\mathrm{d} / / \mathrm{dV}=-\mathrm{I} / \mathrm{V}$

$\mathrm{dP} / \mathrm{dV}>0$ then $\mathrm{V}_{\mathrm{p}}=\mathrm{V}_{\mathrm{mpp}}$

if $\mathrm{dP} / \mathrm{dV}=0$ then $\mathrm{V}_{\mathrm{p}}=\mathrm{V}_{\mathrm{mpp}}$

if $\mathrm{dP} / \mathrm{dV}<0$ then $\mathrm{V}_{\mathrm{p}}>\mathrm{V}_{\mathrm{mpp}}$

these equations can be elaborated by the graph below.

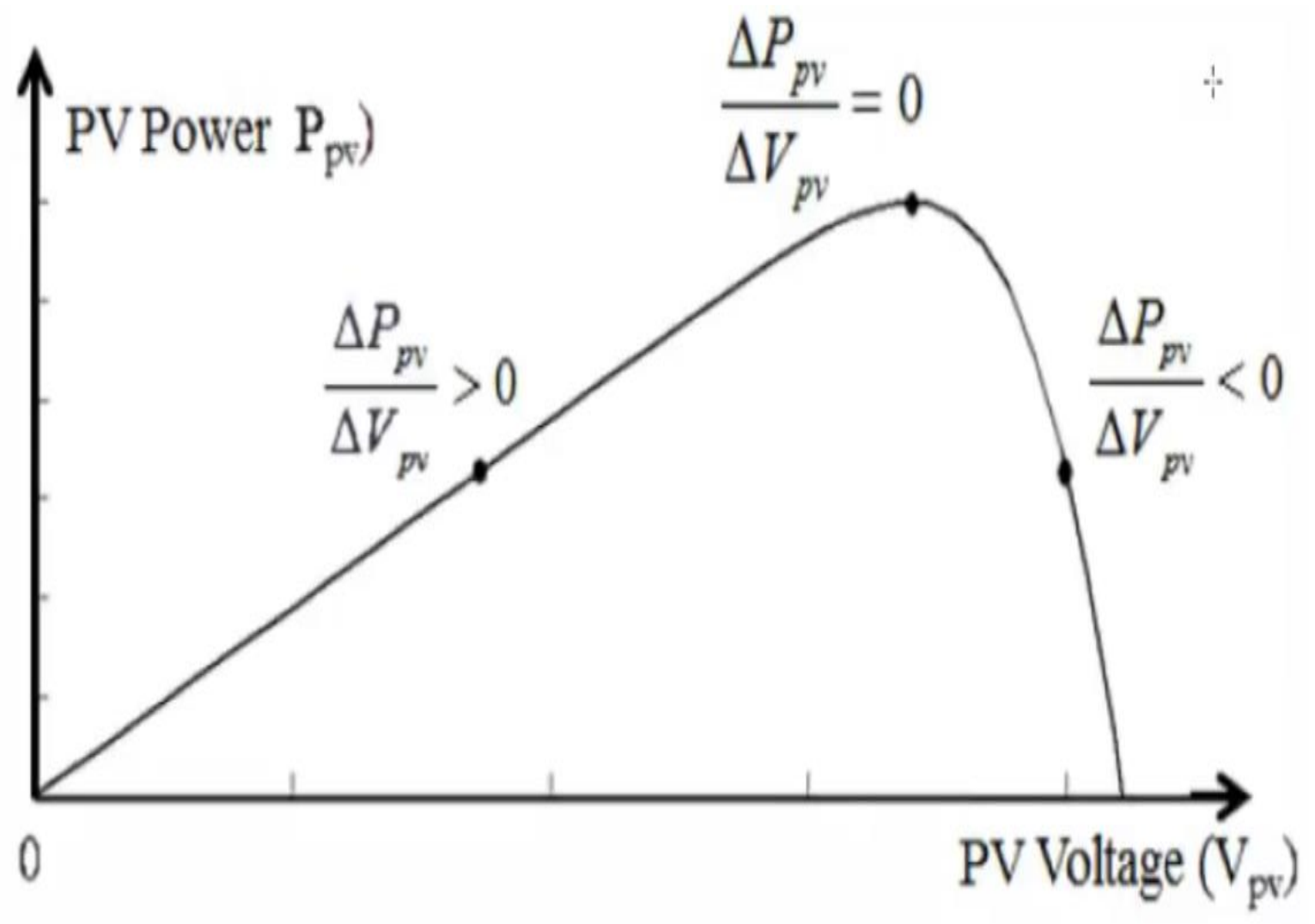

Figure 4-6: MPPT explained 


\subsection{Logic Block diagram:}

Now we have to define the algorithm in the block diagram for this code.

consider we have present time represent by $\mathrm{k}$.

power at this moment $=\mathrm{P}(\mathrm{k})$

voltage $=\mathrm{V}(\mathrm{k})$ and current $\mathrm{I}(\mathrm{k})$

power at previous second $=\mathrm{P}(\mathrm{k}-1)$

power at one second ahead $=\mathrm{P}(\mathrm{k}+1)$

Now change in power $=$ delta $\mathrm{P}=$ power at this moment- power at one second before $\Delta \mathrm{P}=\mathrm{P}(\mathrm{k})-\mathrm{P}(\mathrm{k}-1)$

if $\Delta \mathrm{P}>0$ power increases and if $\Delta \mathrm{P}<0$ then decreases. [38]

Now we will explain the below diagram for the incremental voltage method Similarly, for the voltage and current. This works in conditional statement that and its ultimate goal is to get the maximum. Depending upon the answer it operates in the loop.

The process can be explained as follows. Firstly, the values of current and voltage of PV are sensed. The next these values are stored in the memory till next time interval. Here the values are replaced by the new values from the sensors. This is sample time as one value set is noted here. Next, we find the difference of next and previous values to find the difference or increment. Then the voltage difference is compared with zero. If it is zero then we check the I value if it is also zero it means that during this time interval, I also remain same is remain constant. This indicates that no change so for change in the duty cycle you need to repeat the process contrary to this if the value is greater. than zero than it is increment and thus is will stored as new value and thus the process continues on 
until you get the final updated value.

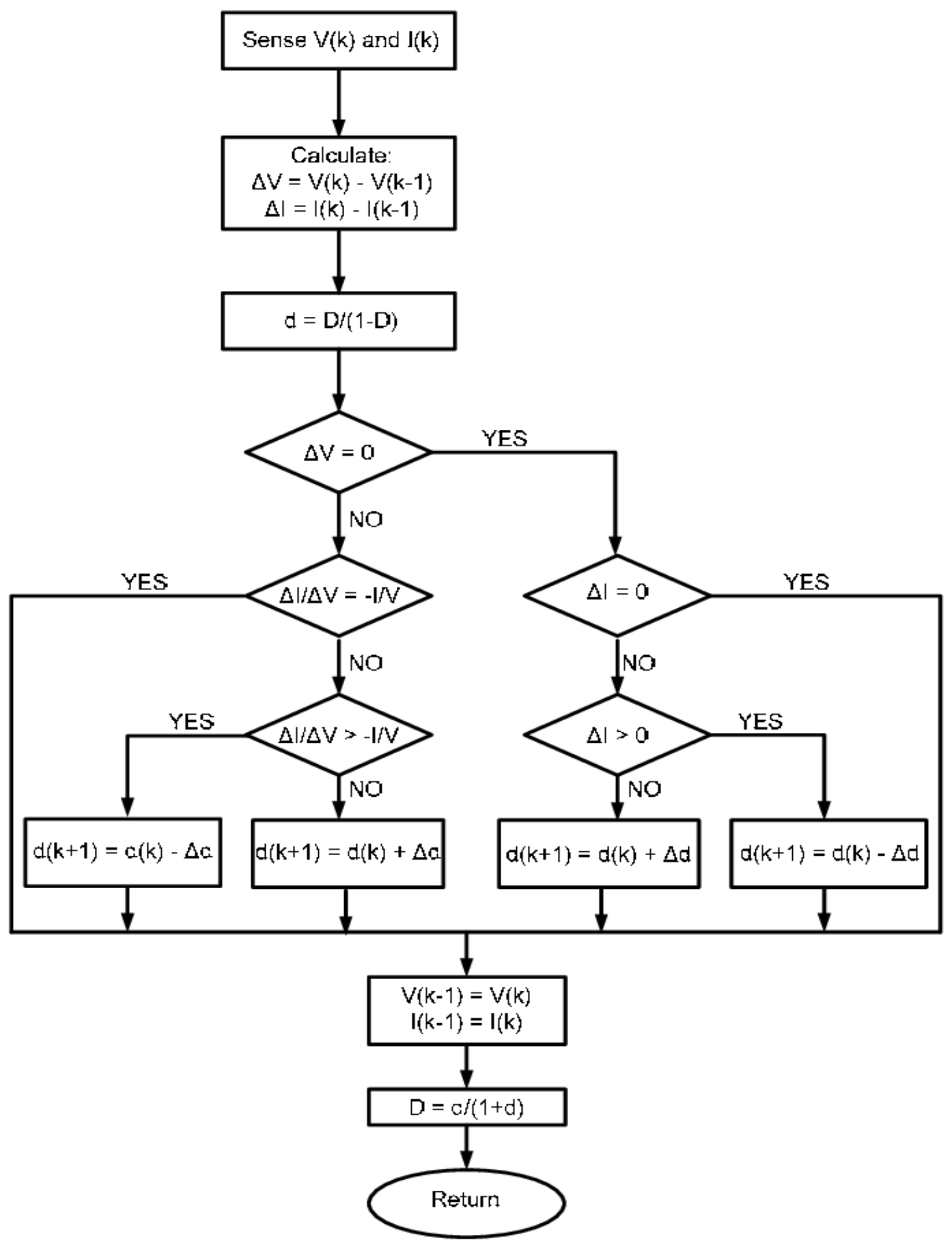

Figure 4-7: Block Diagram of $P \& O$ algorithm 


\subsection{Parameters for the Simulations}

there are certain parameter that we must consider. The frequency plays important role in output oscillation. the switching frequency for the simulation is $20 \mathrm{kHz}$ so that it could oscillate early in short time period. If the oscillation is large then there will be the loss in the signal. And if we keep switching frequency high then time period lowers and cycles travel fast. Hence, we can achieve the stability earlier. This thing is heavy w.r.t computation but this is good way to achieve stability. duty cycle ranges between 0.47 to 0.5. Oscillation reduce sharply after 6 to 10 seconds.

\subsection{Results and Discussion:}

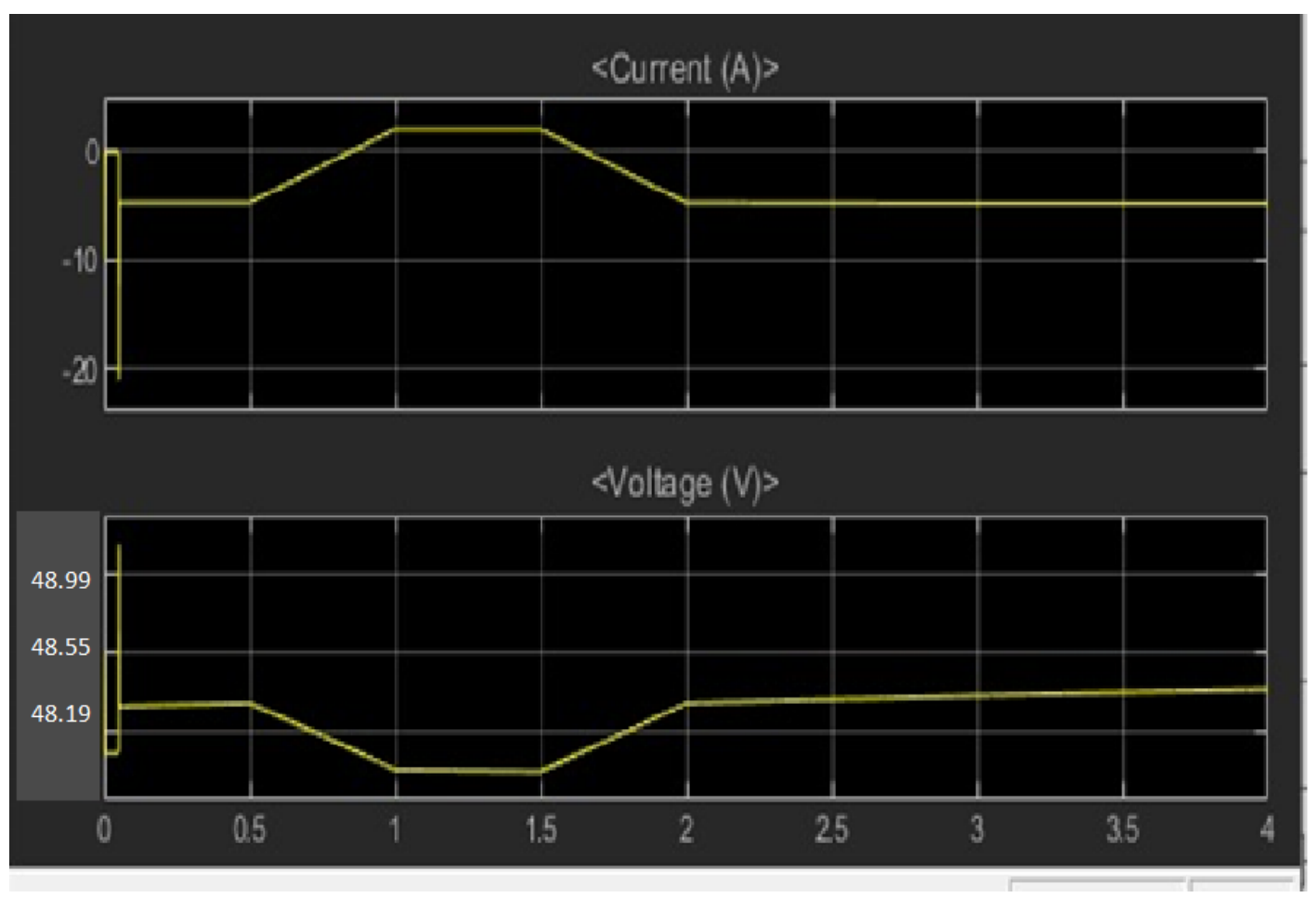

Figure 4-8: Current and Voltage waveform 
In the figure 8 we can see that at the start there is some disturbance in the current and voltage but after then it tends to stabilize and thus, we can achieve less oscillation. Initially the value are not stable but then it stabilized. As time passes on the voltage and current both tends to stabilize it. The value depicts the system. Now consider the figure 9

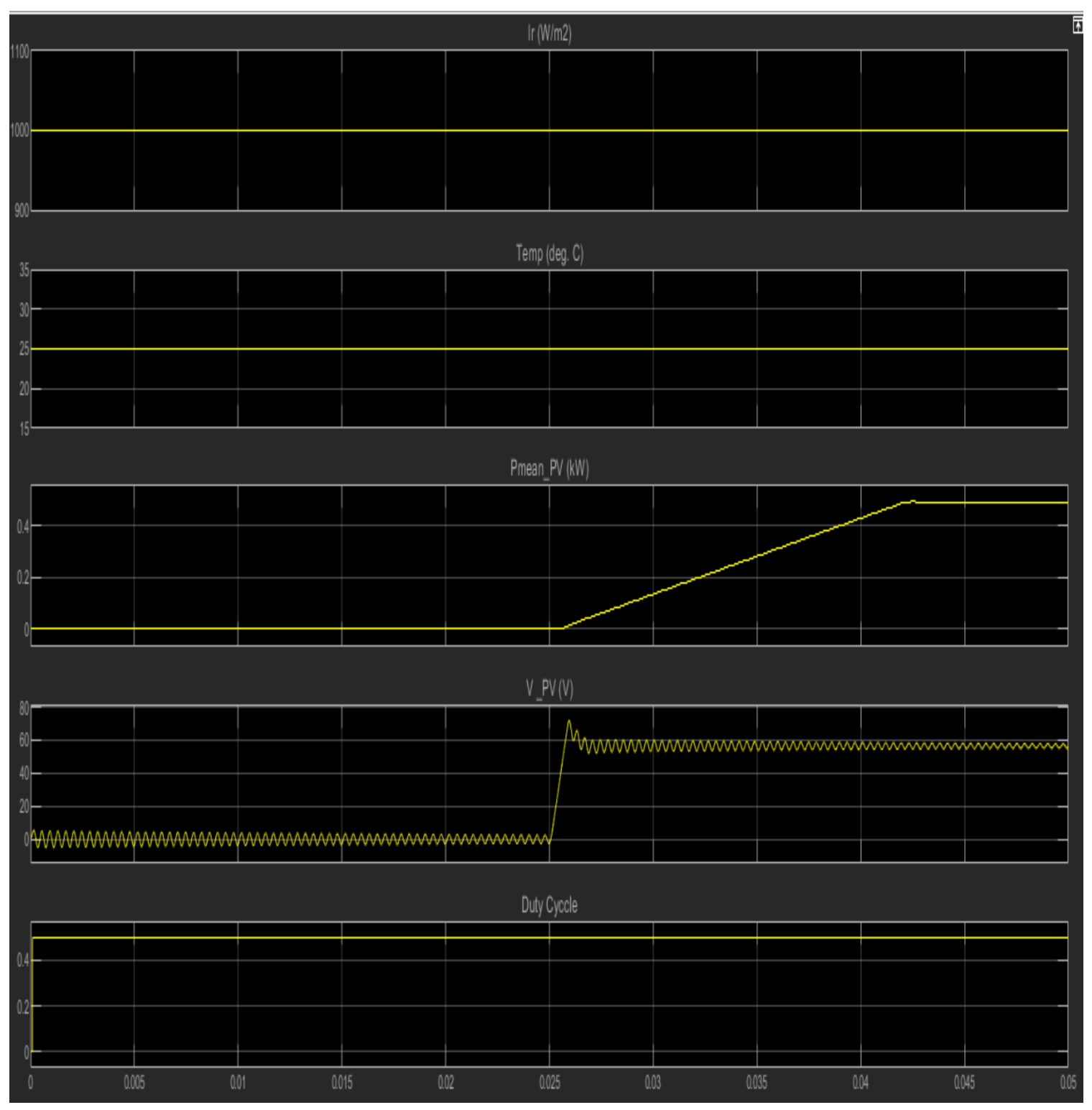

Figure 4-9: Different factor waveform

We can see that from the figure 9 behavior of different factor in the output waveform. The irradiance remains same w.r.t time as it the natural phenomena. The duty cycle show some different behavior. Temperature graph is somehow straight that indicates that there 
is not heating of the plates and the temperature remain same. for the power we see that power is low at the start but with increasing time the power rises. Voltage of the solar panel is less at the start but the after some time the voltage of the panel sudden rises and reach it nominal value. The duty cycle reaches a certain value and remain their w.r.t to time. 


\section{SAFTEY \& PRECAUTIONS OF AC \& DC SYSTEMS}

\subsection{Introduction:}

Safety of the system is one of the crucial factors that ensure the long-lasting performance and safe use. It ensures that protection of equipment and can prevent the system from future loss. In this chapter we have discussed the safety and equipment used in the safety. We have also discussed the design of the plant safety. We have also discussed the design for earthing protection for the system. The calculation of each of them and sizing is also discussed in the chapter.

\subsection{Hazards at the site:}

whenever the solar power plant is installed; the system needs protection. This increases the quality and necessary for improvised efficiency. There are mainly two types of safety. Equipment safety and electrical safety. Equipment includes PV panels, battery bank, inverter, charge controllers, switch board and wiring apparatus. This equipment (other than PV) is sometimes outside and sometime inside any room. If the equipment is outside then this can be damaged by environmental factors such as temp, air storm or rain. We should take in to consideration all of these. External safety can be achieved by making a protection box or a room. This can be made by wood, fiber glass or cement. This can be 
shown in the figure 5-1 [48].

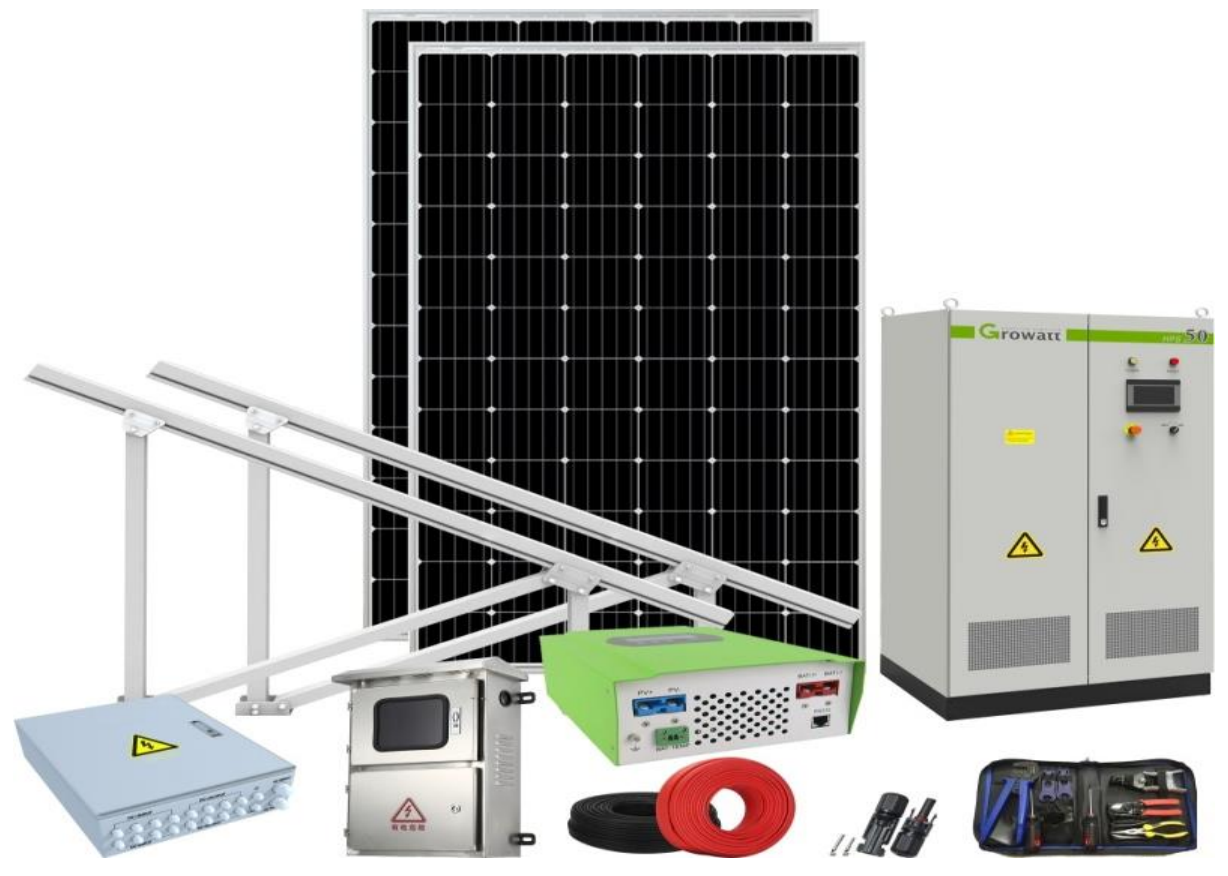

Figure 5-1: Solar Protection equipment

This is mainly used for the equipment protection. In such case the equipment is put under the covers and thus it is made safe from environmental hazards. We have inverter electrical connection, charge controller etc. inside this so that in any environmental condition the equipment must be kept safe

\subsection{Electrical safety}

Electrical faults: In term of electric faults the problem that we faced are as follows ground fault, mounting, lightening surges, power line switching, powerline faults, malfunctioning equipment.

Several devices are used for protection of the electric hazards. The devices and the procedure will be discussed as follows as. 


\subsubsection{Surge protection device}

A device to protect electric circuit from the electric surges is called surge protection device or simply surge protector. It protects the device or circuit by either blocking or bypassing the current to ground. This surge current is mainly due to the electric spike in the voltage caused by multiple ways that could damage the equipment in the circuit. In an electric circuit normaly current flow[49] . Consider the alternating current flowing with certain frequency as shown in the figure 55 . When there is suge the voltage is higher than nominal and we can see a spike higher then normal voltage signal. It may be one or more than one spikes. So with abrupt increment in the voltage current also increase consequently and this could cause damage [50]. The voltage behaviour during surge can be shown in the figure 5-2.

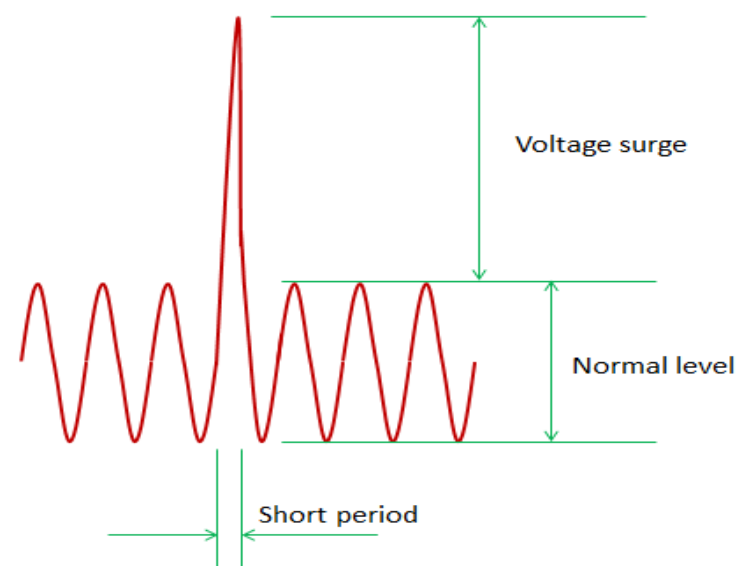

Figure 5-2: Surge voltage waveform

The method of installation of SPD in the circuit is also shown in the figure 5-3. It is connected in parallel to the circuit. 


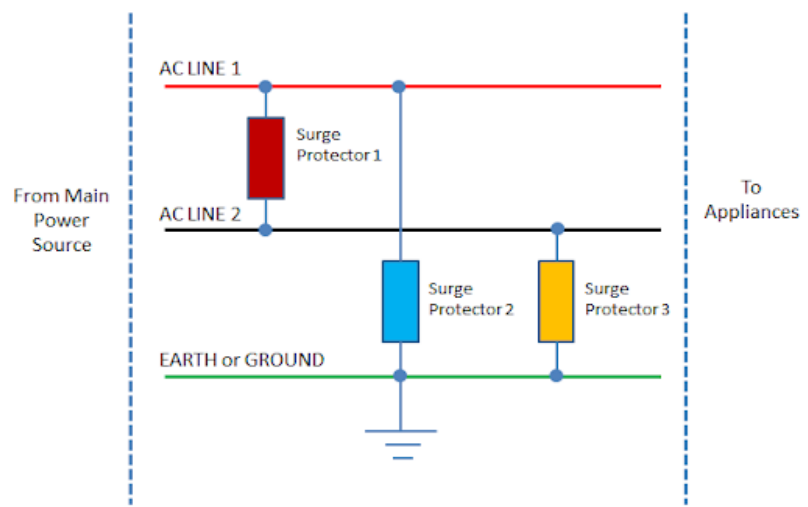

Figure 5-3: SPD installation Scheme

The working principle of the Surge protection device can be shown the figure 57. It can be installed within two power line or between the power line and neutral. When due to short circuit in or any over flowing the value of the voltage increase it shows a spike. This voltage is high and can damage the appliances and delicate equipment [51]. SPD is installed in the parallel of the circuit that can absorb the spike and thus protect the circuit and system. As we can see that SPD is parallel. In the parallel circuit the voltage remains same and so any additional voltage would be captured by the SPD and whole system will be protected from it. Surge protector usually have fixed capacity and they burn out by one 
surge. The internal structure of the Surge protection device is shown in the figure 57

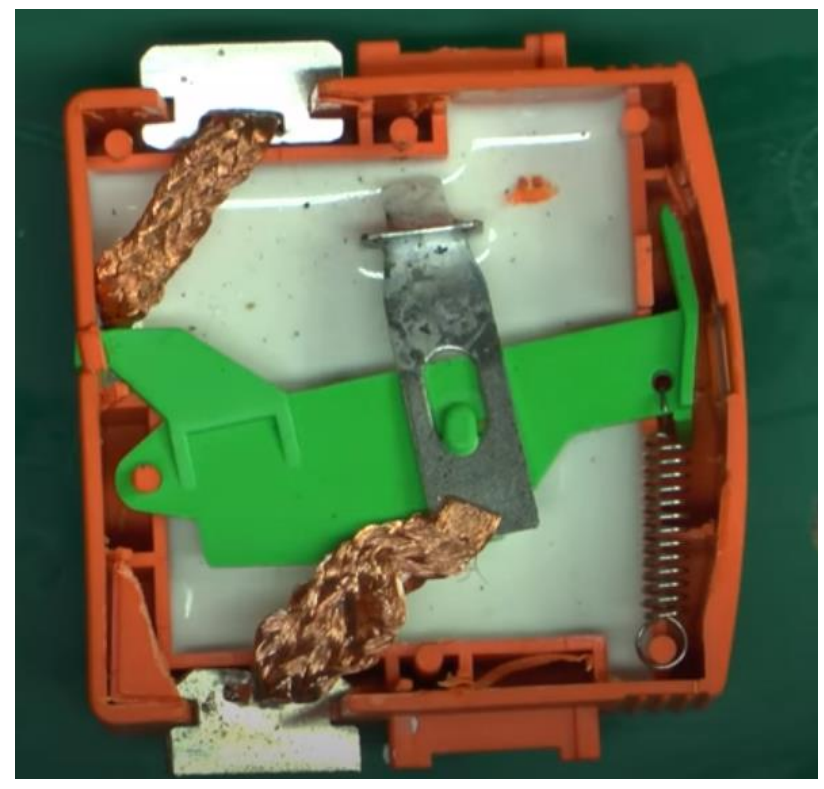

Figure 5-4: SPD inner structure

\subsubsection{Fuse}

It is another safety device that is used to protect overflow of current. It is inserted in series of the circuit. The generic diagram of the fuse is shown in the figure below. it is basically a conductor mostly a wire. In any circuit they are installed in series. Now in case of series the current remains same. Whenever there is any surge or overflow of current, the high current tends to flow through the circuit. Same current flows through the fuse. But fuse is designed in such a way that it has low resistance and high melting point. 


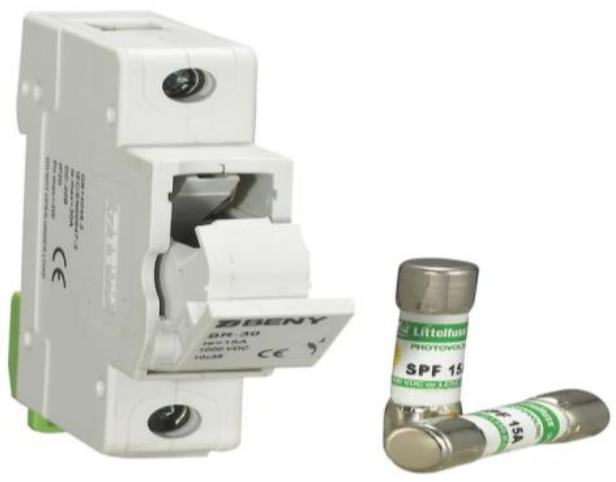

Figure 5-5: DC Fuse

As shown in the figure 5-5 the fuse is usually a wire capsulated in the glass shell. The fuse is inserted in the series. In the series circuit the current remains same. When the current exceeds the allowed limit, the wire heats up and eventually melt and blew up. The circuit is protected from the large current. The glass capsule is used to protect the environment from melted wire and thus to protect it. But it is fixed value and is replaced after once it blew out. So; we have to use alternative solution for the protection. 


\subsubsection{CIRCUIT BREAKER}

The circuit breaker is mainly used as it is variable type fuse. The circuit breaker mainly works of electromagnetic force. A typical circuit breaker principle is shown in the figure $5-6[52]$.

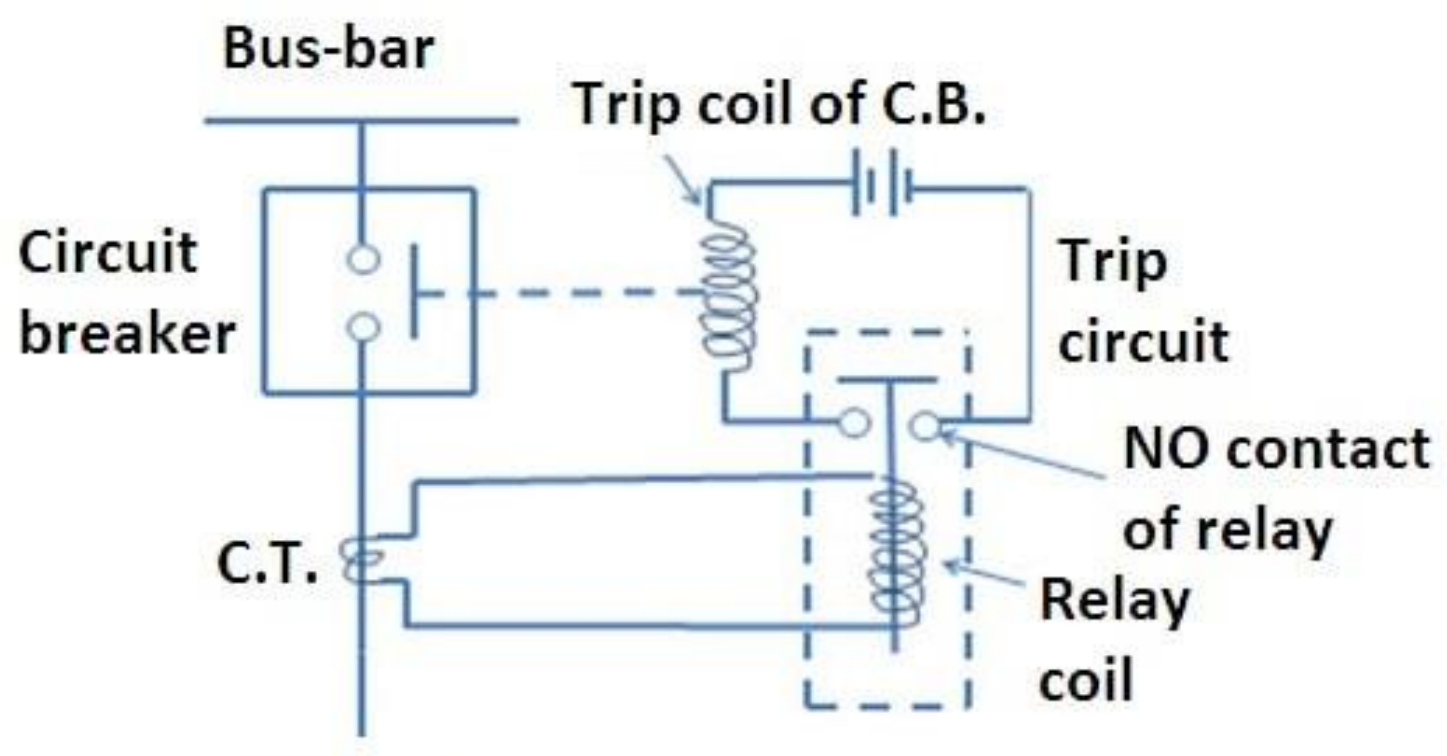

To load

Figure 5-6: Circuit breaker

The circuit breaker works in such a way that there is a relay coil which has a powerful magnetic force. When there is short circuit or any fault in the circuit, the current overflows [52]. Thus, extra amount of the current starts passing through that coil. The magnetic power of the coil attracts the knob and tur off the power supply as it engages the trip circuit This thing with large strength attracts the pivot strip. The strip moves down disconnecting the current flow and thus operation stops. On removal of fault the button is pressed and current flows normally. 


\subsubsection{Circuit breaker Sizing}

Now we will size the circuit breaker. [52]

$$
\begin{aligned}
& \text { Electric Power }=\mathrm{kW} \\
& \text { System Voltage }=\text { Volts } \\
& \text { Power factor }=\text { P.F }
\end{aligned}
$$

know we have to calculate the connected load

$$
\text { Connected load }(\mathrm{kVA})=\text { Electric load } / \text { Power factor }=\mathrm{kW} / \mathrm{P} . \mathrm{F}
$$$$
\text { Rated current } \left.=\mathrm{I}_{\mathrm{rated}}=\text { Connected load } / \text { Voltage }\right)=\mathrm{kVA} / \mathrm{V}
$$

For the circuit breaker we have to use $25 \%$ of safety factor

$$
\begin{aligned}
\text { Required Circuit breaker } & =\text { Current } \times 25 \% \text { of safety factor } \\
& =\mathrm{I} \times 1.25
\end{aligned}
$$

Generally we have a generic rule that required capacity of circuit breaker should be slightly higher than required capacity[4].

\subsubsection{Grounding/ Earthing}

We need to define the basic. In electricity supply we have three wired connection. These are live neutral and earth. Live and neutral are for current flow upon circuit completion and flows normally [53]. This is normal operation but there are some dangerous conditions such as if the bare wire touches the body of the appliance and anybody touches the appliances with hand than the current will pass through this way to the ground and thus person touching it can be caught by the electric shock. This can be shown in the figure 60 [54] 


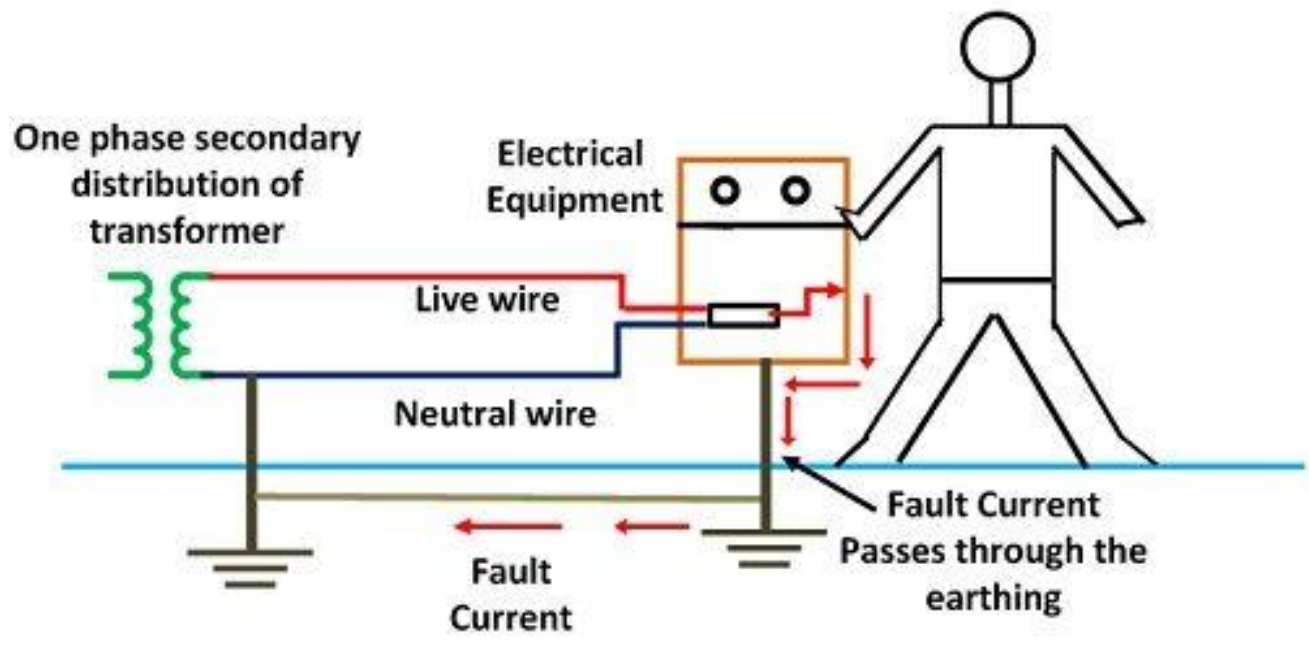

Figure 5-7: Schematic of Short circuiting

Now by giving the earthing gives a bypass and transfer all of the current to the earth. As electricity is merely flow of charges. So, when the surplus amount of charge is providing; the earth is fairly large enough to absorb all the extra amount of charge.

\subsubsection{Component and Procedure of Earthing:}

On the large-scale earthing is necessary in order to protect the equipment from the failure. Because when we have to install some heavy or commercial equipment such as solar plant in th is case, equipment and components are costly and in order to maintain smooth operation we have to ensure the safety of the system.

Earthing system has certain components which are discussed as follows.

\subsection{Earthing wire:}

the wiring is a component of the earthing system. Generally, we have two-line cable in which one is live (higher potential) and the other one is neutral (lower potential). The current flows from higher potential to lower potential. In case of earthing we have 
another cable that is earth wire or ground wire attached to the switch. Normal three phase connection can be shown in the figure 5-8 [54]

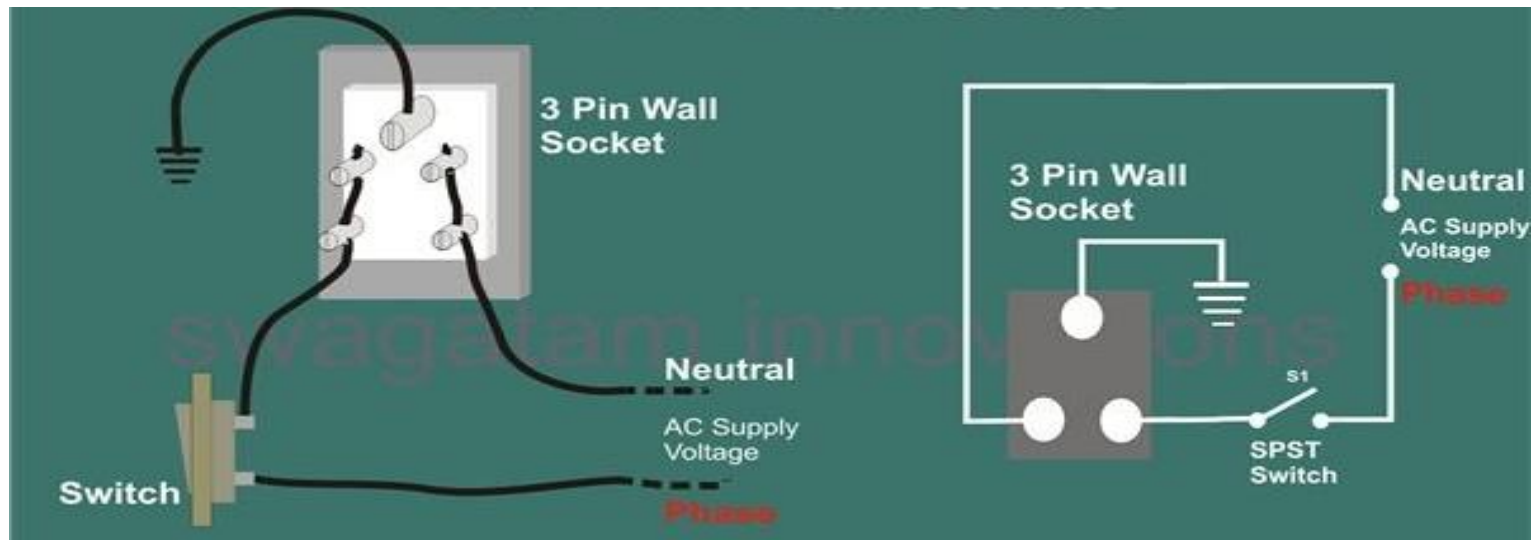

Figure 5-8: Earth wire circuit

This wire is connected to the body of the appliance from one end and to the ground through another end. If the bare wire is touching the body of some person touches the appliance the whole of the current starts flowing through that wire in to the ground. The other end of the earth wire is damped in to the ground through the bare conductor in to pit that are discussed in next topics.

\subsection{Bare Conductor}

As a good practice the earthing is done for every equipment (or at least every crucial component). The damping of each of the wire individually is a mess so we use the bare conductor. In this case a metal conductor with good electrical conductivity is used. All of the earthing connection are attached to the conductor and then the conductor is damped into the soil. Electrical conductivity of soil 110-570 milli Siemens per meter (mS/m). owing to its bad conductivity we need to increase the it so that charge can be damped to the ground frequently, a In this way of grounding the bare conductor is damped in to the ground. The conductor is 6 to 10 meter in length. The most effective way is pipe earthing. The pipe can be copper or GI, but one should select the pipe with good conductance [55] 
We can use GI or copper pipe for this purpose. The schematic diagram is shown in the figure 5-9 below [55].

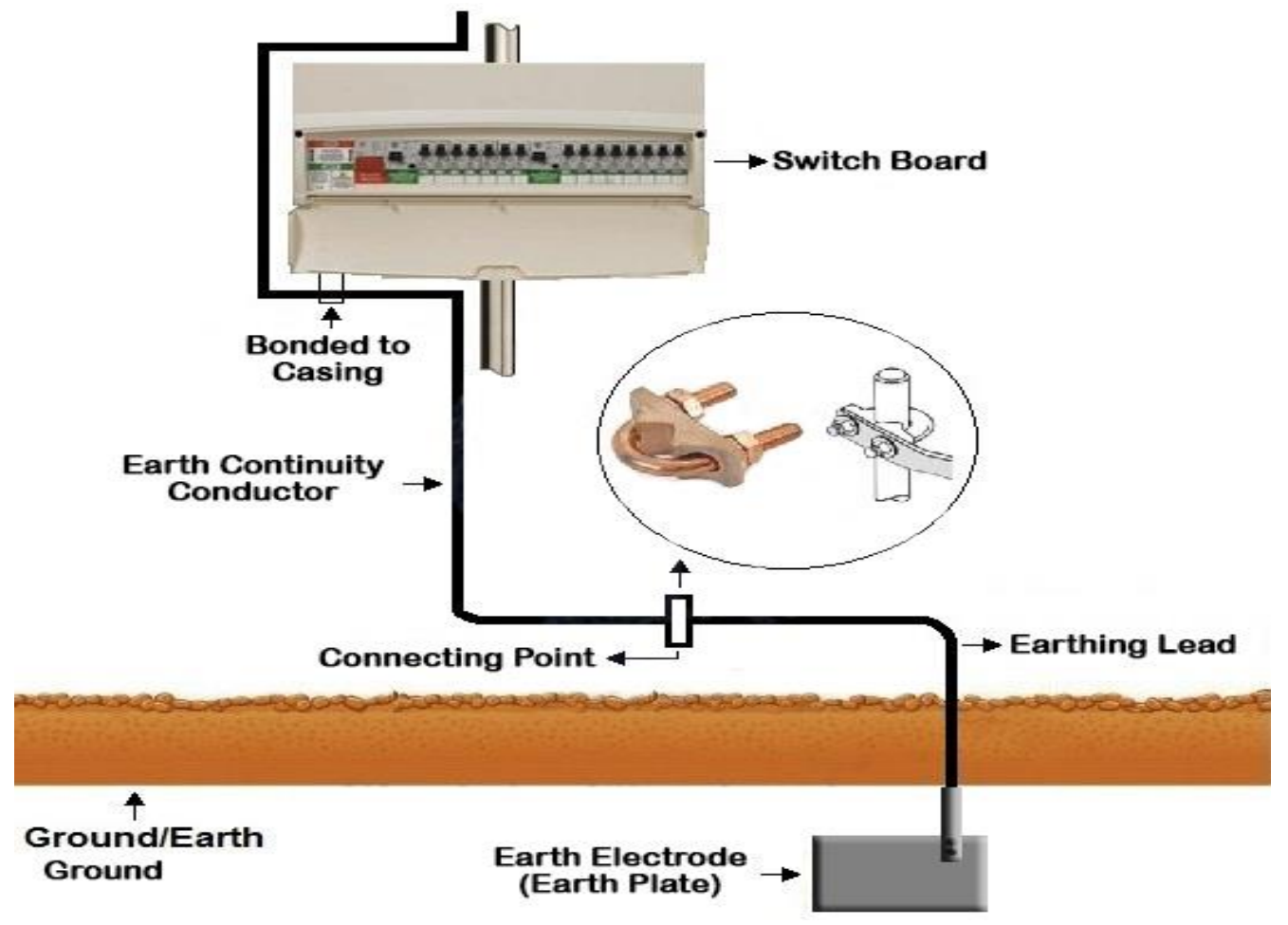

Figure 5-9: Earthing conductor grounding

\subsection{Calculation for earthing conductor}

There are certain steps in calculation of earthing conductor [56]. This can be explained stepwise below.

Resistivity of soil $=\rho_{\text {soil }}$

maximum current $\left(\mathrm{I}_{\max }\right)=$ short circuit current $\times$ number of inverter strings $\times$ safety factor

$$
=\mathrm{I}_{\mathrm{sc}} \times \text { N.O.S } \times \text { S.F }
$$

strip size $($ area of strip $)=\left(I_{\max } \times \sqrt{t}\right) / \mathrm{K}$

in the equation (2) $I_{\max }$ is the maximum current that we found from equation (1) . $t$ is the duration of the time for which we have to design the earthing conductor. $\mathrm{K}$ is the constant 
of the material. It value differs for different material. For GI the value is 78 for 1 second and 46 for 3 seconds.

Finally, conductor size $=1.15 \times$ area of strip

the number 1.15 account for the two things. If the resistance of the soil is between $25 \Omega \mathrm{m}$ to $100 \Omega \mathrm{m}$ we have to use $1.5 \%$ extra size of conductor. Also, we have to consider the corrosion loss $\leq 1 \Omega$. And combining both of the factor we the overall multiplication factor is 1.15 .

\subsection{Resistance of earthing strip}

Now we have to formulate the resistance of the earthing strip.

According to the formula the resistance of the earthing strip $\left(R_{S}\right)$ [57] is

$$
\mathrm{R}_{\mathrm{s}}=\frac{100 \times \rho}{2 \pi L} \ln \left[\frac{2\left(L^{2}\right)}{W \times D}\right]
$$

in equation (4), $R_{s}$ is resistance of the strip in ohm, $\rho$ is resistivity of the soil, $L$ is the length of the strip in $\mathrm{m}$ or $\mathrm{cm}, \mathrm{W}$ is width of strip in $\mathrm{m}$ or $\mathrm{cm}, \mathrm{D}$ is thickness of strip in $\mathrm{m}$ or $\mathrm{cm}$. The above case is for the strip. Now consider the pipe earthing. In case of the pipe earthing, pipe is dumped in pit filled with charcoal and salt and is moist using water to increase the conductivity of pit soil. Consider the pit with damped pipe. Let resistance of the pit

$$
\mathrm{R}_{\text {pit }}=\frac{100 \times \rho}{2 \pi L} \ln \left[\frac{4 L}{D}\right]
$$

In equation (5) $\rho$ is resistivity of the soil, $\mathrm{L}$ is the length of the pipe in $\mathrm{m}$ or $\mathrm{cm}, \mathrm{D}$ is diameter of rod/pipe in $\mathrm{m}$ or $\mathrm{cm}$. Now for the rooftop solar power plant minimum 2 pits are required. Now we will calculate the resistance of whole plant.

$$
\begin{aligned}
& \quad R_{\text {plant }}=R_{\text {pit }} / \text { No. of earthing pits } \\
& \text { mutual resistance }=R_{m}=\left(R_{s} \times R_{p}\right) /\left(R_{s}+R_{p}\right) . \\
& R_{s} \text { is soil resistance and } R_{p} \text { is pit resistance. }
\end{aligned}
$$

\subsection{Methods to increase the conductivity:}

The material used in earthing is salt charcoal and water. It will ground the over or leakage 
current. The salt and charcoal should be added layer to layers and should keep the soil moist in order to increase the reactivity as shown in the figure. Now we have to see why the grounding of the pole is required. Now in case of lightening or electric shock or spark, the panels or the transformers can also hit by that. In this case ground wire come into play and this heavy current is damped into ground and thus prevent hazards of electric shock to the person touching it.

\subsubsection{LIGHTENING/SURGE ARRESTER}

The device used to capture the lightening and protecting form thunder spark is called lightening arrester. As we have discussed the lightening is the fatal for the system as the discharge voltage is 300 million volts. Another instrument similar to it is the surge arrester is an instrument used to divert the abnormal high voltage surges due to lightening or due to abnormal switching thus protecting the system from damage and continuously providing the electricity without interruption. It is also called surge arrester; lightening arrester LA basically lightening arrester only protect against lightening while the surge arrester provides the protection against any type of. Surge or over voltage.

\subsection{Surge Arrester}

The top ring is the gradient ring and on its top is line terminal which is connected to live phase. The black fin type structure is called porcelain housing that zinc oxide $\mathrm{ZnO}$ elemental column that hold the structure intact [58]. At the bottom of each arrester, there is surge arrester ground terminal. It is point at base that transfer surge to the ground. In the ground the termination point of the surge wire is body earthing point, where the surges are dumped into the ground. Usually, the arrester is mounted on GI pole or any frame. Within the frame, there is also LA counter/leakage current meter is installed which measure the leakage current or the amount of the surges falling [59]. The internal dissected diagram of the $\mathrm{ZnO}$ surge arrester is shown in the figure 5-10 [60]. 


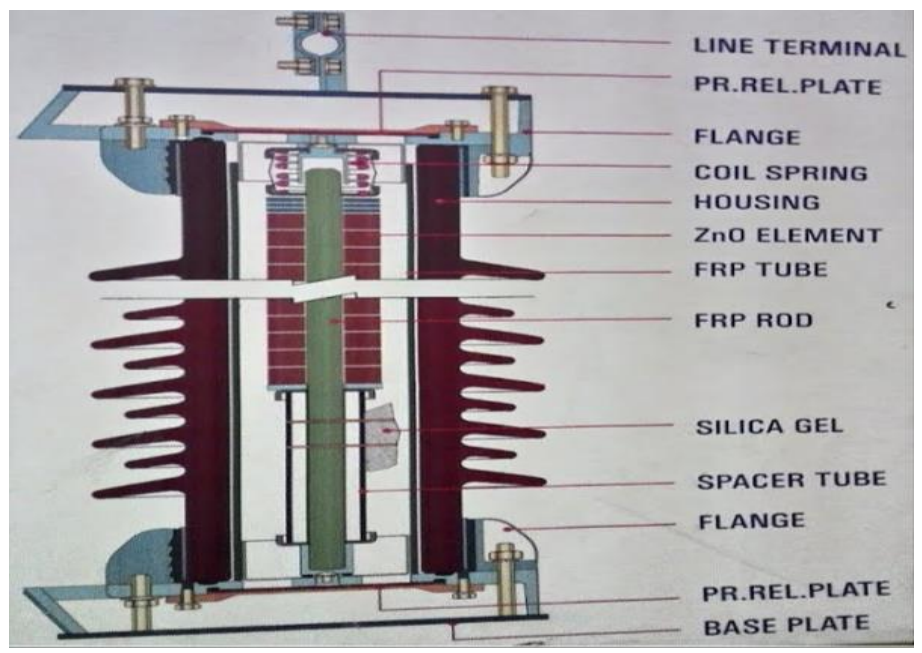

Figure 5-10: Surge Arrester

On the top is a line terminal that is connected to the main phase line. The base plate is connected to the ground terminal. In the middle the structure of arrester is in placed due to $\mathrm{ZnO}$. It offers high resistance at low voltage and relatively low resistance at high voltage level. Due to this property whenever the surge occurs surge offers least resistance lower than any other path in the circuit. Thus, all of the current is transferred to the ground avoiding the damage and all other equipment such as transformer, panels or any other electrical equipment remains safe. Now look at the assembly of the surge arrester shown in the figure. Below the line there is a flange and coil spring. This spring put pressure to hold $\mathrm{ZnO}$ column in place. FRP (fiber reinforced plastic) tube increase mechanical strength and insulation property of the arrester. There is also silica gel present in the arrester. This act as desiccant to avoid the moisture in the arrester. The spacer tube is also there that help to achieve desired height of arrester. In the bottom of the arrester there is PRP (pressure release plate). During working the pressure is built inside. When the pressure is increased, it burst out releasing the pressure.

Gradient ring is usually present in the relatively taller surge arresters. The urge arrester contain the $\mathrm{ZnO}$ plate the plate have capacitance with one another and with the ground. This is called stray capacitance and its value is negligible when the height of the arrester 
is smaller. But when the arrester is longer than value is fairly large. This affects the voltage distribution through the arrester. And so, to avoid this effect the arrester has gradient ring on the top.

earthing is done separately for pole and body.

\subsubsection{Components of lightning protection system:}

\subsection{Lightening arrester calculations:}

Mathematical calculations: we will formulate the lightening arrester as follows as [62].

Expected lightening frequency $\mathrm{N}_{\mathrm{d}}=\mathrm{N}_{\mathrm{g}} \times \mathrm{A}_{\mathrm{e}} \times \mathrm{C}_{1} \times 10^{-6}$

In above equation

$\mathrm{N}_{\mathrm{d}}=$ expected yearly lightning strike frequency to the system

$\mathrm{N}_{\mathrm{g}}=$ Average flash density in region per year (strike $/ \mathrm{km}^{2} /$ year)

$\mathrm{A}_{\mathrm{e}}=$ Equivalent collective area in $\mathrm{km}^{2}$

$\mathrm{C}_{1}=$ Environmental coefficient

average flash density or $\mathrm{N}_{\mathrm{g}}$ can be found from lightning frequency map

The lightning frequency map indicates the amount of lightening falling on particular area throughout the year. Now, Ae is the equivalent area of the building. We have to take a schematic diagram to define our system [62]. Consider the shape below

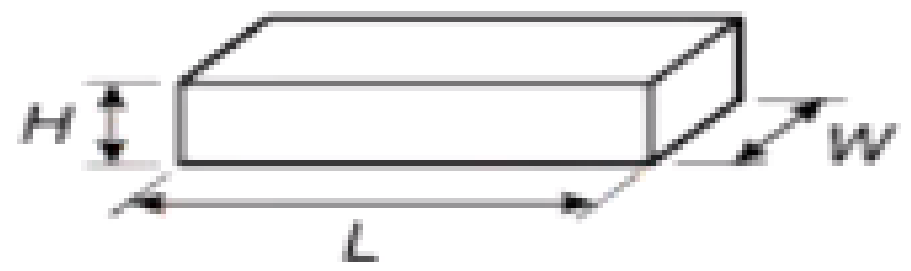

Figure 5-11:Building Sample

Now from the above figure the formula for the equivalent area is

$A_{e}=L W+6 H(L+W)+9 \pi H^{2}$ 
There are another factor and variable that we need to evaluate. We have to consider them in an order.

Now the value of $\mathrm{C}_{1}$ varies according to conditions given in the table

Table 1: Environmental Coefficient C1

\begin{tabular}{|l|l|}
\hline C1 & Relative Structure Location \\
\hline 0.25 & Structure surrounded by taller structure or trees within a distance of $3 \mathrm{H}$ \\
\hline 0.5 & $\begin{array}{l}\text { Structure surrounded by structures of equal or lesser height within distance } \\
\text { of } 3 \mathrm{H} .\end{array}$ \\
\hline 1.0 & Isolated structure, with no other structure located within a distance of $3 \mathrm{H}$ \\
\hline 2.0 & Isolated structure on hill top \\
\hline
\end{tabular}

Next Tolerable lightning strike frequency $\mathrm{N}_{\mathrm{c}}=\left(1.5 \times 10^{-3}\right) /\left(\mathrm{C}_{2} \times \mathrm{C}_{3} \times \mathrm{C}_{4} \times \mathrm{C}_{5}\right)$

$\mathrm{C}_{3}$ is another constant called structure content coefficient and its value depends upon the combustibility of the material. This value can be found from the following table

Table 2: Structure Content Coefficient

\begin{tabular}{|l|l|}
\hline $\mathbf{C}_{3}$ & Structure Contents \\
\hline 0.5 & Low value and non-combustible \\
\hline 1.0 & Standard value and non-combustible \\
\hline 2.0 & High value, moderate combustibility \\
\hline 3.0 & Exceptional value, flammable liquids, computer or electronics \\
\hline 4.0 & Exceptional value, irreplaceable cultural items. \\
\hline
\end{tabular}

$\mathrm{C}_{4}$ is structure occupancy coefficient and depends on how much the structure is occupied. It value is 0.5 for unoccupied, 1.0 for normally occupied and 3.0 for over occupied where the evacuation is difficult 
$\mathrm{C}_{5}$ is factor to determine the lightning consequence. It can be chosen from the following table

Table 3: Lightening Consequences

\begin{tabular}{|l|l|}
\hline $\mathrm{C}_{5}$ & Lightening Consequence \\
\hline 1.0 & Continuity of facility service not required, no environmental impact \\
\hline 5.0 & Continuity of facility service required, no environmental impact \\
\hline 10.0 & Consequence to the environment \\
\hline
\end{tabular}

Risk Assessment calculation: now after finding both $\mathrm{N}_{\mathrm{c}}$ and $\mathrm{N}_{\mathrm{d}}$ we have to assess the risk. We have two conditions here if $N_{d}>N_{c}$; we need to install the lightening protection system but if $N_{d} \leq N_{c}$; then lightning protection system is optional the lightening protection efficiency is given as $1-\mathrm{N}_{\mathrm{c}} / \mathrm{N}_{\mathrm{d}}$. this is also called lightning efficiency.

Now lightning falling on any particular site may vary from site to site. And according to their magnitude we have divided it into certain classes based upon percentage efficiency. Let us explain them in the table below

\section{Table 4: Protection Efficiency}

\begin{tabular}{|l|l|l|l|}
\hline $\begin{array}{l}\text { Lightning } \\
\text { Protection }\end{array}$ & $\begin{array}{l}\text { Peak Lightning } \\
\text { current min.(kA) }\end{array}$ & $\begin{array}{l}\text { Peak Lightening } \\
\text { Current max. } \\
(\mathrm{kA})\end{array}$ & $\begin{array}{l}\text { Capture Probability } \\
(\%)\end{array}$ \\
\hline I & 3 & 200 & 98 \\
\hline II & 5 & 150 & 95 \\
\hline III & 10 & 100 & 88 \\
\hline IV & 16 & 100 & 81 \\
\hline
\end{tabular}


Now in the above table we can see that there are certain classes of lightning protection and so based upon these classes, the application or utilities may also vary. This can be shown in the table below

\begin{tabular}{|l|l|}
\hline Application & $\begin{array}{l}\text { Lightning protection } \\
\text { class }\end{array}$ \\
\hline $\begin{array}{l}\text { Computer centers, military applications, nuclear power } \\
\text { stations }\end{array}$ & I \\
\hline Ex zones in industry and chemical sector & II \\
\hline Photovoltaic systems $>10 \mathrm{~kW}$ & III \\
\hline Museums, schools, hotels with more than 60 holes & III \\
\hline $\begin{array}{l}\text { Hospitals, churches, storage facilities, meeting places } \\
\text { accommodating more than } 100 \text { to } 200 \text { people }\end{array}$ & III \\
\hline $\begin{array}{l}\text { Administrative building, sales points, offices and bank } \\
\text { building of over } 2,000 \mathrm{~m}^{2}\end{array}$ & III \\
\hline Photovoltaics & III \\
\hline
\end{tabular}

\subsection{Air termination systems:}

Now we have to design a system to capture the strikes so in this section we will elaborate this. The lightning conductor is usually $6 \mathrm{~m}$ pole length. This system used is a conventional system and can be replaced with the air termination system. The system has individual rods. one of these rods can provide protection up to $30 \mathrm{~m}$. the protection is provided in the form of a cone that protects the lightening.

The calculations are as distance between two lightning rods $=2 \sqrt{2 R H-H^{\wedge} 2}$ in the above equation the $\mathrm{R}$ is radius of rolling sphere and the $\mathrm{H}$ is height of the rod. 
From this equation we can find out the distance between them.

\begin{tabular}{|r|r|}
\hline \multicolumn{2}{|c|}{ LUGINING PROTECTION } \\
\hline LEVEL (LPL) & $\begin{array}{r}\text { RADIUS OF } \\
\text { SPHERE }\end{array}$ \\
\hline LPL IV & $60 \mathrm{~m}$ \\
\hline LPL III & $45 \mathrm{~m}$ \\
\hline LPL II & $30 \mathrm{~m}$ \\
\hline LPLI & $20 \mathrm{~m}$ \\
\hline
\end{tabular}

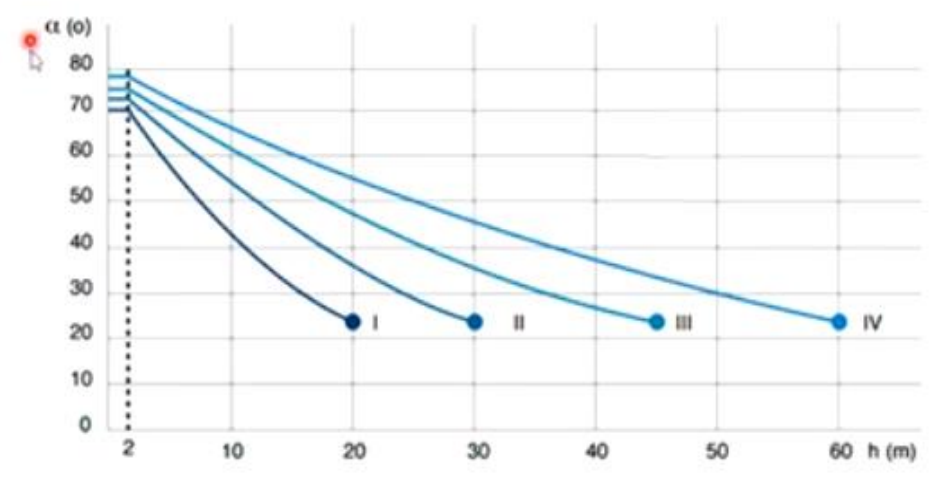

Figure 5-12: LP angle and radius of rolling sphere

The angle and the radius can be found from figure 67 [65]. The rolling sphere ideas is that when you have sphere of huge radius that move over the building than it will touch some point is the building at which we have to mount rods [64] beside air termination we have another system called mesh design that is used for the protection of the flat roof structures and can't be used for the curved surfaces. And then we can measure the rolling sphere radius with following diagram

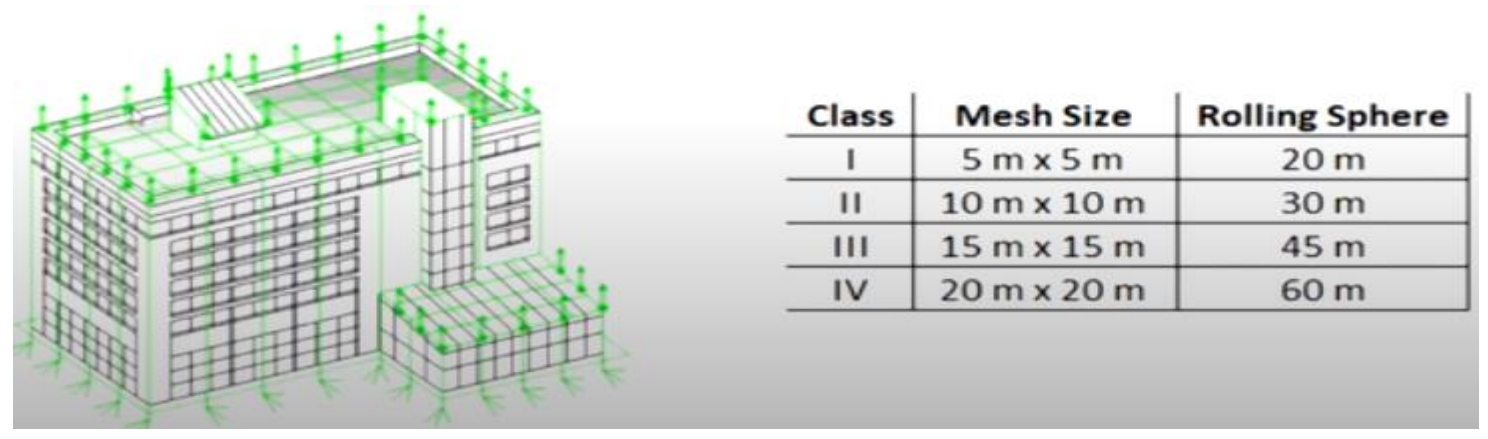

Figure 5-13: Mesh w.r.t radius

the we have a down conductor design that takes lightening to the ground. We have to design it properly in order to dissipate the energy properly. 
now as we will using the conductor, we must need to ensure that that down conductor wire have certain resistance which can be applied to the conductor [64].

\subsection{Lightening counter}

lightening or surges faced by the system are although damped yet we have to measure them so that there is proper schedule repairing and maintenance. In order to do that we use an instrument called lightening counter or surge counter. It measures the amount of surge to a system. Both digital and analog counters are available in the market as shown in the figure 69.

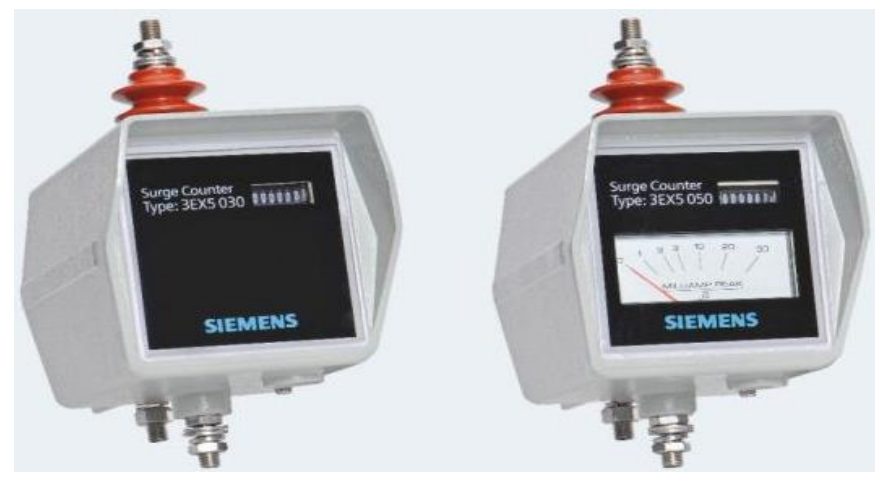

Figure 5-14: Surge/Lightening Counters

These are some of the instruments and precautionary measurement that are necessary and should be taken in order to avoid the danger. Also, it ensures the safety of the plant and equipment as well. 


\section{CONCLUSIONS AND FURTURE WORK}

As the solar energy is increasing day by day so the keeping in mind the ever increasing need we have done a project for DC solar application. In this project we have designed an off-grid DC load solar system with the household use. we have also designed two more systems; one with the DC generator without battery bank and other with DC generator and battery bank. All the designing parameters and steps have been discussed in the details. System is designed with homer using all the parameter and data. The results, calculation and cost analysis for each of the case is also discussed in detail. Then we have done dynamic modelling of the system using MATLAB and the results and output are also shown. Along with that we have discussed the safety devices for the protection, the methodology and calculation for each. We provided safety for each of the system. This whole study will help in modelling of the complete DC based solar system. The research that we have done is an approach towards the sustainable renewable energy. Thus, it will be good approach towards the solar energy.

\subsection{Recommendation:}

Following are some recommendation for the future.

- We should use alternative source of energy such as biomass and wind. Thus, the hybrid energy system will be there and we get the multiple option for the energy consumptions.

- The programming logic control should be use in order to provide the automatic control of the power supply.

- The modern safety devices should be improved to provide the safe supply. 


\section{PUBLICATIONS}

- C. B. Muzaffar and M. T. Iqbal, "Design and Analysis of a Off Grid Solar system for a DC load house in Pakistan," 2020 IEEE $11^{\text {th }}$ Annual Information Technology, Electronics and Mobile Communication Conference (IEMCON), Vancouver, BC, Canada, 2020, pp. 0786-0790.

- C. B. Muzaffar and M. T. Iqbal, "Design and Analysis of a PV system for irrigation of a ten Hectare farm in Pakistan" The 29th Annual Newfoundland Electrical and Computer Engineering Conference, IEEE, 2020. 


\section{REFERENCES:}

[1] P. Kaur, S. Jain and A. Jhunjhunwala, "Solar-DC deployment experience in off-grid and near off-grid homes: Economics, technology and policy analysis," 2015 IEEE First International Conference on DC Microgrids (ICDCM), Atlanta, GA, 2015, pp. 26-31, doi: 10.1109/ICDCM.2015.7152004.

[2] https://www.cleanenergyreviews.info/blog/2014/8/14/what-is-hybrid-solar

[3] Kitson, J., et al. "Modelling of an expandable, reconfigurable, renewable DC microgrid for off-grid communities." Energy 160 (2018): 142-153.

[4] https://www.solarreviews.com/blog/grid-tied-off-grid-and-hybrid-solar-systems

[5] http://www.sunflower-solar.com/index.php?act=content\&scheduler_id=429

[6] https://medium.com/solar-microgrid/battery-showdown-lead-acid-vs-lithium-ion$1 \mathrm{~d} 37 \mathrm{a} 1998287$

[7] Salman, S., AI, X. \& WU, Z. Design of a P-\&-O algorithm based MPPT charge controller for a stand-alone 200W PV system. Prot Control Mod Power Syst 3, 25 (2018). https://doi.org/10.1186/s41601-018-0099-8

[8] https://www.solarreviews.com/blog/grid-tied-off-grid-and-hybrid-solar-systems [9] Ali Najah Al-Shamani, M. Y. (n.d.). Design \& Sizing of Stand-alone Solar Power Systems. Recent Advances in Renewable Energy Sources.

[10] M. M. H. Sajeeb, A. Rahman and S. Arif, "Feasibility analysis of solar DC Nano grid for off grid rural Bangladesh," 2015 3rd International Conference on Green Energy and Technology (ICGET), Dhaka, 2015, pp. 1-5, doi: 10.1109/ICGET.2015.7315109. [11] M. Nasir, M. Anees, H. A. Khan, I. Khan, Y. Xu and J. M. Guerrero, "Integration and Decentralized Control of Standalone Solar Home Systems for Off-Grid Community 
Applications," in IEEE Transactions on Industry Applications, vol. 55, no. 6, pp. 72407250, Nov.-Dec. 2019, doi: 10.1109/TIA.2019.2911605

[12] Sharma, Himanshu, Nitai Pal, and Pradip Kumar Sadhu. "Modeling and Simulation of Off-Grid Power Generation System Using Photovoltaic." TELKOMNIKA Indonesian Journal of Electrical Engineering 13.3 (2015): 418-424

[13] A. Ramachandran, S. Mannar and A. Jhunjhunwala, "Inverterless Solar- DC system design for off- grid and near off-grid Indian homes," 2016 First International Conference on Sustainable Green Buildings and Communities (SGBC), Chennai, 2016, pp. 1-5, doi: 10.1109/SGBC.2016.7936055

[14] Singh, Anand, Prashant Baredar, and Bhupendra Gupta. "Computational simulation $\&$ optimization of a solar, fuel cell and biomass hybrid energy system using HOMER pro software." Procedia Engineering 127 (2015): 743-750

[15] Oulis Rousis, Anastasios, et al. "Design of a hybrid AC/DC microgrid using HOMER Pro: case study on an islanded residential application." Inventions 3.3 (2018): 55

[16] Madziga, Miriam, Abdulla Rahil, and Riyadh Mansoor. "Comparison between three off-grid hybrid systems (solar photovoltaic, diesel generator and battery storage system) for electrification for Gwakwani village, South Africa." Environments 5.5 (2018): 57 [17] Esmail M. A. Mokheimer, Abdullah Al-Sharafi, Mohamed A. Habib \& Iyad Alzaharnah (2015) A New Study for Hybrid PV/Wind off-Grid Power Generation Systems with the Comparison of Results from Homer, International Journal of Green Energy, 12:5, 526-542, DOI: 10.1080/15435075.2013.833929

[18] Tahir, Muhammad Asim, Surface measured solar radiation data and solar energy resource assessment of Pakistan: A review, Renewable and Sustainable Energy Reviews, Volume 81, Part 2, 2018, Pages 2839-2861, ISSN 1364-0321, https://doi.org/10.1016/j.rser.2017.06.090.

[19] Ali, M. A., \& Emziane, M. (2013). Performance Analysis of Rooftop PV Systems. The Mediterranean Green Energy Forum 2013, 689-697 
[20] Prof S. S. Kumbar, N. A. (n.d.). A Review of Net Metering Mechanism and its Process.

[21] Li, Matthew, et al. "30 years of lithium-ion batteries." Advanced Materials 30.33 (2018): 1800561.

[22]

https://www.google.com/maps/place/31\%C2\%B030'15.4\%22N+74\%C2\%B016'48.1\%22 $\mathrm{E}$

[23] https://openei.org/w/images/f/f0/NREL-pak-10km-glo.pdf

[24] Ahmed, M. Akhlaque, Firoz Ahmed, and A. W. Akhtar. "Distribution of total and diffuse solar radiation at Lahore, Pakistan." Journal of Scientific Research 40.1 (2010): $37-43$.

[25] Z.R. Tahir, Muhammad Asim, Surface measured solar radiation data and solar energy resource assessment of Pakistan: A review, Renewable and Sustainable Energy Reviews, Volume 81, Part 2, 2018, Pages 2839-2861, ISSN 1364-0321, https://doi.org/10.1016/j.rser.2017.06.090.

[26] https://www.altestore.com/store/solar-power-systems-c447/

[27] Mahmud, Md Arafat, et al. "Design and Hardware Implementation of a Digital Wattmeter." American Journal of Engineering Research (AJER) 2.12 (2013): 244-251. [28] https://www.homerenergy.com [29] https://www.homerenergy.com/products/pro/docs/latest/navigating_homer.html [30] https://www.homerenergy.com/products/pro/docs/latest/resources_tab.

[31] https://www.homerenergy.com/products/pro/docs/latest/electric_load.html [32] https://www.homerenergy.com/products/pro/docs/3.11/importing-a-load-from-timeseries-file.html

[33] https://www.homerenergy.com/products/pro/docs/3.10/components_tab.html [34]

https://www.homerenergy.com/products/pro/docs/latest/photovoltaic_panels_pv.html [35] https://www.homerenergy.com/products/pro/docs/latest/storage.html 
[36] http://www.buysolar.pk/shop/canadian-solar/canadian-solar-cs6u-325p-325-wattsolar-panel

[37] https://dnmsolar.com/product.php?product=233

[38] Salman, S., AI, X. \& WU, Z. Design of a P-\&-O algorithm based MPPT charge controller for a stand-alone 200W PV system. Prot Control Mod Power Syst 3, 25 (2018). https://doi.org/10.1186/s41601-018-0099-8 [39] https://www.mathworks.com/products/simulink.html [40] Salman, S., AI, X. \& WU, Z. Design of a P-\&-O algorithm based MPPT charge controller for a stand-alone 200W PV system. Prot Control Mod Power Syst 3, 25 (2018). https://doi.org/10.1186/s41601-018-0099-8

[41] Kumar, Saurabh \& Kumar, Rajat \& Singh, Dr. Navdeep. (2017). Performance of closed loop SEPIC converter with DC-DC converter for solar energy system. 10.1109/ICPCES.2017.8117668.

[42] Qi, Jun, Youbing Zhang, and Yi Chen. "Modeling and maximum power point tracking (MPPT) method for PV array under partial shade conditions." Renewable Energy 66 (2014): 337-345

[43] Leedy, Aleck W., Liping Guo, and Kennedy A. Aganah. "A constant voltage MPPT method for a solar powered boost converter with DC motor load." 2012 Proceedings of IEEE Southeastcon. IEEE, 2012

[44] Moorthi. P, Sundara \& Professor, Asst. (2016). A High Gain Soft Switched Interleaved Boost Converter with an Improved MPPT Control for PV Applications. 5. 10.15680/IJIRSET.2016.0507095.

[45] https://www.cleanenergyreviews.info/blog/mppt-solar-charge-controllers [46] Sharma, Dinesh \& Purohit, G.. (2014). Maximum Power Angle (MPA) Based Maximum Power Point Tracking (MPPT) Technique for Efficiency Optimization of Solar PV System. International Journal of Renewable Energy Research (IJRER). 4. 
[47] Kamran, Muhammad, et al. "Implementation of improved Perturb \& Observe MPPT technique with confined search space for standalone photovoltaic system." Journal of King Saud University-Engineering Sciences (2018).

[48] https://simplifiedsafety.com/safety-equipment/solar/

[49] Lee, Benny H. "Surge protection device." U.S. Patent No. 4,901,183. 13 Feb. 1990

[50] http://electronicsbeliever.com/surge-protection-circuit-principle-design/

[51] https://www.youtube.com/watch?v=DWBFHjE5zK0

[52] https://www.yourelectricalguide.com/2017/10/working-principle-operation-ofcircuit-breaker-properties-of-arc.html

[53] https://www.youtube.com/watch?v=tq0IPZFpFkE\&t=1639s

[54] https://circuitglobe.com/electrical-earthing.html

[55] Sundaravaradan, N. A., and M. Jaya Bharata Reddy. "How is earthing done?." IEEE Potentials 37.2 (2018): 42-46

[56] https://youtu.be/3Zm4AZTNAsU

[57] https://www.youtube.com/watch?v=uCxq6g 3mC6E\&t=153s

[58] Zaini, Nur Hazirah, et al. "Lightning surge analysis on a large-scale grid-connected solar photovoltaic system." Energies 10.12 (2017): 2149

[59] Pinceti, P., and M. Giannettoni. "A simplified model for zinc oxide surge arresters." IEEE transactions on power delivery 14.2 (1999): 393-398.

[60] A simplified model for zinc oxide surge arresters." IEEE transactions on power delivery 14.2 (1999): 393-398.

[61] http://www.ijeee.net/uploadfile/2016/0316/20160316114821550.pdf

[62] https://www.youtube.com/watch?v=tq0IPZFpFkE\&t=1639s

[63] Ali, H.M.S. \& Aman, Muhammad \& Ahmed, Syed \& Shaikh, Shariq \& Munir, Abdullah. (2018). Lightning Flash Density Map of Pakistan on ARC-GIS® Software An Empirical Approach. 1-6. 10.1109/EEEIC.2018.8494579 
[64] Nassereddine, Mohamad, and Ali Hellany. "Designing a lightning protection system using the rolling sphere method." 2009 Second International Conference on Computer and Electrical Engineering. Vol. 1. Ieee, 2009.

[65] https://axis-india.com/2020/08/rolling-sphere-method/

[66] https://www.smartpowershop.co.uk/12V190F

[67] https://www.homerenergy.com/company/partners/enersys.html 